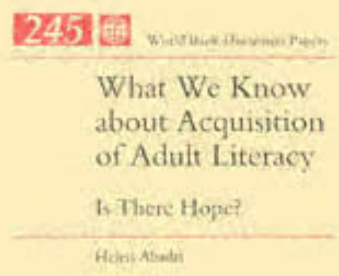

\title{
What We Know about Acquisition of Adult Literacy
}




\section{What We Know about Acquisition of Adult Literacy}

\section{Is There Hope?}

Helen Abadzi

The World Bank

Washington, D.C.

Copyright (C) 1994 The International Bank for Reconstruction and Development/THE WORLD BANK 1818 H Street, N.W. Washington, D.C. 20433, U.S.A.

All rights reserved Manufactured in the United States of America First printing June 1994

Discussion Papers present results of country analysis or research that are circulated to encourage discussion and comment within the development community. To present these results with the least possible delay, the typescript of this paper has not been prepared in accordance with the procedures appropriate to formal printed texts, and the World Bank accepts no responsibility for errors. Some sources cited in this paper may be informal documents that are not readily available.

The findings, interpretations, and conclusions expressed in this paper are entirely those of the author(s) and should not be attributed in any manner to the World Bank, to its affiliated organizations, or to members of its Board of Executive Directors or the countries they represent. The World Bank does not guarantee the accuracy of the data included in this publication and accepts no responsibility whatsoever for any consequence of their use. The boundaries, colors, denominations, and other information shown on any map in this volume do not imply on the part of the World Bank Group any judgment on the legal status of any territory or the endorsement or acceptance of such boundaries.

The material in this publication is copyrighted. Requests for permission to reproduce portions of it should be sent to the Office of the Publisher at the address shown in the copyright notice above. The World Bank encourages dissemination of its work and will normally give permission promptly and, when the reproduction is for noncommercial purposes, without asking a fee. Permission to copy portions for classroom use is granted through the Copyright Clearance Center, Inc., Suite 910, 222 Rosewood Drive, Danvers, Massachusetts 01923, U.S.A.

The complete backlist of publication from the World Bank is shown in the annual Index of Publications, which contains an alphabetical title list (with full ordering information) and indexes of subjects, authors, and countries and regions. The latest edition is available free of charge from the Distribution Unit, Office of the Publisher, The World Bank, 1818 H Street, N.W., Washington, D.C. 20433, U.S.A., or from Publications, The World Bank, 66, avenue d'Iéna, 75116 Paris, France.

ISSN: 0259-210X

Helen Abadzi is an educational psychologist working as an education specialist in the Population and Human Resources Operation Division, Country Department I, of the World Bank's South Asia Regional Office.

\section{Library of Congress Cataloging-in-Publication Data c}

Abadzi, Helen, 1951

What we know about acquisition of adult literacy : is there hope? / 
Helen Abadzi.

p. cm. - (World Bank; 245)

Includes bibliographical references and index.

ISBN 0-8213-2862-X

1. Functional literacy-Developing countries. 2. Literacy

programs-Developing countries. I. Title. II. Series.

LC161.A23 1994

374'.012091724-dc20

94-20038

CIP

\section{Contents}

Foreword $\underline{\mathrm{v}}$

Abstract vii

Acknowledgments $\underline{\mathrm{ix}}$

Chapter 1. Adult Literacy: A Problem-Ridden Area 1

Little Research has been Conducted in Literacy Acquisition $\quad 1$

Chapter 2. The Reading Acquisition Process $\underline{3}$

What Skilled Readers Do $\quad \underline{3}$

Chapter 3. The Four Big Obstacles to Adult Literacy $\underline{6}$

Obstacle 1: Low Initial Enrollments $\underline{6}$

Obstacle 2: High Dropout Rates $\underline{6}$

Obstacle 3: Frequent Low Performance $\underline{8}$

Obstacle 4: Relapse into Illiteracy $\underline{11}$

The Effectiveness and Practices of Post-Literacy $\underline{13}$

Chapter 4. Determinants of Adult Literacy Acquisition $\underline{15}$

Attitudes and Beliefs

Role Modeling

Self-Concept and Status $\quad \underline{16}$

Motivation $\quad \underline{17}$

Cognitive Processes $\quad \underline{19}$

Psychophysiology $\quad \underline{23}$

Visual Perception $\quad \underline{23}$

Chapter 5. Effective Instructional Methods

How to Attract and Keep Participants

How to Make Information Memorable $\underline{26}$

How to Teach Reading Efficiently $\underline{27}$ 
How to Minimize Relapse into Illiteracy $\underline{29}$

The Problems of Training Teachers $\underline{30}$

Chapter 6. Conclusions $\quad \underline{33}$

Operational Implications $\quad \underline{35}$

Research is Urgently Needed $\underline{37}$

Appendix A. Data and Assumptions on Literacy $\underline{40}$

Appendix B. Possible Age-Related Difficulties in Acquisition $\quad \underline{42}$ Literacy

Appendix C. How Illiterates Think $\underline{55}$

Appendix D. Age-Related Difficulties in Literacy Acquisition: A $\underline{57}$ Literature Review

Notes

References

Index

\section{List of Tables}

3.1 Efficiency Rates of Literacy Campaigns $\quad \underline{9}$

B.1 Post-Test Data from Two Bangladeshi NGOs $\underline{52}$

B.2 Achievement Comparisons in Nepal $\underline{52}$

B.3 Chi Square Tests of Completion Rates by Age $\underline{53}$

\section{List of Figures}

B-1 How Reading Takes Place

B-2 Results from Two Bangladeshi Literacy NGOs $\underline{54}$

D-1 Paired-Associate Learning $\underline{61}$

D-2 Phonological Awareness $\underline{62}$

D-3 Verbal Memory Spans (Age 18 Standard Deviation Units)

D-4 Verbal Memory Span (Young Adult Standard Deviation $\quad \underline{65}$ Units)

D-5 Working Memory Tasks $\quad \underline{66}$

D-6 Working Memory

\section{Foreword}

Governments and donors are frequently interested in effective programs that will provide stable skills to illiterate men and women so that they can obtain information from printed materials. Faced with a request from the Government of Bangladesh for a literacy project, the human resources division responsible for Bangladesh, 
Bhutan, and Nepal obtained a small research grant in August 1992 to review the existing literature.

If adult literacy were effective and easy to implement, it might be a standard item in the project portfolios of many countries. However, the performance of adult literacy projects or components of projects in the 1970s and 1980s has fallen short of expectations, and World Bank lending has focused on primary education and on prevention of adult illiteracy. Nevertheless, the population in many countries has increased faster than access to primary education, and the need for literacy training in the adolescent and adult years remains. The shortcomings of literacy programs have often been attributed to economic and sociological factors, but there have been few efforts to understand how information-processing issues limit effectiveness and efficiency.

This publication discusses findings related to the acquisition of literacy in light of cognitive psychology principles and proposes applications that may make literacy projects more effective. It is worth noting that it was produced by an operations division as a response to a need for innovative solutions.

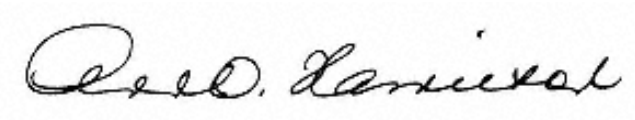

\author{
ANN O. HAMILTON \\ Director \\ Country Department 1, South Asia Region
}

\title{
Abstract
}

Governments and donors expect that their investments will provide permanent skills to illiterates and help alleviate poverty through reading of usable information. Literacy acquired in childhood positively influences quality of life, but the effects of literacy acquired in adulthood are not well known. Experience shows that literacy is not easily disseminated to adults and that the skills of neoliterates are not stable. Dropout, mastery, and retention rates are about 50 percent at each stage, so the effectiveness rate of some projects may only be 12 to 15 percent. As a result, literacy projects are now rarely funded by the World Bank despite requests from governments.

To find causes for the low effectiveness of programs, two literature reviews were conducted on the topic of literacy in general and cognitive correlates of age and performance. It was concluded that:

- Adult illiterates seem to face a combination of social, motivational, instructional, and cognitive obstacles, which together prevent many from attending classes or mastering and retaining the material. However, these obstacles have not been studied through valid experimental or quasi-experimental research. To understand their importance separately and in combination, international donors should systematically study the process of literacy acquisition, dropout, and relapse into illiteracy.

- Thus far there has been a tradeoff between quantity and quality in adult literacy. In previous decades, large-scale programs that taught literacy as an end in itself were less effective than smaller but more complex programs, which taught literacy as a means to carry out other activities. Small programs, however, cannot satisfy the large need for literacy instruction. The challenge, therefore, is to design large-scale programs that are effective as well as implementable.

- Apparently, no one ever becomes too old to learn sound-letter correspondences and to acquire basic literacy. But it is possible that functional literacy becomes increasingly difficult to acquire with age. The skill becomes permanent when its use is automatic, and adults may require much more practice to reach that stage. 
- If it is indeed harder for adults to acquire functional literacy, perhaps large-scale literacy-only programs should target out-of-school children and adolescents (through the age of about nineteen years). These age groups constitute a large part of the population in many countries. The little evidence available indicates that they may have lower dropout rates, may be trained at relatively low cost, and may remain literate if they become literate during a course. Adults of all ages should be encouraged to participate, but programs might refrain from setting numerical targets for them.

- Methodological improvements can increase the effectiveness of literacy programs. The following lessons might be extrapolated from cognitively oriented research and hypotheses:

- Find out early from the prospective beneficiaries what goals and activities they consider meaningful and would spend their little free time to pursue. If formal schooling is of interest, develop a program leading to a primary school certificate rather than mere literacy.

- Emphasize methods that reinforce adults for their performance early to make the literacy class a priority in their lives. Demonstrate the immediate utility of literacy by helping learners read items such as currency, movie advertisements, and store signs. Reinforce them with texts on familiar issues so that they can rely on the context and read better. Role-model reading in various ways, including the reading of interesting material aloud to them.

- Explain to illiterates what they should expect from literacy, including possible relapse into illiteracy, and teach them techniques that will help them maintain their skills.

- Package the reading information so that it can withstand the vicissitudes of long-term memory.

Culturally-appropriate mnemonics, including rhyming and songs, may make the memory of letter shapes permanent.

- To diminish dropout and help with study, work with existing groups wherever possible. If this is not possible, foster supportive networks among illiterates; some successful programs include action-oriented community work that is planned in the classroom.

- To provide maximal reinforcement and yet leave no participants behind, develop within-class groups of similar performance.

- Capitalize on the strengths of adults who may learn the reading strategy more quickly than children, though they may consolidate information less efficiently and perceive letter patterns less easily than children. Use multiple inputs as well as a lot of writing to consolidate the memory of letters and patterns. Maximize opportunities to show script in context and minimize the incidence of unconnected words and sounds.

- Attempt to remedy potential cognitive-perceptual problems of illiterates during instruction by making adults phonologically aware. Emphasize pattern formation and recognition and teach the critical shapes necessary to distinguish letters from each other when they are scribbled or written artistically.

- Invest heavily in teacher training and in a functional training-supervision network from the central level down to village teachers. Train teachers on adult classroom management issues such as early reinforcement and prevention of dropout, on instructional methods which maximize the probability that the reading strategy will be understood early, and on the importance of arriving on time and treating participants with respect. To counteract their tendency to teach with the methods their own teachers used, train teachers through role modeling and feedback, not just through lectures. 
- The difficulty and magnitude of the literacy task may demoralize implementation agencies. Make the task more achievable by breaking it down into manageable units, such as local-level campaigns with finite schedules.

\section{Acknowledgments}

I wish to thank the Research Committee of the World Bank for supporting the literature review on age-related information in the acquisition of literacy, as well as Dr. Timothy Salthouse, Professor of Psychology at the Georgia Institute of Technology, who conducted the review.

I also wish to thank Martin Karcher, Chief of Population and Human Resources Division, South Asia Country Department 1, for his support as well as the experts who critiqued this document, notably John Oxenham, Thomas Eisemon, Nicholas Bennett (World Bank); John Comings (World Education); Alan Rogers (Education for Development, Reading, UK), Mary Jager Adams (Bolt, Beranik, and Newman), and David Red (Foreign Service Institute). Special thanks are due to Deborah Ricks for her secretarial assistance.

\section{Chapter 1- Adult Literacy- A Problem-Ridden Area}

It was once believed that if the illiterate poor learned to read they would have access to information that would improve their lives. For that reason many countries undertook large literacy campaigns in the 1950s, 1960s, and 1970s with the help of international organizations, and the World Bank included literacy in thirty education projects between fiscal years 1963 and 1985. In contrast to children's education, however, adult literacy programs have yielded disappointing results worldwide. They generally fail to teach stable literacy skills to the intended beneficiaries, who thus cannot access useful information. About 50 percent drop out during the course and about 50 percent of those who stay fail to meet performance criteria at the end. Not only are dropout rates inordinately high, but relapse into illiteracy seems widespread, particularly among populations with few opportunities for daily reading. In campaigns conducted during the 1970s, efficiency could be as low as 12 percent (UNESCO/UNDP 1976).

The ineffectiveness of literacy programs has been a major disappointment to development organizations and an educational puzzle that defies common sense. Following a discouraging review (Romain and Armstrong 1987), literacy virtually disappeared from World Bank projects. However, many government officials of developing countries continue to consider adult literacy a political and social priority and request Bank funding for such projects. The 1990 Education for All Conference has given new impetus to adult literacy, and some projects are now financed again. In 1993 one project was under implementation in Ghana (cost \$27.4 million), and two others were under development in Indonesia (proposed cost \$139.7 million) and Bangladesh (proposed cost \$25 million) 1 . Continuing requests by governments may increase the frequency of such projects in the future.

\section{Little Research has been Conducted in Literacy Acquisition}

One would expect that with disappointing performance and limited options, extensive research would have been done by some organizations to understand and possibly remedy the problems adults encounter in literacy acquisition. An extensive literature review conducted by the author found countless documents about literacy. The UNESCO Experimental World Literacy Program, for example, published 229 documents and reports from projects carried out in 11 countries (for example, in Algeria, Ecuador, Ethiopia, Guinea, India, Iran, Madagascar, Mali, Sudan, Syria, and Tanzania) from 1967 to 1972. The vast majority of the documents, however, present policies, political declarations, organizational issues, philosophy, methodological ideas, and a "best practices" (for 
example, Ouane 1989; Ouane, Armengol, and Sharma 1990). Rigorous research and robust evaluation designs have been rare (Jennings 1990; Wagner 1991). The few studies attempting experimental manipulation or ex post facto analysis have typically used simplistic methodology, inadequate or nonexistent controls to safeguard internal validity, and no experimentation. As a result, cause-and-effect relationships cannot be clearly established between potential determinants and outcomes of literacy training (appendix A).

Can literacy instruction become more effective? The more successful programs teach literacy in an environment of support and reinforcement through income-generation programs or explicit community participation and planning. Income-generation programs, however, are complex and can reach relatively few people.

Community-based programs (such as those in Thailand and the Total Literacy Campaigns in India) require a level of education and involvement that may not be sustainable in poor communities with large illiterate populations and high birth rates, as in Bangladesh and Yemen. Given that there are about 900 million adult illiterates in the world (Lind and Johnston 1990), it is imperative that literacy instruction be delivered effectively and efficiently to large numbers of participants if it is to have a significant economic impact. Yet there seem to be few effective ways to teach illiterate adults in poor

environments. This is why innovative methodologies are sought and bodies of knowledge that are outside the narrow domain of literacy, such as cognitive psychology, are being consulted.

One problem with adult literacy methods may be the lay person's assumption that adults learn to read as easily as children or through the same processes as children. For several reasons, this may not be so. Anecdotal accounts of educated adults who learned to read foreign languages with non-Latin scripts indicate persistent difficulties in learning to read fluently_-slow speed, difficulty in perceiving letters as patterns, dependence on sound to understand words, high error rates, tendency to forget quickly, and difficulty in reading artistic letters. These adults apparently learn sound-letter correspondences quickly, but remain in a beginner stage for a long time thereafter. Unless they are exposed to intensive practice (such as university studies in a foreign script) they may acquire basic literacy (knowledge of letter values) but not functional literacy, which is necessary for the acquisition of information $\underline{2}$. While it is possible that this phenomenon is due to deficient knowledge of the second language or to biases of a highly selected sample, one may not preclude the possibility that it illustrates a systematic, age-related phenomenon that might in some way also affect native adult neoliterates. (Appendix B presents information and some supportive data.)

Since adult illiteracy has been rarely researched, it is largely unknown how adult illiterates think and learn, or which characteristics make them more amenable to literacy training (appendix C). The analogy with foreign readers, however imperfect it may be, may serve as a springboard to scrutinize the many variables that affect the acquisition and retention of literacy by adults. Some may be incidental to adulthood, such as priorities in different periods of life, while others may be substantively related to aging processes, such as pattern-recognition speed. This paper discusses the possible effects of variables (such as cognitive, neurological, perceptual, instructional, social) in the acquisition of literacy, and proposes avenues which may help increase the probability that adults will become and remain literate. In order to illustrate the complexity of the reading issues, the following chapter examines how people read.

\section{Chapter 2- \\ The Reading Acquisition Process}

What does the reading skill consist of? Most research on this issue has been conducted with English-speaking children and the Latin script; it is widely assumed, however, that the reading process involves universal psycholinguistic processes and is not specific to culture or language (Downing 1973). In all writing systems the 
What We Know about Acquisition of Adult Literacy

reader faces the task of dividing strings of symbols into manageable segments and integrating the segments into meaningful units (Stevenson 1987). Unless a child has some sort of a reading disability, learning to read seems deceptively simple after the fact. As a result, adult literacy is often considered a simple subject to teach. (It is noteworthy that many literacy experts have themselves never made an adult literate.)

\section{What Skilled Readers Do}

- They read with high speed and accuracy. Skilled readers read five words or more per second. They can recognize even very long words (twelve to fifteen letters) exposed for very brief durations, (for example, one-tenth of a second) and in capital letters, which are uniformly square and harder to distinguish. They can perceive whole words as quickly and accurately as single letters and they can recognize whole phrases as quickly and easily as strings of three or four unrelated letters. Moreover, the speed and accuracy of their reading seems impervious to the mutilation, substitution, or omission of letters within words. Distorted typography, mixtures of capitals and small letters, or uneven sizes seem to have no effect on the accuracy and speed of recognition (Adams 1990).

- They move their eyes selectively, yet unconsciously. The visual cues are of paramount importance. Readers might use their predictions to guide their visual inspection of the text. They might skip, skim, or pore over individual letters only as needed to confirm or correct their expectations as to its message. The eyes of the reader do not move smoothly across the letters, words, and phrases of a text while reading. Instead, they leapfrog through the text, alternately pausing on a word and jumping quickly to another. About 95 percent of the time they stop on words. They may skip prepositions, but they fixate on most other words, particularly longer words, regardless of text difficulty. If the words are long, the eyes fixate on about the fourth letter of a word and again at the end of the word. With normal text, the eyes can resolve up to three or so letters to the left of their fixation point and about six to the right. Relatively lengthy words are segmented. If the text has spelling errors, the eyes fixate on them and a resolution seems to take place—often without the individual's conscious knowledge of the error.

- Comprehension is critical to them. Visual cues are very important, but reading is also a psycholinguistic guessing game. The skilled reader uses contextual information in an efficient matter to facilitate recognition. She or he constantly and automatically generates predictions about what is to come. English-speaking readers read real words faster than regularly spelled pseudo-words (for example, fint, poat, or sust), and read the latter faster than irregularly spelled pseudo-words (for example, epkr, rsai, or tgyo). According to the most widely accepted theory, rapid word identification is possible because of information provided by the context in which a word occurs. This information, in conjunction with knowledge of the language and general world knowledge, allows the reader to formulate hypotheses concerning the identity of subsequent words. This process is rapid and

unconscious for skilled readers, who are typically aware only of the results, not of the manner in which processing occurs (Adams 1990).

- They go directly from print to meaning. Unless the meaning is unclear, skilled readers do not have to sound words. Skillful word recognition involves direct visual processing and almost simultaneous phonological translations.

Text, then, is processed visually and understood through parallel operations that take place at the same time. How do visual cues and prior knowledge come together? The most widely accepted model (Seidenberg and McClelland 1989) involves four interconnected processors: phonological, orthographic, meaning, and context (appendix B). Literacy evidently results from a complex sequence of steps, some triggered by biological maturation and others by particular instruction (Bertelson and De Gelder 1989). Roughly, four stages have been identified in the reading acquisition process (IDRC 1979) $\underline{3}$ : 
(a) Preparing for reading

(b) Establishing initial reading attitudes and skills

(c) Growing rapidly in the ability to read

(d) Acquiring more mature reading habits.

Reading specialists have focused on stages (a) and (b), since these areas are prominent for children. Reading preparation is an area of much commercial activity for preschoolers, including television programs such as Sesame Street . Because acquisition of reading skills presents major problems for some children and because acquisition of the basic reading strategy is a prerequisite to reading, stage (b) has been the focus of intensive study and methodology development. However, stages (c) and (d) do not seem to present difficulty to children; if they master stage (b) they are very likely to progress into fast and effortless reading with comprehension.

Adult literacy programs and post-literacy programs mainly impart skills of stages (a) and (b) above. In contrast with children, however, passage to stages (c) and (d) is uncertain. The extent to which adults and children use the same cognitive processes in learning to read is unknown (Wagner 1987), and it is not certain under what conditions adults progress to stages (c) and (d). Many adults in various evaluations have reported utilizing their reading skills; (for example, more than 50 percent of participants in two Nepalese programs (New Era 1990). However, no data have been found which indicated that adult participants were in the stages of rapid speed increases and acquisition of mature reading habits during literacy and post-literacy programs. What is achieved in typical literacy programs may or may not prove useful for participants, but it is a far cry from the skills that experienced readers demonstrate or that children easily acquire.

Several researchers (for example, Downing 1987) have indicated that the skill is retained only after reading becomes automatic 4 . Until the reader has automatized the word recognition skills, reading may be a laborious and frustrating process. Slow, capacity-draining word recognition uses up the cognitive resources that should be allocated to higher-level processes of text integration and comprehension (Stanovich 1986, p. 364). As a result, neoliterates may understand little of what they read and may avoid this tedious task, thereby practicing less and less. However, there are no data to indicate how the acquisition of automaticity changes from childhood to adulthood. Do adults need more practice? If so, how much more? Can the process be somehow accelerated during instruction? No answers exist at this time.

Some practitioners argue that the rapid reading encountered at stage (d) is not really necessary and perhaps should not be a goal of adult neoliterates. Its existence is probably a recent phenomenon in history, a function of the abundance of contemporary written information. In countries with limited availability of books one can find relatively well-educated individuals with stable literacy skills who read slowly, silently moving their lips as they do. In a similar mode of thinking, some government officials expect to impart only rudimentary reading skills to illiterates, in hopes that these would be sufficient for reading small items, such as fertilizer instructions. It is unknown, however, what level of reading skill must be acquired in order for the skill to become permanent at a lower stage and not to be lost. There may be a critical minimal competency level that can make the skill self-reinforcing, but no one knows what it is in the various languages of the world.

\section{Chapter 3- The Four Big Obstacles to Adult Literacy}


Imagine for a moment that among humans some people can fly. Government staff come and tell you that you can take a course that will teach you how. This sounds great, and one hears of emotional accounts of what it is like to soar in the sky. But you have no personal experience of what flying feels like. To learn it you must go for six to nine months daily to school. You do exercises like flapping your arms but you never really take off. And you do not often need to fly anywhere. Whenever you do, you can either take the plane or send a relative who can fly to do what is needed. So, is the benefit worth the effort?

Each stage of a literacy program is fraught with problems: low initial enrollments in relationship to the illiterate population, extensive dropout, failure to achieve mastery, and relapse into illiteracy. The sum of these problems has made the broad dissemination of adult literacy thus far impossible to achieve. This chapter will review international experiences and efforts to increase efficiency.

\section{Obstacle 1: Low Initial Enrollments}

Statistics are lacking, but it appears that a large number (probably the majority) of potential students fail to enroll in literacy classes (IDRC 1979) for unclear reasons. Dysfunctional beliefs may be to some extent responsible (see below), but the beliefs and apprehensions of illiterate adults are not sufficiently understood to combat this problem (IDRC 1979).

The literacy campaigns of Thailand as well as the Total Literacy Campaign of India have attempted to deal with this problem by registering all illiterates in a village. However, financial constraints make it possible only to deal with specific age ranges, for example up to age thirty-five. Given the potential population, even the best programs may enroll a relatively small portion of illiterates.

\section{Obstacle 2: High Dropout Rates}

The biggest scourge of literacy programs has been high dropout rates; 50 percent of a class appears to be an average (IDRC 1979; Jennings 1990). Literacy projects tend to start out with enthusiastic subscriptions of enrollment, but attendance soon becomes erratic and after a few weeks only a few learners are left. Even if programs were extended to cover all adult illiterates, the majority would drop out.

The extent of dropout has been shocking. For example, the well-supported and well-organized literacy program that was implemented in Iran in 196772 showed a 40 percent average dropout rate in each of its two stages (UNESCO/UNDP 1976). In other programs it ranged from 37 percent in Tanzania to 68 percent in Sudan (Edstroem 1976). The poor results, which were reviewed in an extensive study (UNESCO/UNDP 1976), made the financing of literacy programs increasingly unpopular (table 3.1) $\underline{5}$.

One gets the impression that agencies and instructors may drop out of the programs as much as the students. Although there are many literacy promoters who tirelessly plod on, it has been repeatedly observed that agencies and professionals who are faced with a large, difficult, or endless task (such as caring for mental retardates) tend to barricade themselves behind bureaucratic procedures or other excuses and deal with their clients as little as possible while undertaking tasks (like materials development) that make them look as if they are making progress (Miller and others 1978). This problem might be

responsible for target scalebacks of the large literacy projects as well as for possible teacher burnout and may be an underlying factor of frequent institutional weaknesses that seem intractable. In a more recent example (198991), the Mass Education Program of Bangladesh met 6 percent of its target and opened only 1,620 centers out of the planned 17,600, although much energy was diverted to developing textbooks through specific methods. 


\section{What We Know about Acquisition of Adult Literacy}

Inadequate logistics exacerbate the problem. The program of the United Nations Educational, Scientific, and Cultural Organization (UNESCO) tended to oversupply resources at the start and undersupply them in later stages of implementation (Street 1990, p. 53). All the projects evaluated by UNESCO/UNDP showed a large scaleback of targets due to difficulties in starting centers. Large differences between planned targets and achievements are frequent and in the order of 10 to 50 percent (for example, from 51,000 adults to about 5,000 in Madagascar).

Dropout is frequently attributed to a lack of motivation. People would like to be literate, but the strength of their desire and its ability to carry them through to completion may be insufficient (Oxenham 1975). Extreme poverty and exhaustive work make other priorities much more important than literacy. Illiterates may not have a good conception of what literacy can do for them and do not necessarily connect it with information acquisition (Jennings 1990). Learners, therefore, may become disillusioned when they realize that no immediate benefits are derived from literacy and that prospects for future financial gain are unclear (Lind and Johnston 1990). However, this serious issue of motivation may mask cognitive processes that are not yet understood. (See the section on motivation.)

What reasons do dropouts themselves give for quitting? The reason most frequently stated in a Nepalese study was domestic work. In two Nepalese programs, for example (New Era 1990), 44 percent of dropouts cited housework (75 percent were women, median ages 19 to 20); only 4 to 5 percent stated a lack of interest. Other factors were marriage ( 22 to 27 percent, migration (13 to 23 percent), sickness, ( 8 to 9 percent), and transportation (20 to 8 percent). In a three-year 1988 Save the Children program in Nepal, which had a completion rate of 45 percent, stated reasons for dropout were pregnancy, marriage, sickness, and death. It was also found that women with three or more children were more likely to drop out as well as people over thirty in general. Dropout may also happen for social-cognitive reasons. When informal group leaders drop out, several other participants may also do so (appendix C).

Sometimes dropout is not permanent, and persons who quit one class may subsequently attend another. In Nepal participants who had attended literacy classes previously were found to score higher than learners who had not (Comings, Shrestha, and Smith 1992) However, no data are available from other sources.

The main factor research has identified thus far as associated with dropout has been quality and interest of teachers (see next section). Comings, Shrestha, and Smith (1992) observed considerable variability in dropout, ranging from 100 percent to less than 30 percent, and teacher absenteeism was found to be an important reason. Another was teachers' treatment of learners as if they were children, or lack of attention to slower learners. Anecdotal reports exist of teachers pushing students out. These data point to potential improvements in an area that is complex and expensive, teacher recruitment, supervision, and support. If teachers show up in class and treat people well, then dropout rates significantly lower than 50 percent should be expected (Comings, Shrestha, and Smith 1992).

One reason why it has been difficult to reduce dropout is that very little is known about the process . Informal observations indicate that it tends to happen after a few weeks of the class, but patterns have not been studied. Absenteeism seems to be a harbinger of dropout and a predictor of performance, but attendance data are rarely reported. In the few reports that exist, absenteeism averaged 30 percent in the urban locations of Kenya with the best record and 50 percent in rural areas (Carron, Mwiria, and Righa 1989), though in some recent programs it was lower (17 percent in Surkhet-Nepal). How does performance and attendance before dropout relate to the event? A longitudinal study of Egyptian primary-school children showed that dropouts, or those still in school but about to drop out, were at least two grade levels below those of continuing students (Hartley and Swanson 1986). Could the same be happening to illiterates? Since absenteeism contributes to low performance, maintaining participants' attendance in the crucial first few weeks may help raise their performance, reinforce them, and ultimately prevent them from dropping out. But little is known about the underlying causes and processes of absenteeism. 
Dropout is a difficult area to study, particularly when it is necessary to track down the urban poor. As a result, studies mainly consist of surveys that report at face value the explanations given by illiterates. However, the illiterates themselves may not be able to articulate their motives and problems. Since staying in class is crucial to disseminating literacy, sensitive and experimentally robust research (not mere post-hoc surveys) is badly needed.

\section{Obstacle 3: Frequent Low Performance}

Many illiterates complete a course and still fail to acquire basic literacy. $\underline{6}$ The UNESCO/UNDP data (table 3.1) indicate that fewer than 50 percent of participants in the campaigns reviewed met the mastery criteria set by the programs, resulting in efficiency rates around 25 percent at the end of a course. (The well-designed campaign of a later program in Surkhet, for example, had a high efficiency rate of 47 percent.) In a nine-month course in Nepal, for example, 76 percent of the participants scored above 60 percent on a post-test; in a six-month course, only 39 percent scored above 60 percent. Although varying definitions of literacy and mastery criteria make comparisons across programs and countries problematic, failure rates seem to hover at around 50 percent.

Between initial enrollments and the number of students who pass a final test, most adult literacy programs have a level of efficiency of about 30 percent (Lind and Johnston 1990). Overall, large government programs (which have generated most of the reported data) may be less efficient than subsequent and smaller non-governmental organization (NGO) programs that may have benefitted from experience and may be more client-oriented. $\underline{\text { Over }}$ half of the relatively successful programs in Nepal were implemented by agencies other than the Ministry of Education (Comings, Shrestha, and Smith 1992).

Table 3.1. Efficiency Rates of Literacy Campaigns

$\begin{array}{lllllll}\text { Country } & \begin{array}{l}\text { Initial } \\ \text { enrollment }\end{array} & \text { Examines } & \text { Percent } & \begin{array}{l}\text { Pass } \\ \text { (Number) }\end{array} & \begin{array}{l}\text { Pass } \\ \text { (Percent) }\end{array} & \begin{array}{l}\text { Efficiency } \\ \text { (Percent) }\end{array} \\ \text { Tanzania } & 466,000 & 293,600 & 63 & 96,900 & 33 & 21 \\ \text { Iran } & 94,700 & 46,900 & 50 & 13,900 & 30 & 15 \\ \text { Ethiopia } & 36,800 & 21,700 & 59 & 9,300 & 43 & 25 \\ \text { Ecuador } & 17,500 & 10,000 & 57 & 4,100 & 41 & 25 \\ \text { Sudan } & 7,400 & 2,400 & 32 & 600 & 25 & 8 \\ \text { Surkhet } & 7,474 & 3,756 & 50 & 3,541 & 94 & 47 \\ \text { (Nepal) } & & & & & & \end{array}$

Source : UNESCO/UNDP 1976; data on Surkhet: New Era 1989.

Classroom Processes Matter Very Much

Attempts to improve performance have centered on making instructional methodology and materials more relevant to participant interests. However, in an observational study of the determinants of achievement, Comings, Shrestha, and Smith (1992) found that teacher-related variables were the single most important predictor of achievement in Nepalese programs, after instructional materials:

- Instruction-related variables, materials, and instructional design, probably had the largest effect on achievement in Nepal. For example, the readability scores of a literacy text correlate 0.44 with achievement scores.

- Teacher-related variables explain 38 percent of variance in the total literacy achievement scores (language and math) in Nepal. A composite variable of proper class management, participatory method of teaching, active adult 
participation, and periodic evaluation of adults' learning was a strong and consistent predictor of literacy achievement. Evaluators of the Kenya program also concluded that the teacher was the most important factor (Carron, Mwiria, and Righa 1989).

- Participant-related variables accounted for 31 percent of the achievement-score variance. Contrary to general perception, interest, motivation, and free time were not the most important determinants of achievement, but they did play a considerable role. For example, unmarried participants aged fifteen to nineteen were more likely to study at home and had somewhat better performance. Stated degree of interest correlated a rather weak 0.23 with achievement in the Surkhet (Nepal) program.

The most comprehensive study of program performance that has been found (Comings, Shrestha, and Smith 1992; Comings 1993) concluded for Nepal that:

- A 50 percent dropout rate is acceptable and does not necessarily indicate that materials and instructional design need improvement. Attention to teacher-related variables, particularly selection, training, and supervision can help diminish dropout and improve the performance of participants.

- Effective use of supervisors (supporters as well as monitors) improves time on task and teacher attendance. Then the attendance of participants increases (83 percent in Surkhet), and so do pass rates.

- Some participant-related obstacles can be overcome with appropriate logistics. When classes are provided in a convenient manner, women and girls can overcome the barriers to their participation in education.

- Literacy classes can serve as an effective vehicle for teaching knowledge and attitudes in relation to other development sectors such as health, family planning, ecology, and agriculture.

- A literacy program in a national language can be successful with regional-language participants if they want to learn in the national language. An additional outcome of such a program can be improved oral fluency in the national language.

- Economies of scale can significantly lower per capita costs in literacy programs. In largescale programs with reasonably good quality, costs can be significantly lower than the cost of one to three years of primary school needed to acquire the same skill level. (In 1991 it cost $\$ 5.75$ to $\$ 10$ per entering participant in Nepal while government primary schools cost $\$ 12$ a year per student, in addition to parents' expenditures of $\$ 10$. $) \underline{9}$

- A significant percentage of completing participants retain or improve the skills acquired in literacy classes.

- Lack of experience with testing may underestimate the achievement of adults. When neoliterates were given testing practice, which children get in schools, their performance improved significantly.

It appears that substantial increases in program efficiency can be made through improvements in program elements that already exist. These findings are probably the most useful information that has been found on program efficiency.

\section{Optimal Course Duration}

Length of study has been found to correlate with achievement and subsequent retention in several studies (for example, Roy and Kapoor 1975); but the short duration of most literacy courses, the wide variation in programs, and extraneous factors make research-based conclusions on the optimal length for courses difficult. Family background, socioeconomic status, occupation, family income, availability of books, and personal factors are 
important (Comings, Shrestha, and Smith 1992). Six-month classes of 200 hours or less are often preferred for their lower costs but have high failure rates. Three-year courses, on the other hand, may force considerable self-selection due to the lengthy time investment.

There seems to be a consensus in recent publications that courses should last at least nine months and a minimum of 300 hours in order to provide sustainable skills. The 1992 task force on literacy materials of Bangladesh, for example, recommended a training package that consists of nine months of basic literacy ( 300 hours), three months of post-literacy ( 72 hours three times a week), and six months of continuing education for sustainability ( 48 hours once a week).

Innovative approaches to course structure may respond to difficult, localized needs. A ten-day residential crash course was conducted for tribal women in Rajasthan, India (McGivney and Murray 1991 p. 5456). During daily ten-hour sessions, women learned the alphabet and numbers up to thirty, and practiced recognizing words they were likely to meet. The course was followed by thrice-weekly sessions and a five-day crash course for skill development. Although mass practice is generally considered less effective than distributive practice, basic literacy may be a skill that can be taught in this way.

It appears that the process of teaching adults to read is quite delicate, and many things can go wrong. However, adults may learn basic word-letter correspondences in a relatively short time; under favorable conditions and in an atmosphere of social desirability it may only take two to three months. (Adults of the Vai tribe in Liberia apparently learn in a few weeks with relatively little practice; see appendix C). It is possible that the short courses that prevailed in previous years, in combination with unfavorable classroom environments and administrators who had little understanding of the task are responsible for the high failure rates reported in the programs of the 1960s and 1970s. Improved instructional methodology may make the difference between adults understanding the reading strategy and continuing versus dropping out or failing.

\section{Obstacle 4: Relapse into Illiteracy}

Many motivated participants learn to read while in class, but after its termination many seem to forget and lapse back into illiteracy. Roy and Kapoor (1975) found that 45 percent of people who received their literacy training three to ten years prior to the research had lost the skill. Particularly prone to decline seem to be the numeracy skills generally taught in literacy classes (Jennings 1990). Since recognition of learned items is easier than recall, writing skills tend to lapse to a greater degree than reading skills (Sheffield 1977). Predictably, rural area residents with fewer opportunities for reading show greater decline. An Indian study found that 35.5 percent of urban male, 49 percent of rural male, and 51.3 percent of rural female neoliterates had lapsed back into illiteracy.

Only a few studies present findings on the retention of literacy, and they paint a rather complex picture. Comings, Shrestha, and Smith (1992) argue that the level of literacy skills acquired during a course tends to be retained or even improves.10 In Nepal 2,656 adults who had acquired literacy one to five years earlier (some in an agricultural program) were tested. No pre-test data were available, but no relationship was found between the number of years elapsed since completion of the literacy classes and the score achieved on the test. (Average scores were 47.7 to 51.1 percent.) Another study tested 210 women who had acquired literacy two years earlier, some of whom entered income-generation programs directly after literacy. Sixty-two percent of these women scored above 60 percent, 30 percent between 30 to 59 percent, and only 7 percent scored below 30 percent. Where test data from literacy courses were available, it was possible to gauge changes: 32 percent of the persons post-tested improved, 21 percent had some loss, and 47 percent had a significant loss of skill. In writing, 70 percent improved and 30 percent had some loss. A third study indicated that participation in income-generation activities was related to higher reading performance (Manandher 1989). 11 
What We Know about Acquisition of Adult Literacy

Similar results have been obtained in other countries. In Zimbabwe, about twelve students (mean age forty-seven) who were tested after six months scored as well as they had at the end of the course and were judged able to continue reading and writing on their own (Comings 1993). In Tanzania, Semali (1991) studied 379 neoliterates who mastered reading, writing, and comprehension in the campaign five years earlier (only 34 percent had no schooling). Of them, 75 percent retained literacy, with comprehension and writing at a lower level. Comings, Shrestha, and Smith (1992) have concluded that retention and improvement appear to have occurred in at least 50 percent of the sample populations, even when there was no organized post-literacy program. For lost skills they hypothesized that skills were not learned; instruction may have been too short; or contrary to the reports of local education officials, instruction may not have taken place.

Results from the Kenyan campaign, on the other hand, showed that students had low levels of skills despite claims that they read various materials. The graduates ( 55 percent of whom had about three years of formal schooling) reported in large numbers using the reading, writing, and numeracy skills they learned rather frequently; 45 percent read newspapers, 47 percent wrote, 60 percent calculated. Urban and periurban areas showed higher performance than rural areas. Women tended to use their literacy and numeracy skills less frequently than men. Of a random sample, however, only 30 percent (291 people) were able to read and understand a short text related to their daily life. Another 51 percent could write a paragraph, 47 percent could write simple sentences, 25 percent could write words, and 6 percent wrote nothing legible. Seventy-three percent of learners could do the four arithmetical operations correctly with simple numbers. (Correlations between the three skills were about 0.5; Carron, Mwiria, and Righa 1989.) It is uncertain whether skills were lost or whether the quality of instruction had been very low to begin with.

The above studies have not overcome the serious methodological problems of locating and retesting neoliterates, such as self-selection. Without randomized selection, pretest data, or other measures, it cannot be ascertained to what extent the people who consented to being retested were representative of the neoliterate population. It is quite likely that the higher-performing persons and those with more time available would be more eager to show their skills. After a process of self-selection through enrollment in a course, survival of dropout, and passing a course, the persons who retained literacy after two years may have been truly exceptional in some ways. None of the studies statistically separated the effects of skills-use from performance; on the contrary, some neoliterates tested were involved in agricultural and income-generation programs, which may offer neoliterates extra practice. However, the studies made valiant attempts to implement difficult quasi-experimental designs. It is hoped that some future large programs will incorporate such research from their inception and have available the variables necessary to conduct robust studies that will demonstrate relationships between cause and effect.

Even if the conclusions of Comings, Shrestha, and Smith (1992) — that at least 50 percent of participants tested seem to retain or improve their skills - can be generalized, the efficiency of the programs remains low. If half of the participants remain literate, the average efficiency of about 30 percent at the end of a program drops to 15 percent after some time.

\section{The Effectiveness and Practices of Post-Literacy}

Extensive funding for formal and nonformal literacy would be justified only if instruction produces a stable, permanent skill. Governments and organizations that fund multi-million-dollar projects expect to impart knowledge that can be used whenever needed by the neoliterates without the need for constant practice.

The instability of the skill is a major concern. Adults who complete literacy programs are often only marginally literate. Most writers (for example, Lind and Johnston 1990) believe that most or all lapse back into illiteracy unless they participate in post-literacy activities. A 1992 task force on literacy materials of Bangladesh concluded that a person receiving training of about 300 hours relapses into illiteracy if she or he is continuously out of practice for about 250 hours. Similarly, Roy and Kapoor (1975) concluded that there is a relationship between 


\section{What We Know about Acquisition of Adult Literacy}

program duration and relapse into illiteracy. Taking this a step further, the 1976 declaration of Persepolis (IDRC 1979) stated that post-literacy should not merely reinforce literacy techniques by providing materials but should also create an environment that encourages individuals to act effectively as literates in daily life and to react critically to their understanding of reality.

Conclusions are mainly speculative; the international literature shows few data that can document the benefits of post-literacy or compare rates of retention as a function of the amount and type of post-literacy given. It is unknown after how much practice the skill is finally consolidated. No dropout data have been found for post-literacy classes nor test results after post-literacy. (It is possible that data have been collected in Thailand, but they are not readily accessible.) As a result, Comings (1992) as well as earlier reviewers such as La Belle (1986), doubt that post-literacy is essential to retention per se, though it can provide useful practice, particularly in environments deprived of written materials.

NGOs in many countries (for example, Bangladesh) are offering two- and three-year courses to small children and to adolescents in hopes of making them literate and under the assumption that they will remain literate.12 The need for post-literacy and skills consolidation is pertinent to programs for children as well, but there is some evidence that primary-level students may acquire stable skills. Through a longitudinal design, Hartley and Swanson (1986) found that dropouts from Egyptian primary schools showed no significant loss of skill during the first year after dropout, and slow or no loss thereafter. On the contrary, the skills of some students had improved; the illiterate dropouts had probably never become literate in the first place. A study in Morocco with fifth-grade leavers showed similar results (Wagner and others 1989). This finding supports Comings' conclusion that if skills are acquired, they may be retained even without post-literacy classes. It implies that if neoliterates acquire a minimal level of competency in decoding messages, they may use the skill and thus improve it through practice.

If the amount of post-literacy needed for a stable skill depends on age, then advocates of post-literacy as well as Comings might be right. Educated foreign readers seem to have difficulty maintaining or improving their skill when the reading process is too laborious (appendix B). Could adults somehow have less effective consolidation of memory traces and pattern recognition ability than children? If so, then reading for adult neoliterates would be slow, tiring, and certainly not automatic or fun. The difficulty may discourage people who complete a course from further reading and may bring about relapse into illiteracy if post-literacy is not available. A corollary of this hypothesis is that ability to merely decipher labels and short messages (which some government officials consider a sufficient goal) may

indicate unstable skills and may not be maintained for long. Adolescents and children, on the other hand, might more easily reach a skill level that is self-reinforcing.

If age during acquisition of literacy is a significant factor, then younger neoliterates (for example, adolescents) might require less or no post-literacy. Somewhat older neoliterates, on the other hand, might have to commit a priori to a certain (as yet unknown) amount of post-literacy, without which literacy instruction might have no long-term effects.

There is some evidence that skills are retained better or improve in income-generation programs or after primary-school students drop out (and presumably start working). This would indicate that people will persevere more when they see the need for a skill than they will persevere in a mere academic setting. Material whose purpose is clear is more likely to be recalled and used (Perfetto, Bransford, and Franks 1983), and literacy might be more effectively taught in conjunction with activities that require it instead of the usual detached classroom activity. "Reading to learn", therefore, should be more effective than mere "learning to read", and literacy should come second, after more important activities. However, the apparent greater effectiveness of income-generation projects may be due to other reasons, such as an absolute requirement to become literate and a highly selected population that might do well even in a classroom-only program. Given the known greater cost and complexity of 
What We Know about Acquisition of Adult Literacy

income-generation programs, we should research what makes them more effective and attempt to produce similar effects (such as early reinforcement and immediate demonstration of utility) in classroom-only programs. (See chapter 5.)

\section{Chapter 4- Determinants of Adult Literacy Acquisition}

Many variables influence the probability that someone will become functionally literate (Jennings 1990). Literacy studies tend to focus on factors exogenous to the learners, such as instructional and methodological problems, including the use of poorly trained teachers; competing needs for the time of the poor; lack of reading stimuli, particularly in rural areas; and institutional weaknesses. These factors are important, but participant-related variables have been rarely measured and their role is not yet understood, although in the Comings, Shrestha, and Smith (1992) study they accounted for 31 percent of the reading-score variance.

As with many other complex issues, a multiple regression model can be assumed. The probability of becoming literate is probably a function of many variables with different weights. We have very little information regarding the regression weights variables carry or which interactions among them significantly raise or lower the probability of becoming literate. Variables probably include physical health, gender, number of small children, parental education, stability of home life, and opportunities to practice literacy outside the classroom; also attitudes and beliefs about literacy and its role in individual and cultural advancement. Affective and personality variables may also be important in literacy-related decisions, such as dysfunctional beliefs about schooling, prior teacher abuse, optimism versus pessimism, and locus of control. Neurological and cognitive variables probably play a role that is not well understood. This section and appendices $\mathrm{B}$ through $\mathrm{D}$ review potential variables that affect the acquisition of literacy and supplement them with hypotheses based on cognitive research.

\section{Attitudes and Beliefs}

The role of attitudes and beliefs with respect to literacy has been mentioned only in passing, and no research has been found on this issue. However, social psychological theories may explain to some extent the patterns of facilitation and obstacles met during literacy attempts. According to the norm theory (Kahneman and Miller 1986), people are accustomed to the presence of certain factors in their lives, which they regard as normal (these may include illiteracy and lack of sanitation). This familiarity may diminish their desire to improve conditions. At the same time, literate workers may regard literacy as the norm and not understand how illiterates can function without reading.

Important also are beliefs regarding the reading skill itself. The 1976 adult education campaign in Burma found that adults often did not enroll in classes because they believed they were too old to learn (IDRC 1979). Specific beliefs about the undesirable behavior of literate women may have prevented an unspecified number of them from enrolling or from staying in classes.

\section{Role Modeling}

Some authors believe people may imitate the actions of literates (or illiterates) if these actions are seen as desirable. In literate homes people have multiple uses for reading, such as writing messages and letters, paying bills, and reading prayers, which young children have been observed to imitate. There are common patterns in reading and writing activities in any community, and membership is partly defined by knowing and participating in these practices (Barton 1990). When the literacy-related functions in a community reach a critical level of frequency (it is unknown what that level is), illiterates (adults and children) may try to model their behavior after the literate members. Conversely, when illiteracy is the norm in a family, there may be social pressures against the 
What We Know about Acquisition of Adult Literacy

pursuit of reading

(Fitzsimmons 1991). The tendency to model may also provide practice opportunities, which strengthen skills. This may be one reason why literacy seems easier to disseminate as its incidence goes up and why it seems difficult to sustain in circumstances where related activities are unusual.

Illiterates may be more likely to learn reading if they perceive literacy activities as close to their daily concerns and literate persons as people relatively similar to them. Conversely, they may not pursue literacy if they perceive literate persons as totally different or remote from their daily concerns (Rogers, in print). An example was a UNICEF experimental program in Mahbubnagar, India, which attempted to teach health and nutrition, and literacy to village women. Although the literacy material was written by teaching agents in a form that they thought was closely related to the central concerns of the learners, the women still saw literacy as removed from themselves; they saw it as the domain of men and teachers, or only useful for younger, freer, and more ambitious members of the community who might search for jobs in towns. Literacy was not for village women, and they did not find it easy to role-model literacy activities.

\section{Self-Concept and Status}

Publications frequently mention the positive effects of literacy on the self-concept and self-confidence of neoliterates. Interviews with neoliterates in Tanzania showed that literacy had made a powerful and positive impact on the quality of life of the majority if not of all the learners (IDRC 1979). They were less alienated and afraid, more politically involved and self-confident, and felt more dignified. Interviewees in Bangladesh expressed the same feelings (Rogers 1991a).

The health and income benefits of literacy on women, in particular, have been greatly emphasized (for example, Ezzine 1993). It has been suggested that even if women do not actually become literate, their self-concept and social status will improve through class participation. However, as in other literacy-related areas, there is a paucity of research-based information. Data that could be related to self-concept contrast women schooled in childhood with adult illiterates. It is possible, however, that adult neoliterates do not identify with the literate population but see themselves as illiterates who learned to read (Joshi 1991). Even if the assertions of literacy personnel are taken at face value, it is unknown how the self-concept is influenced by relapse into illiteracy.

Literacy is often see as a status symbol, and persons who may not have a clear idea of what literacy can do for them, may nevertheless pursue it for its social value (Jennings 1990). But the possible increase in status may actually be a deterrent in some circumstances. Improvement in reading skills may alter positions of learners in their social networks, and that may lead to ambivalence about the improvement of such skills (Fitzsimmons 1991). The ambivalence may act as a disincentive to continue the classes, particularly for women and their changing relationships with in-laws and husbands.

Research on the self-concept of illiterates has been conducted in the United States and mainly concerns the disadvantaged who failed to become functionally literate in school. The research suggests that literacy training increases self-confidence and improves the self-concept of female participants. However, a modicum of self-confidence and ability to make decisions may be needed in order to persist in a class. It is possible that those who persist in reading programs are more inner-directed, with an internal locus of control, while those who do not persist may be more influenced by social pressures (Fitzsimmons 1991). If this phenomenon is significant in low-income countries, motivational techniques focused on reinforcing the inner desires of individuals might be effective in combatting dropout. 
Typically, the self-concept is measured with paper-and-pencil instruments. Besides script difficulties, neoliterates may be unaccustomed to answering questions that require considerable introspection and self-evaluation. It is, therefore, not an easy area to research with illiterates and neoliterates. Nevertheless, innovative attempts to measure this must be made if improved self-concept is to be considered a proven benefit of literacy.

\section{Motivation}

The literature search did not find any rigorous studies on adult or children's incentives or on motivational barriers with respect to reading. 13 Many anecdotes have been published, and several evaluation reports mention the reasons people have given for learning to read (see, for example, Sawyer and Rodriguez, undated). According to a very comprehensive document (Lind and Johnston 1990), adults would like to become literate in order to:

- Read and write letters, particularly to migrant relatives

- Help their children who attend school

- Get employment or a better job with higher salary and status

- Gain social prestige

- Avoid deception by checking calculations and reading contracts

- Strengthen self-confidence

- Get further education

- Acquire more knowledge about social rights and duties

- Participate in and influence social and political life

- Keep accounts and minutes within social or political organizations

- Teach others

- Improve the living conditions of themselves and of others.

The long-term goals of illiterates often seem to be compromised by short-term constraints. These include lack of time to attend classes, difficulty in mastering reading strategies, limited attention span, boredom, and lack of a grasp of what literacy has to offer. Women face additional barriers, such as the double workload and prohibition of male relatives who are afraid that women may learn more than they know. To the Lind and Johnston list of obstacles, the acquisition of coping skills could also be added, because it might account for low initial enrollments in literacy programs. Adults learn to get around their illiteracy by doing jobs that do not require it, by memorizing certain facts, or by asking for the help of literate relatives, often their children. Therefore, they believe that they no longer need literacy. To deal with this tendency, well-designed programs (for example, the Thai campaigns of the 1980s) presented sketches of illiterates unable to read signs in hospitals and highlighted the inconvenience of asking for help.

Is lack of motivation a satisfactory explanation for dropout in literacy classes? Dropout is actually a more serious problem in formal primary schools than among adults; in some countries, 70 to 80 percent of children drop out before they have acquired basic reading skills, and become the future illiterate adults. However, children's dropout 


\section{What We Know about Acquisition of Adult Literacy}

is attributed to external factors - need for the child's labor, low value of girls' education, teachers' rejection of poor and dirty children, or teacher absenteeism. Authors seem to assign different motives to children than to adults. Adults are seen as lacking the motivation to carry

through their desires (despite multiple handicaps), but children are somehow assumed to be eager to continue school despite school-related problems. The reasons for the difference may be partly ideological; it is easier to assume that children want to go to school. It is possible, however, that ease of reading acquisition is at the base of the perceived difference. Reading acquisition seems to be fun for children without reading disabilities (Feitelson 1988; Adams 1990), but no documents were found that described it as fun for adults. Of course, the difference may be due to what is considered fun by children versus adults; nevertheless, an age-related issue may exist. An undetermined number of adult participants in a class may drop out because of unspecified difficulties (for example, in telling similar letters apart) and subsequent discouragement, which seem like lack of motivation. They might also drop out at a time when they are revising their reading strategies and their performance temporarily deteriorates (see the section on making information memorable in chapter 5). Dropout may, therefore, reflect unwillingness to continue a tedious task, and housework may provide a useful excuse. (Educated adults in industrial countries can find excellent excuses not to attend aerobics classes.) The need seen by some experts for non-reading strategies to entice illiterates to class after the first few sessions (such as group action or social events) as well as the importance of instructional factors may also be indicative of the problem.

According to some writers, dropout may also be due to a lack of concern for participants' desires and a lowering of their self-esteem (for example, Rogers 1991b). The typical adult literacy class gives control to a teacher who may have negative attitudes toward poor illiterates. The material to be learned is dictated by a central agency, and learners are expected to obey. When they escape from this directive environment, they are blamed for lack of motivation. Instead, control could be given to the learners, who would decide who should facilitate their learning, what they would like to learn, and even how the local budget should be spent. One NGO in Bangladesh that adopted this participant-centered approach reported dropout rates at near zero. Nevertheless, participant-oriented approaches are considered by many agencies difficult to implement on a large scale.

Many poor illiterates do persist in classes and are known to overcome serious obstacles (IDRC 1979), perhaps due to favorable external factors, such as less housework or a good teacher. Possibly, those who stay learn more at earlier stages or are somehow reinforced by success. Dropout, therefore, may act as a screening device. The survivors may have enough motivation or intellectual ability to counteract the various obstacles and may be more likely to become literate. Since multiple systematic selection processes operate, the neoliterates may be quite exceptional individuals in some ways. If so, the incidence of adult neoliteracy may approach the incidence of advanced academic degrees in industrial countries. This is not a pleasant consideration, but one must examine the question whether programs intended for the general population only help exceptional individuals.

Psychological research suggests that among the very poor, learned helplessness may be a motivational constraint. Experience may teach people in dire circumstances that there is nothing they can do to improve their lives, so they stop trying (Smith, Sarason, and Sarason 1982). It is this situation that the famous literacy promoter, Paulo Freire, tried to ameliorate by raising the consciousness of the poor regarding their predicaments and by teaching them how the related words were spelled (for example, "poverty", "landlord").

Despite much discussion, there are few hard data about the role of motivation in adult literacy. Experimental evidence is needed to indicate how various motivational processes affect the probability that illiterate adults, adolescents, and children will go to a class and stay through it. Information on the effects of endogenous and exogenous factors on class attendance for adults and for children would help 
What We Know about Acquisition of Adult Literacy

structure both formal and nonformal programs so as to maximize the probability of attendance and, hopefully, achievement.

\section{Cognitive Processes}

Ultimately, human learning and thought consist of a retrieval and processing system that constructs knowledge on the basis of related information. These systems seem to operate quite similarly among people of various cultures and appear to be neurologically determined. The brain structures and biochemical processes involved in the formation of memories and thoughts are only now beginning to be understood. Research on the effects of age on memory and other aspects of information processing has largely focused on remedying problems such as mental retardation and dyslexia among children, as well as on Alzheimer's disease and other types of dementia among the elderly. Little is known about intermediate ages and virtually nothing about changes in the adolescent and the early adult years (see, for example, Newport and Johnson 1989). The hippocampus that mediates short-term memory consolidation undergoes changes with the onset of adolescence, but the effects are not yet well understood.

Very little is known about how illiterate adults purposefully learn new information. Adult education theory maintains that adults are able to determine by themselves what they should learn and how, and that a teacher is only a facilitator of the process (the concept of andragogy; see Knowles 1973 and many subsequent authors). Research on learning styles highlights individual differences in learning modes. However, it is unclear how people with no schooling experience may structure learning tasks and it is unknown which learning styles might best suit them. Some studies indicate that illiterates may process information somewhat differently from schooled people, an issue which may influence in undetermined ways the probability that they will retain and then use information acquired in literacy classes (appendix C). This hypothesis lends support to the participatory method for course development; but even when special participatory efforts are made, literate and illiterate adults may not communicate efficiently (Rogers 1992, p. 231). Differences in information processing constitute one more possibly important issue that has not been researched.

\section{Effects of Malnutrition on Cognitive Functions}

Malnutrition creates cognitive deficiencies that have been studied with school-aged children (Levinger 1992). Iodine deficiency occurs in many areas, including areas of heavy rainfall, which causes iodine to be leached from the soil (as in Bangladesh.) Iodine deficiency is associated with reduced intelligence, psychomotor retardation, impaired hearing, and mental and neurological damage. Protein-energy malnutrition has long-term effects on cognitive functions, such as the ability to learn categories, to process and structure information, to learn and react to social and environmental cues, to ask appropriate questions within a given environment, and to identify and solve relevant problems. The deficiency is more prevalent among females and may contribute to performance differentials and likelihood of dropout.

It is not known how malnutrition affects adults nor to what extent malnutrition in childhood has lingering effects on the ability to learn of adults who are adequately nourished. One would expect effects with respect to attention span, energy level, and vision for night classes (due to lack of vitamin A). Research in this area is yet to be undertaken.

\section{Cognitive Prerequisites of Reading}

Three variables have been identified for which there is substantial evidence documenting a relation with success in learning to read (see appendix D for more details): 


\section{What We Know about Acquisition of Adult Literacy}

- Phonological awareness - the ability to understand that words (and possible morphemes within them) are made out of smaller parts;

- Verbal memory — the ability to retain the identity and/or order of words or other verbal material for brief periods of time;

- Working memory — the mechanism coordinating simultaneous processing and storage in reading acquisition.

Phonological awareness 14 is the only variable that has been researched with adult illiterates (Bertelson 1986; Bertelson, De Gelder, Tfouni, and Morais 1989; Bertelson and De Gelder 1991). It seems to be a prerequisite for effective reading skills, but also a byproduct of the reading process. Illiterate adults and children seem to be unaware that words consist of consonants and vowels and score much lower than literate people on tasks that require them to delete the initial letters from words, particularly consonants. Existing research is unclear as to whether illiterates would benefit from drills that would teach them the building blocks of the sound system in their languages. If phonological awareness proves to have a beneficial effect, such drills could easily be added in literacy courses.

No research exists to indicate how well verbal memory and working memory measurements can predict success in reading for illiterate adults. The ability to read nonsense words is correlated with the ability to comprehend text, and a critical period for acquiring this skill may exist in life (Mattingly 1984). However, it is conceivable that research could be carried out and that candidates for literacy classes could be screened through tests that might predict success. The ethical questions and social desirability of such screening have not been dealt with before.

\section{Age-Related Problems with the Acquisition of Literacy}

A literature review on age-related issues in the acquisition and retention of literacy was financed by the World Bank in 1992 and was carried out by Dr. Timothy Salthouse, Professor of Psychology at Georgia Institute of Technology and a prolific researcher of age-related effects on cognition, particularly among the elderly. His review (condensed in appendix D) found very little research that directly addressed literacy and also found very little research that covered the adolescent and early-adulthood years. The available information indicates that:

- There is no evidence to show that people ever become too old to learn to read. Actually, adults may find reading acquisition easier or faster in some respects, because the levels of relevant cognitive abilities during most of the adult years are higher than those of children at ages when they are generally successful at learning to read.

- There is little or no relation between age and measures of acquired knowledge or the accumulated products of past processing, sometimes referred to as crystallized intelligence; however, moderate to large negative correlations are frequently reported between age and measures of the efficiency or effectiveness of processing at the time of assessment, which is sometimes referred to as fluid intelligence. Older individuals might acquire literacy but may read more slowly and make more errors.

- Age-related declines have been found in paired-associate learning, verbal memory span tests, and working memory tests. However, differences are relatively small; the performance of adults in their seventies is only one or two standard deviations below the mean of young adults. Age-related declines between children and older adults have been found in variables that represent the processes of segmentation, spatial integration, and rapid access to longterm memory. However, no information is available for the ages in between. Older adults may be less capable than younger adults of acquiring automaticity, but both groups benefit from practice. Declines are reported after age thirty-five in the rapid processing of visual and spatial information. 


\section{What We Know about Acquisition of Adult Literacy}

- There is almost no information regarding the relationship between age and retention of cognitive correlates of reading. The few studies that exist show little or no difference in the retention of perceptual-motor skills, mental calculation skills, and aspects of a newly learned language.

- In second-language acquisition (a frequently used analogy for literacy), adults have an advantage early in learning, but children are superior in the ultimate level of proficiency. The later the language is learned, the less its use resembles native use.

- Neurological and physiological changes occur with increased age (for example, the number of functional neurons in the brain, and the rate and amplitude of electroencephalograms), but the significance of these changes for cognitive activities is not fully understood.

The cognitive literature search did not focus on attentional resources, which appear to decline significantly with age (Solso 1988). Neoliterates may spend so much attention on deciphering a text that they may not have enough resources left to understand what the text says. At any rate, it would appear that data from literate persons, who have learned to maintain attention in school, might not be helpful in understanding how the attention span of illiterates waxes and wanes. Since attention is the gateway to retention and retrieval, this subject also needs to be studied in literacy classes.

Age clearly plays a role in some long-known variables, such as the ability to remember relatively meaningless material. Despite the paucity of data in the adolescent and early-adulthood ages, age-related differences that have been researched thus far in larger age spans seem to be relatively small. It is possible, that significant interactions are created by these variables, which by themselves show no significant effects. It is also possible that the difficulties of foreign readers (see appendix B) are due to variables that have not been investigated, as many have not yet been. It must be concluded that systematic age-related cognitive problems are probably not very important in the acquisition of basic literacy, the realm of literacy courses. Yet the difficulties reported by foreign readers (for example, in pattern formation and decoding speed) may still prove to affect achievement of automaticity and may surface when neoliterates attempt to reach more advanced reading levels. That these levels are usually

beyond the goals of literacy programs is in itself ominous and raises the concern that the quality of programs may improve but that functional literacy may still not be easily attained due to as yet unidentified cognitive problems. The age-related hypothesis, therefore, may merit academic research with populations of foreign readers as well as with neoliterates in the process of acquiring reading experience (appendix B).

\section{Cognitive Processing of Numbers}

This paper has not discussed numeracy, which is almost always taught along with literacy. Various cognitive issues are involved in this skill, which have been outside the focus of this review. Evaluation studies (for example, Jennings 1990) indicate that numeracy is forgotten more easily than literacy, that women often score lower (possibly because they use numeracy less), and that certain concepts (such as decimal places) may be particularly difficult for neoliterates (New Era 1989 and 1990).

The ability to add and subtract has been identified in babies a few months old. Although illiterates lack word-attack skills, they do have a numeracy system in their minds (however imperfect and error-prone) before they enter literacy classes. It is apparently unknown how the formal system taught in literacy classes substitutes the one(s) illiterates already use, or how permanent the substitution is. It is possible that the old system interferes with the new, and this may be one reason why numeracy may be more easily forgotten. The systems illiterates use to count and to calculate have been rarely researched (notable exceptions are Gay and Cole 1967; Cole and Means 1981; and studies of New Guinea natives around 1979). Findings, apparently, have not been used to improve literacy programs. 
What We Know about Acquisition of Adult Literacy

The literature of numeracy and the information processes it involves must be researched separately. Perhaps literacy courses should try to improve the numeracy systems of illiterates or to link the old with the new rather than substitute them with incompatible methods doomed to fall into disuse.

\section{Psychophysiology}

Recent research has shed considerable light on how the brain processes information biochemically. There is an increasing amount of evidence to indicate that experience changes the physical structure of the brain. The poverty of experience in childhood, for example, may reduce the basic maps and networks that are needed for complex learning (ASTD 1993). It is possible that the capacity to read depends on the appropriate structures being developed in the brain, which poverty might somehow compromise. If this is so, unforeseen obstacles may lie ahead for agencies involved in teaching literacy to the poor.

Studying the brain while it processes information may give us some clues on how literacy is acquired and how neoliterates process texts. Positron emission tomography (PET scan) enables researchers to observe how the blood flow in various parts of the brain changes as particular tasks are carried out. Petersen, Fox, Snyder, and Raichle (1990) studied decoding processes in the brains of undamaged volunteers while they were reading actual and artificial words. When volunteers looked at a real word, such as "board", a spot in the very hind part of the left cortical hemisphere (the left, medial extrastriate region of the occipital lobe) lit up. It also lit up when they looked at artificial words that conformed to the rules of English spelling (such as "tweal" or "floop") but were not words. But when they looked at a set of meaningless markings that had vertical, horizontal, and curved strokes comparable to real letters, the spot remained quiet. This word-recognition spot also remained quiet when volunteers viewed random strings of real letters that did not make up a word, such as "nlpfz".

These findings showed that the brain does not recognize a word merely by the shapes of its letters. The word-recognition spot lies anatomically very near the part of the brain that deals with visual information. So, determining whether a set of letters conforms to the spelling rules or is pronounceable must be one of the first steps that the brain takes in the process of reading. This spot has to be "wired up" as a person becomes literate.

A disorder called alexia results from brain damage to this word-recognition spot and prevents a formerly literate person from reading. The person can write perfectly spelled words, but to read he or she must slowly go over each word letter by letter. As discussed before, this is how many neoliterates read. It is conceivable that changes in the brain as it reaches adulthood influence the "wiring up" of this spot and that adult neoliterates become in some ways "alexic". Research on the brains of neoliterates and foreign readers of non-native scripts as they read, might provide valuable information on how people process a new script and what can be done to help "wire up" the word recognition spot of neoliterates.

Psychophysiological findings on memory creation and consolidation have not helped educational methodology very much in the past, but are increasingly becoming more relevant. One example of how reading skills may be influenced by psychophysiology is the recent discovery that the dream stage of sleep plays a role in the consolidation of skills acquired during the day, particularly for motor coordination skills. Experimental subjects who were exposed to computer patterns and who then slept improved their ability to recognize the patterns by 300 to 400 percent over subjects who subsequently stayed awake. Subjects who were interrupted while dreaming recalled almost nothing (Karni in USA Today 1992).

It is unknown how the skills involved in the acquisition of literacy can be affected by this process, or how much time must elapse between learning and sleep. Many classes take place at night, which could, in theory, facilitate the consolidation of skills (but could be counteracted by fatigue and diminished attention). However, many young mothers would be likely to be woken up while dreaming, an additional factor that might militate against the acquisition of literacy by women with small children. (See appendix B.) 
What We Know about Acquisition of Adult Literacy

\section{Visual Perception}

As mentioned in chapter 2, visual perception may be the most important issue in reading, yet studies involving illiterates have been very few. The best known involve the decoding of pictures. It is unknown how adults unaccustomed to studying tiny two-dimensional patterns perceive the often minute differences among letters. A study in Zambia (Courtault 1989) showed that illiterates may experience significant difficulties in understanding pictures and drawings if they live in an environment that is poor in written signs. Pictures that showed the front view of an object without details were perceived correctly by two-thirds of Courtault's subjects; pictures that represented the classical rules of perspective were perceived correctly only by 25 percent, while pictures representing a part of the object from a particular angle were perceived correctly only by 10 percent of the subjects. Of sixty-three adult illiterates who were asked to recognize a pictorial presentation in Zambia, only 4 percent recognized a simple drawing and 7 percent recognized outlines, while 57 percent recognized a situation with a whole photograph. A black and white picture was understood by 50 percent of the subjects and a colored one by 70 percent of the subjects. The results indicate that frontal colored photographs are most likely to be understood, and anecdotal accounts indicate that illiterates can be easily trained to "read" pictures. However, it cannot be assumed that pictures in literacy books facilitate instruction, particularly when they are not frontal colored photographs.

Aside from concerns regarding the effectiveness of much-used pictures in literacy books, perceptual difficulties with pictures illustrate potential difficulties with letters. Some research with animals indicates that visual perception is altered quite drastically if their visual field is somehow altered during their development (in Smith, Sarason, and Sarason 1982). Is it possible that nonexposure to written stimuli or to pictures during the childhood years has a permanent effect? No related research has been found.

Another problem may exist with visual perception. Educated foreign readers seem to have trouble deciphering nonstandard shapes or they confuse them with other similar shapes (appendix B). This might indicate diminished tolerance for perceptual inconstancy in later years. It is unknown how people develop perceptual constancy for letters. Does the process change with age? Perhaps, if they are trained to look for the constant features of each letter that tell it apart from other letters, the learning process may be speeded up and neoliterates may mix up letters less easily.

An undetermined number of illiterates have eye refraction problems (for example, astigmatism, myopia, or presbyopia) that may prevent them from seeing a blackboard or their textbooks. The incidence among illiterates in developing countries is not known, but 51 percent of all people in the United States have refraction problems, and nearly all adults above age forty have some degree of presbyopia (American Optometric Association 1992). A study in the Philippines showed that poor eyesight is an important contributor to dropout in children (cited in Levinger 1992). Perhaps simple eye tests incorporated in the instruction of the first few days could identify such individuals early before they become discouraged by their apparent learning difficulties. Test charts that could be used by teachers have been printed by the Helen Keller International Foundation.

\section{Chapter 5- Effective Instructional Methods}

It is a dictum of cognitive psychology that unless something makes sense to a learner, it will not be remembered or used when the need arises. Information is remembered only when learners can find in their minds classification schemes on which to attach an incoming piece of information. But attaching the information to just any scheme is not enough to make it usable, because an item is retrieved through the network in which it is stored. For example, if it has been attached along with unconnected items learned in sequence (such as the lines of a poem), it may be 
only retrievable in that sequence rather than when it is needed. (For a review see Abadzi 1990.) A corollary of this theory is that people are much more likely to remember and utilize information if they clearly understand its utility (Perfetto, Bransford, and Franks 1983).

These principles are the basis for the methods discussed below. Some may require a more instructionally enriched environment than is often available. They are nevertheless presented, in hopes that literacy programs will gradually provide more options to participants.

\section{How to Attract and Keep Participants}

It is more likely that adults will persist in the study of reading if they clearly understand its utility in their own world and see how they can solve their problems with it. A literacy expert in Bangladesh, for example, tells adults during the first day of a class that by the end of the session they will know how to write a letter to their uncle asking for money-"Kaka, 1 taka chai". Students copy the letters from the one-taka note and from a can of tea. The teachers of an NGO (Gono Shahaja Shangstha) that mainly serves destitute children read stories aloud in the beginning of the class, showing children where the words are located on the page. Students in the Total Literacy Campaign of India write prepaid postcards to local officials early in the course, and officials later meet with them.

To minimize dropout, reinforcement should be delivered early. Besides reinforcement for learning skills, small rewards could be provided to encourage attendance. A small NGO in Bangladesh, for example, hands out shirts or soap about once a month to its out-of-school children and finds the method effective in encouraging learners to return to class. Behavioral research, however, suggests that such rewards should be given at irregular intervals to prevent set expectations and low tolerance to delays. There have been examples of participants learning to expect material rewards when they attend. Recognition and badges may be more preferable rewards.

Illiterates may be inspired by their peers to persist, whereas alone they might give up (Fitzsimmons 1991). (As mentioned elsewhere, the opposite might also be true.) Some experts consider group action important in making reading activities socially acceptable and in creating group cohesion that will keep members from dropping out. Activities planned by groups during class could include cleaning of the village or planting trees, for example. In a program in Nepal that emphasized collaboration, 40 percent of the women were involved in helping others with literacy (Manandher 1989). This is one of several reasons why literacy instruction to existing groups, which are engaged in a specific purpose, is considered more effective than assembling literacy classes (Rogers 1992). It combines support-group features with meaningfulness of literacy activities, such as learning to keep accounts of products sold and reading labels.

It appears that strategies to attract and keep participants are not as systematically used in literacy classes as one would expect; they require creativity, which not everyone has. To the contrary, teachers

may present information in such a way that learners fail to grasp the strategy of reading and may be misled about the use of letters. For example, letters may be presented with their descriptive names and learners may be asked to recite them in combination with the result (for example, in Bangla tolobyo sho + hashoi $=$ shoi ). Unfortunately, teachers tend to teach the way they learned, a problem that must be dealt with during training. (See section on teacher training.)

\section{The Role of Reading Materials}

Many efforts have been made worldwide to create innovative textbooks that readers would find meaningful, and this paper will not discuss them at length. Some practitioners advocate other solutions to keep participants in class, such as loose-leaf pamphlets, which may attract immediate attention; or regional materials developed with the help of participants, which are therefore meaningful to them. Dropout in an Indian program was reduced to 
What We Know about Acquisition of Adult Literacy

almost zero when students were asked to bring materials which caught their attention. Many brought movie advertisements, which they learned to read in groups (Rogers 1993).

\section{Formal Schooling as a Motivator}

Formal degrees are a powerful motivator, and people who might not clearly comprehend the utility of literacy might, nevertheless, work for the status of a primary-school diploma. Literacy courses could be linked with formal schools so that children, adolescents, and adults could complete primary school. This arrangement is often available to children but is rarely available to adults. Yet such arrangements could be relatively easy to establish with ministries of education.

\section{Development from Inside-The Participatory Method}

The need for adult illiterates to be treated with respect rather than like children or ignorant poor has been pointed out by Comings, Shrestha, and Smith (1992) as an important teacher-related variable. One could expect, therefore, that adult-centered teaching methods would be the most effective. Examples would be substantive consultations with adults and their needs as well as programs designed so that they can be modified by participants and teachers according to these needs (IDRC 1979).

Much emphasis has recently been given to development from "the inside," according to how the learners perceive their needs (Rogers 1991b; 1992). When participants are consulted, their views very often vary from what schooled individuals consider effective or important. Although the design of participatory programs is more complex, such programs may be more effective than those developed by schooled people. Hopefully, quantitative data will be gathered in the years to come.

\section{How to Make Information Memorable}

Enabling the useful information to be retained and retrieved when needed is the goal of instruction and the reason why teaching methods are so important. An item initially classified by the learner in a network that is less likely to bring it up when needed, must be elaborated upon so that cognitive bridges can be formed to make that information accessible by other networks. Means to create this cognitive elaboration include analyses, participant discussions, explanations of when and why something is useful, problem solving, applications, illustrations, grouping, cuing, thinking aloud (Bernhardt 1991b); also included are visualization, plenty of writing exercises, instruction of arithmetic in meaningful ways, and

the use of meaningful words and sentences rather than meaningless letter combinations. Since information that has direct relevance to oneself is most easily retained, personal connections must be stressed. Games, role-playing, and encouraging people to give opinions have all been considered effective means to make information pertinent to oneself. Due to the connection with oneself, funny and emotional material has a better chance of being remembered. Reading culturally appropriate jokes would probably provide immediate reinforcement and increase the probability that the reader will continue to decipher texts despite difficulties.

Various instructional methods exist to reach the same goals. Systematic review from session to session of concepts and words is important and frequently a part of literacy text designs (Jennings 1990). But cognitive elaboration of concepts and skills is also important-dissecting the information, combining it with other items, and in general thinking about its applicability. A comparison of two Nepalese programs (New Era 1990) showed that the most effective teaching methods were discussion of posters (52 and 47 percent), a small group work (34 and 39 percent), and provision of (14 and 21 percent) explanations. To illustrate the utility of information, and to bring about transfer of learning from textbooks to the real world, neoliterates could be shown newspaper headlines midway through the course. They could be taken on a field trip to read store signs and graffiti on walls. 


\section{What We Know about Acquisition of Adult Literacy}

They should be given specific instructions to read anything they find with letters on it, including the texts written on coins and bills. Their opportunities to read anything should increase.

Preparatory activities for reading (pre-literacy) are advocated by some. The use of shapes familiar in the community, such as pottery decorations might facilitate the acquisition of reading and writing (Courtault 1989). Although such techniques seem to make sense to many, there is no evidence for or against their effectiveness. The culturally meaningful shapes, however, might be useful in creating mnemonics to facilitate the retention of letter shapes in the long run.

\section{How to Teach Reading Efficiently}

Phonics or whole words? There are lengthy arguments on how people should be taught sound-letter correspondences. In a comprehensive review, Adams (1990) concluded that phonics are more effective in helping children understand the strategy of how letter combinations create sounds. The whole-word approach may conform better to children's ease in perceiving letter patterns but may also force them to develop guessing habits. Though the same discussion has taken place in adult literacy (see Jennings 1990 for a review), no conclusion has been reached, although most adult literacy primers seem to teach phonics.

Progress in reading is not linear. People in the process of learning build models with the information they have, which they revise as they acquire more information and change their strategy accordingly. When that happens (as it often does at the end of first-grade or beginning of second grade for English-speaking children) reading performance may temporarily deteriorate. Literacy teachers are typically not aware of how the reading strategy is acquired and therefore cannot help this process. It is possible that people may drop out during that stage.

Reading is a quick and efficient process because accomplished readers perceive patterns rather than individual letters. As mentioned earlier, it is possible that adults have difficulty perceiving letter combinations as patterns. This implies that the whole-word method would be of limited use to adults, and that special emphasis would need to be placed in teaching adults to see adjoining letters together as

patterns. Except where it is necessary to teach diphthongs, the latter is not frequently done. To make reading more efficient for adults, agencies might study which letter patterns take longest to decode in specific languages and provide extra practice on those using flashcards or other means.

Word segmentation (that is, reading and processing a long word in segments) is another important reading skill in which adults might be less efficient (appendix B). No literacy primers were found that directly taught this skill. Yet another is phonological awareness . Perhaps adult illiterates could benefit from exercises in initial consonant deletion. However, the research has only been correlational; a cause-and-effect relationship has not been established between reading achievement and performance in tests of phonological awareness.

Reading aloud to participants may help to promote interest and achievement. In a multicountry study of the reading achievement of children, reading to children showed the highest correlation with achievement among many measures, such as attention to phonics and encouragement to read (Lundberg and Linnkylä 1993). Although the success of this method has been documented only with children, it seems to demonstrate the direct utility of reading and to provide role modeling at the same time.

For many reasons, literacy class participants do not progress at the same speed. (Some may be school dropouts who know many letters shapes.) Within-class grouping may be effective in addressing such differences and in preventing dropouts that are either due to boredom or due to being left behind. Peer tutoring and cooperative learning may take place in such groups, which has been found effective in strengthening skills of both tutors and tutees (Slavin 1986). However, grouping procedures require specific teacher training. 


\section{What We Know about Acquisition of Adult Literacy}

Writing seems to be one of the first activities children undertake. Anecdotal evidence indicates that it may be a very important activity and could make programs more effective by:

- Creating an additional, psychomotor pathway to store letter shapes

- Helping people figure out that words are made up of smaller units and promoting phonological awareness

- Consolidating a series of letters into recognizable letter patterns

- Enabling learners to become better spellers; it appears that better spellers are faster and more accurate readers.

The contribution of writing to the consolidation of the reading skill is not widely understood. As a result, writing is used relatively little in literacy classes and often to copy rather than to create text. Emphasis on reading at the expense of writing may make learners see words as inert pictures rather than jigsaw puzzles with constantly changing parts (a problem dislexics have). More time needs to be devoted to this activity within the short timeframe of a literacy course, and participants must be encouraged to write on their own outside the class time as early as possible.

Other issues with respect to adult illiterates may merit consideration. Attention is the most important prerequisite to the retention of information, and has been studied with schooled individuals. But the attention spans of adults who never sat through school sessions have not been studied. Another

issue is the tendency among illiterate adults to use consensus validation rather than rules of logic (appendix C). Frequent use of inductive reasoning (IDRC 1979) may reinforce this cognitive skill.

\section{How to Minimize Relapse into Illiteracy}

Cognitive psychology research provides some ideas on how to make letter shapes more durable in long-term memory and thus reduce relapse into illiteracy:

\section{Creating Permanent Memory Traces}

Although children seem biologically predisposed to learn material that initially has little meaning to them, adults are much more likely to remember items when they can associate them with other entries in their cognitive networks. Adults are also much more likely to remember concepts when images are associated with them, particularly interacting images (Solso 1988). Rather than teaching letter shapes to adult illiterates that are meaningless by themselves, efforts could be made to create associations of letter shapes with specific objects and to create interactive images among the objects to the extent possible.

Rhymes and words to a tune seem to help retain unrelated items serially in long-term memory. The words evoking the letter images could be put in a song, which neoliterates could sing and search in its lines whenever they need a letter shape. Songs very effectively package material for long-term retention. Dance movements could be added to form the shape of letters along with the song in order to reinforce material through psychomotor means. The neoliterates would be specifically taught the means to retrieve a letter shape by going through the song and identifying the shape they need.

Numerous efforts have been made to create memory aids (mnemonics) for letters (Feitelson 1988). Laubach, a missionary who worked in the beginning of the century, developed such techniques, and a literacy text was found in Bangladesh that made a systematic effort to relate objects to letter shapes. But few attempts have since been made to create an entire mnemonic system, and no method has been found that packaged the material in a song. 
Although mnemonics should help people remember letter shapes in the long run, their utility is not well understood. Users of this method in Bangladesh realized that the naming of objects for letters in the beginning of a course interfered with the learning strategy, and learners did not understand what the shapes were for. To ascertain that the mnemonics are meaningful to illiterates and to promote cognitive elaboration, they might be taught later in a course, when the reading strategy has been understood as means to prevent relapse into illiteracy. Class participants rather than literacy specialists might be asked to give names to images evoked by the letters.

Relapse into illiteracy might be minimized by focusing on what is actually forgotten and offering extra practice during a course. Along with finding out which letter patterns take longest to decode, it agencies might also study which letter shapes illiterates confuse or most easily forget in a particular script (assuming differences are systematic rather than individualized). Extra practice or mnemonics could be given specifically for those.

Research has shown that multichannel inputs (visual, auditory, tactile, gustatory, and olfactory) create longer-lasting memory traces. In theory, illiterates could be given multiple presentations of letters and patterns on a screen along with auditory input. Letters could be presented as forms for illiterates to manipulate (such as, cookies with different tastes or smells), which illiterates would be asked to elaborate upon. Such techniques, which are sometimes used with dyslexic children in industrial countries, would

be too unwieldy and expensive or appear ridiculous in the developing world. However, the effectiveness of multichannel inputs is well established, and culturally acceptable low-technology methods need to be experimented with.

Another tool against relapse into illiteracy might be the development of participants' metacognitive skills : to make participants aware of how they process information so that they can monitor what they remember and forget and figure out what to do to in order to forget less. Nowhere in the literacy literature is there a mention of teaching adult learners to monitor their own cognitive processes. This has been mentioned as a powerful method for teaching low-achieving children in the United States, but it requires teachers who themselves understand metacognitive strategies. The frequent low levels of formal education of literacy teachers make this difficult, but this could be taught and tested as one more possible avenue to improving the instructional effectiveness of adult literacy programs.

Provision of opportunities to practice reading and writing should maximize the probability that the skill will be retained once it is acquired. Yet in many villages around the world there is not even a store sign. Some programs make the environment "literate". In China in the 1950s materials were brought into largely illiterate villages to accustom people to their presence and to provide opportunities for reading as they progressed. This approach can be explored more systematically in future programs.

\section{The Problems of Training Teachers}

Literacy teachers (who are often called facilitators or animators in the adult education literature) often lack the skills and level of education needed to understand the problems of literacy and effectively teach adults. They are often primary-school teachers, who are trained to teach children. They may be low-paid or volunteer local recruits with limited education, although some are more effective than primary-school teachers in teaching adults (Noor 1982). Teachers often show negative attitudes as well as a lack of confidence and ideological commitment. Their dropout rate may be high (for example, 40 percent in a program for Tamil Nadu, India) and classes may be cancelled as a result of teacher absenteeism (Rogers 1992).

Substantive proposals for increasing the probability that course participants will become and remain literate typically hinge on teacher dedication and expertise. Unfortunately, training programs for literacy teachers last only a few days and mainly consist of lectures and discussions of the materials. Often, curricula do not include 


\section{What We Know about Acquisition of Adult Literacy}

adult classroom management issues such as dealing with absenteeism and dropout, providing early reinforcement, the need for post-literacy, what to do with the children who come with parents, or with the attention span of adults. Curricula may also fail to take into account the variable backgrounds of the teachers, and may not teach them how to improve and to make decisions regarding the needs of the specific groups they are working with.

The extent to which teachers benefit from training as it is usually administered is uncertain. In Bangladesh it was found that many simply ignored instructions and taught letters through the traditional order and names they themselves had learned. Another problem is lack of support after training, particularly during those crucial first weeks when many dropouts occur. Despite efforts, program administrators in Nepal found that they did not have the resources to provide teachers with consistent support during that time. A possible solution would be to form study circles so that teachers who were trained together would meet and discuss their problems in an organized fashion. Team teaching might also remedy the problem, despite higher cost, and might facilitate within-class performance grouping.

It seems that the cognitive processes of teachers as learners must be dealt with before positive effects can be seen on the cognitive processes of students. For example, if metacognitive strategies are to help participants, teachers themselves should know what they are. The problem is that such material is best understood by well-educated and highly trained teachers. Behavior that was learned through imitation usually cannot be changed simply by lectures, but it must be replaced with behaviors modeled from effective instructors as well as through performance feedback. Audiovisual methods, such as instructional videos and performance videotaping, are used extensively in industrial countries and would probably be very effective with literacy teachers (considering also the novelty of the medium for them). However, audiovisual equipment has traditionally been difficult to use and maintain in rural areas and needs a power source that often does not exist. Furthermore, teacher trainers ought to be trained to use it and benefit from its messages, and this issue in itself requires development.

Modification of teacher behavior and the methodology for doing so in low-income environments is an area that is slowly developing. For example, Innotech in the Philippines, an agency of the Southeast Asia Ministers of Education Organization (SEAMEO) is oriented toward materials in this area. Special equipment for rugged environments might be available, and power is slowly becoming affordable in remote areas through rural electrification schemes as well as through solar and wind installations.

Teacher effectiveness is perhaps the single most important determinant of literacy program effectiveness, and must be given the importance it deserves. Much emphasis needs to be placed on creating teacher training curricula that can be carried out in five to ten days initially and for shorter repetitive periods thereafter, that can be conducted locally, and can actually modify behavior. Curricula should include adult classroom management issues (dealing with absenteeism and dropout, and arranging for activities of children who come with their parents) as well as instructional problems pertaining to adults (the importance of early reinforcement, attention span, understanding reading strategies, demonstrating the immediate use of reading and writing, using materials from the environment, forming and monitoring within-class groups, prevention of relapse into illiteracy, and improvising according to the needs of the group). Curriculum should also emphasize appropriate behaviors and attitudes - the importance of showing up for class regularly, treating participants with respect, and not looking down on them or blaming them for low performance. Training should provide to trainees role models of teachers performing more effectively than the teachers they themselves have known. Actually, a network of structured, effective cascading training activities should be established, from master trainers in a capital to local teachers and supervisors in the villages. The benefits of such a network may prove to be worth the challenge and expense.

Ideally, teachers should have as much formal education as possible. Research in formal education has shown that teacher achievement consistently influences student achievement, and higher education might make it easier for well-educated persons to learn intricate teaching techniques. But perhaps a low level of education is not as big a barrier as one might expect. Neoliterates have been used on occasion, and many NGOs use teachers with five to 
eight years of training. A successful NGO in Bangladesh, Gono Shahaja Shangstha, has demonstrated that teachers with ten years of schooling can learn to perform intricate and structured grouping and activity patterns, which are usually expected of better-educated teachers. Some writers (for example, Rogers 1991b) believe that attitudes of teachers toward participants and their lack of personal growth are more important issues than formal education of teachers. It might even be argued that highly educated teachers would tend to belong to a different social class from learners and might not have much empathy for them.

To help individuals with limited education and low or no remuneration carry out a complex instructional program, heavy investment is needed in substantive supervision and support. Supervisors need to communicate problems and findings to local and central authorities. A support network, therefore, must exist from the center to local officers, to supervisors, to teachers. Supervision and support cost at least as much as direct instructional delivery. However, there seems to be consensus that the cost of intensive supervision is well worth the benefit.

\section{Chapter 6- Conclusions}

What are the characteristics of people most likely to become and remain literate? It might help if they are inner-directed and study with a constructive peer group that inspires them, in an environment which uses reading as a means to a goal, such as an income-generation program. Youth might help them learn advanced skills and retain literacy. They should have good eyesight, a means of using their literacy or grasping its immediate benefits, and an appropriately trained teacher who shows up for class, treats them with respect, and uses instructional methods targeted toward maintaining literacy. They should have some time to study, not too much housework or too many young children to look after, and an interest in learning to read. They should stay in a program long enough to acquire automaticity (however long that is). Courses should be in a convenient location and at convenient times, possibly at night to facilitate skill consolidation during dream sleep. It might also help if the agency and its teachers know how to train illiterate adults and are not demoralized by the magnitude of the task. Even so, there is no guarantee that students would become effortless, fluent readers.

Most illiterates are not in such ideal circumstances, and donor agencies are not prepared to deal with the usually imperfect conditions. Large gaps of knowledge exist on crucial issues such as attendance and dropout, and research results cannot be found in areas other than instructional methodology. Given this lack of knowledge, it is unlikely that any literacy program as typically designed can drastically reduce illiteracy. The question is whether literacy programs should only be implemented in the limited cases where favorable circumstances exist or whether extensive research should be conducted to find out what can work under less favorable circumstances. Since the external environment may not have a large scope for manipulation, research in the information processes of literacy participants may lead to answers that will increase program effectiveness. There seems to be some reason for optimism; the more recent (albeit smaller) programs that emphasize teacher variables and meaningful instructional materials have lower dropout rates and higher achievement rates.

The quality of programs and their ability to hold participants might improve by using the principles of information processing. The following lessons might be extrapolated from cognitively oriented research and hypotheses:

- Whenever possible, integrate literacy in the activities of existing groups rather than form new groups of little cohesion. If it is impossible to teach existing groups, foster supportive networks among illiterates that may discourage dropout. Some successful programs include action-oriented community work that is planned in the classroom and needs or uses literacy. 


\section{What We Know about Acquisition of Adult Literacy}

- Find out early from the prospective beneficiaries what they find meaningful and would spend their little free time to pursue. If formal schooling is of interest, develop a program leading to a primary school certificate rather than to literacy alone.

- Explain to illiterates what they should expect from literacy, including the possibility of relapsing into illiteracy if they do not practice, and teach them how to minimize the probability of relapse.

- Reinforce adults for their performance early in hopes of diminishing dropout. Emphasize the immediate utility of reading (as in the Bangladesh example of writing a letter to the uncle requesting money on the first day of class). Offer them texts on issues they are quite

familiar with, because people read more easily material that they know about. Ask them to bring to class materials that interest them. Take them on "field trips" where store signs or billboards are displayed.

- Package the reading information so as to withstand the vicissitudes of long-term memory. Give adults extra practice on letters and patterns that they find difficult to remember, distinguish or quickly recognize. Culturally appropriate mnemonics, including rhyming and songs, may make the memory of letter shapes permanent.

- Attempt to remedy the potential cognitive-perceptual difficulties of illiterates during instruction (for example, make students phonologically aware, and teach the critical shapes necessary to distinguish letters from each other when they are scribbled or written artistically).

- Since adults do not remember meaningless items as easily as children, maximize opportunities to show script in context and minimize unconnected words and sounds. Connect the information with what adults already know.

- Make participants write a lot and spell words they have not seen. Although writing is most useful for communication, the initial purpose is to develop reading strategies and make letter shapes memorable.

- To provide maximal reinforcement and yet leave no participants behind, develop within-class groups of similar performance. To the extent possible, use peer tutoring and cooperative learning techniques.

- Role-model reading for participants in various ways, including the reading of interesting material aloud to them.

- Test the eyesight of participants through simple tests in the beginning of the course.

To carry out the above recommendations, large investments must be made in teacher training. Teachers must be trained on adult classroom management issues, such as early reinforcement and prevention of dropout and on instructional methods that maximize the probability that the reading strategy will be understood (rather than allow traditional methods, such as letter names). In order to counteract their tendency to teach with the methods their own teachers used, teachers should be trained through role modeling and feedback, not just lectures. Furthermore, it must be ascertained that teachers will show up on time and treat participants with respect. To help individuals with limited education and low or no pay carry out a complex instructional program, investment is needed in intensive supervision and in a support network that should extend from the center to local officers, supervisors, and teachers. To fund and organize the complex structures needed to delivery literacy, social and high-level political support is necessary. 
What We Know about Acquisition of Adult Literacy

\section{Operational Implications}

Given what is known, what policy issues arise for the World Bank and other donors of literacy programs? Below are some thoughts.

\section{Is There a Need for Literacy Programs?}

A need certainly exists. In a 1993 speech, the Secretary in Charge of Primary and Mass Education in Bangladesh said that primary education in that country resembles a narrow bridge without rails. Children attempt to cross it, but many fall into the water; nonformal education resembles boats that can save the children who fall. Expansion of primary education is clearly preferable, but high dropout rates and limited access in the poorer countries leave many people unserved. The demographic explosion in the developing world means that there are now more illiterates than ever, despite strong international commitment to primary education. Therefore, if literacy were disseminated efficiently to adults, literacy programs would be under implementation in most developing countries.

\section{Should Literacy be Financed?}

Adult literacy is probably not the most effective way to disseminate development-related knowledge (such as family planning or agricultural methods). If specific information must be disseminated there are more cost-effective ways to do it. These include the media as well as organized activities such as the functional education programs of the Bangladesh Rural Advancement Committee (BRAC). However, the original goal of governments in the 1950s to disseminate knowledge through literacy remains sensible in theory and has formed the rationale for primary education. Furthermore, illiteracy is now seen as a social problem, somewhat like malaria. Governments want to be seen as doing something to eradicate this problem. It is difficult to persuade government officials who believe that literacy instruction is a simple thing that this is not the case and that the reasons for failure are not well understood.

Given the existing need, however, it may not be wise to wait until more research is conducted on adult literacy. There is scope for considerable methodological improvement on the basis of what is already known, and future projects can provide opportunities for research and pilot testing of new ideas. Development agencies should cautiously proceed again and systematically refine techniques that emphasize early reinforcement, immediate utility, and materials that are meaningful to participants.

If literacy is to be financed, what size of programs should be developed ? At this time there seems to be a tradeoff between effective methodology and size. Small higher-quality programs will not eradicate literacy. This is why it is important to find out how to develop large as well as efficient programs. Large but locally focused campaigns with finite time limits (such as the total literacy campaigns of India) coupled with instructional improvements might achieve the goal of making large numbers of people literate.

\section{Who Should be Encouraged to Participate in Literacy Programs?}

Several authors have emphasized the right of illiterates to learn, particularly since they have not benefitted from the educational expenditure of their countries. Everyone who wants to study should be able to do so without barriers to access. However, given the vast potential demand, the costs of large

literacy programs, the large wastage, and the disappointment by participants and organizers, it may be wise to target programs to specific segments of the population.

Age has been the most common targeting criterion. Out-of-school children, with lower dropout rates and a 
longer life expectancy, are often the highest-priority group. Adults' programs often focus on adolescents and adults up to age thirty-five. The limit of thirty-five is an empirical criterion. Although older individuals do not often become literate and all adults may experience some information processing difficulties (appendix B), research offers no clear justification for or against various age groups. There are almost no data on the motivational processes, dropout, or performance rates at various ages. (Do various age groups have different unit costs per person made literate?) The main argument in favor of younger groups seems to be longevity, but one could also argue that there is greater value in teaching literacy to adults (and providers of today) than to adolescents, who could afford to wait. Anecdotal accounts also indicate that adult literacy programs seem to stimulate demand for children's primary education. Should people who have not benefited at all from educational investments be discouraged from literacy instruction because they are too old or too burdened?

If it is indeed harder for adults to acquire functional literacy, perhaps large-scale, literacy-only programs should target out-of-school children and adolescents (through the age of about nineteen years). These age groups constitute a large part of the population in many countries. The little evidence available indicates that they may have lower dropout rates, may be trained at relatively low cost, and may remain literate if they become literate during a course. Adults of all ages should be encouraged to participate, but programs might refrain from setting numerical targets for them.

Other targeting methods could potentially be used. One is likelihood of using literacy for long periods of time and on the likelihood of becoming literate and promoting the education of one's children. Some practitioners (notably some NGO leaders in Bangladesh; Rogers 1991a) advocate teaching literacy to those who have an immediate use for it, such as village councilmen. Since they would practice their new skills, they would indeed have a higher probability of retaining literacy. However, such people may also be the more advantaged of the poor.

It is possible that cognitive predictors of success (that is, phonological awareness, working memory, and verbal memory) could be used to decide which adults might benefit more from instruction. If studies show that the predictive validity of these variables (individually or in combination), is high, they could be potential screening tools. Age targeting seems acceptable to implementers, but the latter methods might raise ethical issues which have not yet been considered.

\section{What Activities Should be Financed?}

Given the donors' willingness to spend funds for high-priority programs if they are effective, per-capita cost may not be the most important issue. If money can significantly improve effectiveness, perhaps it is money well spent. Donor agencies might emphasize direct implementation as much as possible and heavily invest in supervision, support, and innovative, behaviorally oriented teacher training as well as in the equipment and procurement logistics needed to deliver these components. Peripheral activities such as textbook development are important, but in most countries usable textbooks already exist, and spending a long time and a lot of money in new development may not constitute optimal use of resources, particularly if teachers do not use the books as they should be used.

Donors might also show understanding about the problems of the implementing agencies . As mentioned earlier, the magnitude and difficulty of the task may demoralize administrators. Rather than providing more training and fellowships, assistance might be targeted toward dealing directly with the problem and finding solutions, such as cutting the task down into manageable geographic or target-group bits. Learning to manage teachers and their instructional problems would also be important. Then progress may be more easily measured and may give a sense of achievement to literacy professionals. In many countries with high illiteracy, the task may indeed be manageable. The Thai campaigns showed that there is light at the end of the tunnel and that attention to project design can indeed improve the chances of eradicating illiteracy. 
If literacy projects are to be developed by donors, such as the World Bank, much attention should be given to detail. The methodological nuts and bolts cannot be left to short-term consultants or relegated for resolution after project effectiveness. If a program is to have above-average effectiveness, someone must make sure that the details that will make it so (for example, teacher training and methodology) are chosen early, that they can be implemented on a large scale, and that the staff of implementing agencies agree that they will improve project performance.

It appears that successful mass literacy has a better chance when it is integrated in a national plan of development and where the political will to implement it is clearly articulated in theory and in practice (Lind and Johnston 1990). There is a lesson to be learned from the fact that some of the more successful campaigns (in China, Cuba, and Nicaragua) were conducted for specific purposes, such as political indoctrination (Noor 1982). Governments should have a purpose, effective frameworks, but also realistic expectations regarding literacy programs.

\section{Research is Urgently Needed}

This review has demonstrated that we know very little about processes in an area that has a record of expensive mistakes and disappointing results. The mistakes have indicated to some extent what does not work, but lack of knowledge on important underlying principles prevents us from understanding and building on what does work. If significant investment in literacy is to take place, substantive research is needed to understand how illiterates think, learn, remember, forget, and act on information. This research would also facilitate IEC (information, education, and communication) activities for family planning and nutrition, which have been largely carried out with an inadequate understanding of information-processing principles for illiterates. Some topics to investigate might be:

- In general, what cognitive processes do adults marshal while learning to read? What information is being processed when learning a script and in what order? What is considered more salient, easier, and important for processing at different ages? How much practice is needed before reading becomes automatic in learners of various ages? Does age affect the time needed to acquire pattern recognition and the complexity of patterns acquired? How does the attention span of illiterates fluctuate during a class?

- What processes are involved in forgetting? What is actually forgotten after relapse into illiteracy? (Shapes? Patterns? Reading strategy?) What is the minimum amount of instruction that will create sustained skills in illiterates of various ages and what characteristics should that instruction have? What techniques can maximize retention of letter shapes (for example, culturally appropriate mnemonics)?

- Why do illiterates actually drop out? What are the warning signs and what can be done to prevent dropout? What are the skill levels of at-risk individuals before and after dropout? Studies would monitor dropout patterns and causes, performance of people and level of skills before they drop out, incidence of rejoining classes, and absenteeism.

- Which socioeconomic and cognitive variables predict sustainable literacy? Which correlates of literacy (such as phonological awareness) can be taught so that more people can become and remain literate?

- How do illiterates calculate? What are the issues underlying difficulties in retaining numeracy?

- How much difference do income-generation programs make in the retention of literacy? What program characteristics account for the increased effectiveness? Are the benefits worth the greater costs?

- Which teacher characteristics are the most and the least conducive to the dissemination of literacy? How effectively and at what cost can these characteristics be modified during teacher training? Which training methods 


\section{What We Know about Acquisition of Adult Literacy}

are most likely to bring such changes about?

- What effects do post-literacy classes have on the probability that literacy will be retained? How should they be structured so as to be most effective? What factors can substitute or compensate for lack of post-literacy classes?

- What differences are there in the quality of life between adult neoliterates and people made literate in childhood (particularly women)? Several years after instruction, how do these groups differ in processing written material, obtaining information through reading, and acting on the information?

- How does the self-concept and status of neoliterates (particularly women) change in the short and in the long term?

- What are the problems behind the inadequate performance and scaled-back programs of many literacy institutions? How can they be addressed?

Answering these and other questions would serve to fill in the blanks of the hypothetical regression equation regarding predictors of literacy acquisition. The research should not just evaluate projects ex post facto. It should also be experimental or quasi-experimental. Answers might be most effectively provided through a research project of about $\$ 1$ million to $\$ 2$ million that would last about five years and would collect data from many countries and from different scripts. Funding should be flexible and provide for basic scientific research, including equipment that would monitor how illiterates learn and remember information (for example, by meaning measure reaction time, and monitoring pattern recognition, and eye movements). Funding would also enable experienced and highly skilled researchers to reach illiterates outside their own countries and give incentives for doing so. This way the subjects, the expert researchers, and the donor agencies may finally come together.

A fund could be formed by cofinancing from donor agencies, such as: the World Bank's Research Committee, the Asian Development Bank, UNESCO, and the Ford Foundation; governments, particularly through the evaluation and monitoring components of their nonformal-education projects (financed by the World Bank or by other donors); and institutions with research capability and access to other funds. Examples would be Innotech in the Philippines, the International Association for the Evaluation of Educational Achievement in the Netherlands, the Institute for International Educational Planning (IIEP) in Paris, the Max Planck Institute for Education in Berlin, the British Association for Literacy in Development (BALID) in London, the Swedish Agency for Research in Developing Countries, the Adult Literacy and Basic Skills Unit in London, Deutsche Volkshochschule Verband in Germany, and the National Center on Adult Literacy in Philadelphia. Academics in universities could apply for grants.

A possible deterrent to extensive research on literacy is the short-term frame that often dominates policy development. Multilateral and bilateral donors need answers quickly and may focus on literature searches, best-practices, case studies, or secondary data analyses. The primary data collection and basic research necessary to increase the effectiveness of literacy projects may be seen as too academic or too long-term for development purposes. The problem is that the basic research that would make quick policy-based studies possible is missing in the field of adult literacy, and more descriptive studies will not provide the needed information. Donors do not need to carry out such research themselves. Instead, they should plan for it and develop financing avenues that will enable highly experienced academics to do the work. 
What We Know about Acquisition of Adult Literacy

\section{Appendix A- \\ Data and Assumptions on Literacy}

Data and evaluations of literacy programs have not been systematically collected or published. In earlier years, articles on literacy often appeared in little-known journals, some of which may have become defunct (such as "Literacy Work" or "Literacy Discussion") and are not easily accessible. For example, several programs were implemented in Turkey, but published information cannot be located. Similarly, little has been published about the successful Thai programs of the 1970s and the many programs implemented in Latin America. (For a review see Abadzi 1994.)

The state of the published data on literacy is disappointing, and secondary analyses, which could answer some research questions, are generally impossible to do. Publications typically present averages or frequencies with little if any statistical treatment. Data sets are incomplete because of the large-scale dropout and the difficulties of tracking down course participants. The within-groups variance seems large, and there is a wide variability of average scores in classes using the same method and by individual scores within each group (Lind and Johnston 1990). This may point to unreliable measurements or may mean that methods do not matter as much as other, unresearched, variables (IDRC 1979). Background or correlational measures (various aptitude measures, sibling number and order, or income, for example) that could potentially account for the large variances are not provided. Other variables, which are rarely if ever measured, are amount and quality of instruction, age disparity between teacher and student, frequency of attendance, time and effort invested in learning, rural or urban residence, marital status, and social or economic status (perhaps as determined by land ownership).

Definitional problems complicate the research picture even further. UNESCO literacy statistics classify persons aged fifteen or over as adults, but in many 'adult' literacy classes participants are twelve years or younger. The definition of literacy also varies. In some cases, anyone who can read the letters of the alphabet is regarded as literate. In others, one must be able to decipher a text of an agreed length. In countries with a high educational level the standards are higher, and people are regarded as functionally illiterate if they are incapable of filling out a complicated questionnaire or of assimilating written instructions containing technical language (Jennings 1990).

Also, the measures of literacy tend to be very rough and may either overestimate or underestimate achievement. Marginally literate people may be able to read familiar material adequately but perform much lower on unfamiliar material. Also, when neoliterates are asked to read aloud, they may become too nervous to perform. More sensitive methods of measurement are needed, such as asking subjects to read a text silently and then explain it orally (LeVine 1992). Competency-based assessment, which compares performance to a specific standard and rewards what individuals can already do, is also a little-used option in developing-country research (Imel 1990). Whether literacy should be measured on familiar rather than unfamiliar material is an issue under discussion (appendix B).

Why is the quality of literacy research so low? The quality may be due to the absence from the field of literacy of professionals who are highly experienced in quantitative, experimental research. This may be happening because countries with large literacy problems usually lack the resources to perform sophisticated research. (The socialist countries that conducted large programs, such as China, Cuba, and Nicaragua, were more interested in making political statements than objective evaluations.) The international organizations that generate most of the evaluation work tend to hire generalists, who usually lack the necessary level of research sophistication. On the other hand, educational researchers in industrial countries cannot conduct the research needed in the industrial world because there are very few illiterates who have been deprived of schooling aside from immigrants, who may be older and possibly not 
representative of typical illiterates. Due to the prohibitive costs of overseas research and to language differences, academics who research reading have not been able to reach large illiterate populations. Instead, they have extensively investigated programs for which funding is available, for example, reading disabilities. As a result, the literacy acquisition process of "normal" populations (either children in low-efficiency schools or adults) has not been studied in developing countries (Wagner 1987).

\section{Little is Known but Much is Assumed}

Although research-based knowledge on literacy is scarce, assumptions abound. Programs seem to be designed on beliefs that, however laudable, may not correspond to reality. Examples are:

- Learning the mechanics of reading will liberate poor people worldwide from the bonds of ignorance, disease, and hunger. The literacy doctrine that emerged in the 1950s was treated almost as a new religion (Jennings 1990). Thirty years later the world still faces the problems literacy was to solve. A corollary is that neoliterates will obtain useful health or agricultural information through reading. However, neoliterates apparently prefer to read fiction and religious books rather than pamphlets on diarrhea and family planning. At any rate, data indicate that after a literacy course (or even a post-literacy course) many neoliterates have rather limited reading comprehension and may not be able to glean information extensively from written materials.

- Literacy has many development-related benefits, particularly for women. Women's school attendance increases their children's chances of survival and well-being in several ways. This research, however, has been conducted with persons made literate in childhood through formal schooling (for example, LeVine, and others 1991; LeVine 1992; Joshi 1991). The same assumptions cannot be made for adult neoliterates, who are often limited to basic literacy. Most development-related benefits might actually come from elaborations of the information inserted in literacy texts, which seems to be effective.

- Literacy is good for the self-concept. This is a frequently cited emperical outcome, but there is no research-based evidence for significant short-term or sustained effects.

- Anyone can teach literacy. This assumption has sustained programs worldwide that would otherwise have cost much more. Literacy teachers are often young volunteers and primary school teachers with little or no special training; yet program success depends on them. Inattention teachers on how illiterates retain and use information may compromise the effectiveness of literacy programs in ways that are as yet undetermined. Perhaps anyone can teach literacy constructively, but only after considerable training, as discussed in chapter 5 .

- Everyone can learn to read. All people have a right to the opportunity to learn; the literature search in cognitive psychology shows no evidence that adults ever become too old to acquire basic literacy. Functional literacy, however, is a different and possibly more complex issue. The acquisition of relatively sophisticated reading skills by the general population of illiterate adults is still only an assumption.

\section{Appendix B- Possible Age-Related Difficulties in Acquisition Literacy?}

This appendix presents the hypothesis that aging makes visual processing of newly learned letter patterns increasingly less efficient. This difficulty may not affect the learning of reading strategy or sound-letter correspondences, but may make fluent and relatively effortless reading difficult, thereby discouraging neoliterates and causing many to lapse back into illiteracy. 
What We Know about Acquisition of Adult Literacy

Some empirical evidence for this hypothesis comes from the reading experiences of educated fluent foreign speakers who learned foreign scripts as adults. The following sections present the information available on learners of new scripts.

\section{What Can Be Learned from Foreign Readers}

Three American Peace Corps workers spent about seven years in Nepal in their mid-twenties. Although they spoke Nepali fluently and taught in it, they had to make an effort to read the Devanagari script despite its very orderly sound-letter correspondence. They tended to avoid it and forgot to read faster than they forgot to speak after they left the country. Another volunteer who worked for five years in India reads with the fluency of a second grader. An educator who spent fifteen years in Bangladesh developing literacy materials has the vocabulary to understand news on television but finds newspaper reading of the same vocabulary tiring. An American woman in her mid-thirties, who has lived in Japan for six years and speaks to her children in Japanese, still does not fluently read the two syllabic scripts, including katakana, the script reserved for foreign words. A man who studied and worked in Israel for twenty-three years after secondary school instantly identifies many words and reads materials in his field fluently but still finds general Hebrew books tiring and believes that he reads general material two to four times faster in his native Greek language, in which he rarely reads.

It appears that adults learn the basics of reading faster than children (Oxenham 1980). But anecdotes suggest that children become fluent in reading more quickly than adults do. During observations in nonformal education classrooms in Bangladesh, twelve-year olds after a year of study could read an unknown text with notably greater fluency than twenty-year olds. Most very poor but young children in an innovative NGO class typically read fluently after less than a year of instruction, while adult learners of the same NGO do not. Second-graders in rural Morocco have been observed by the author while reading Koranic texts, which they do not even understand, at high speed. There are also anecdotal examples of people who learned to read foreign scripts as children and who seem to have retained them with little practice as adults. An elderly professor who learned to read Hebrew as a child can still do so although she only reads about once a year. A Greek girl who was born in Ethiopia and went to school there for two grades, could still write letters in Amharic three years after her family returned to Greece. It is conceivable that something in the brains of children enables them to become fluent in reading and to retain the fluency more easily than adults.

A discrepancy seems to exist between fluency in a foreign language and fluency in reading its script, if the latter is entirely new. If adults had no special problems in learning to read new scripts, one would expect that educated people would read a foreign language about as well as they could speak it. These people know the value of literacy well, and occasions for reading in urban areas (at least) of foreign countries are almost as frequent as occasions for speaking; there are store signs, street signs, newspaper headlines, billboards, or television titles, which do not require sophisticated vocabulary. Yet

many fluent foreigners pass these by without decoding them unless they need the information. They seem stuck with a skill level that native children display at the end of the first grade. Why?

The origins of this question lie in the personal experience of the author and a study, after age eighteen, of seven languages that had non-Latin scripts. Personal performance has been monitored extensively, and other people's experiences have also been systematically recorded. In 199194, informal interviews were held with ten people who had spent five to forty-three years in a country with a non-Latin script and were fluent in the language. These foreign readers consistently reported the following problems:

- A brisk start but an early plateau. With a knowledge of reading strategy, foreign readers learn letter-sound correspondences fast; in a few days they can cover the material presented in a six-month adult literacy course. But their reading speed increases very slowly thereafter. By contrast, children may take longer to learn basic 


\section{What We Know about Acquisition of Adult Literacy}

sound-letter correspondences, but their pattern recognition skills rapidly improve thereafter (Feitelson 1988; Adams 1990).

- Limited pattern recognition. Children develop very rapid recognition of many frequent words and as they become experienced native readers they typically perceive combinations rather than individual letters (Adams 1990). Foreign readers, by contrast, tend to see individual letters rather than combinations. Words of two to three letters may be recognized immediately as well as very frequent words (such as names of cities). The rest must be deciphered letter by letter. The need to read letter by letter makes scanning a text difficult or impossible. When scanning is necessary, some easily identifiable letters (for example, rare letters) may be searched for rather than a whole word. Nevertheless, they seem to learn quickly which letter combinations are more or less likely in a language and can predict probable words. (Infrequent combinations tend to produce extra difficulty.)

- Low speed and difficulty with consolidation. It takes much longer to read a passage of known words in a foreign script than in a native script. It may take a foreign reader, for example, five seconds to read a two-line sign on a ministry door, while an expert reader may need only 1/10 of a second (Adams 1990). When asked to read aloud a text of known vocabulary, foreign readers often read haltingly. One of them reports trying to imprint in mind the letters of a store sign while in a passing car in order to finish reading them from visual memory. Speed may increase after practice, but it may drop again if a few weeks pass without practice. Even after considerable practice, people may eventually forget the shapes of letters.

- High error rates and overdependence on context . Letters are often misread, resulting in delays and aggravation due to wrong interpretations. Like low-performing young readers (Adams 1990), foreign readers may depend too much on context and read what they expect to see, thereby significantly misreading the print. Some letters may be recognized faster than others, and readers may read only those when they read fast, often coming up with guesses that scramble the order of the letters.

- Continuing need to sound words. Expert readers translate letter patterns directly into meaning (Adams 1990). Foreign readers have to sound out most words to get the meaning.

- Infrequent segmentation . Expert readers read long words by cutting them in parts (Adams 1990). Foreign readers seem less likely to do so. Long words, therefore, create frustration.

- Difficulty with nonstandard letter shapes . Artistic, computer-generated letters, or simple handwriting may present particular reading problems. By contrast, native readers seem to be influenced very little by variability of shapes (Adams 1990).

- In a perpetual beginner stage. Native experienced readers read effortlessly and unconsciously. They cannot help but read a message thrust in front of them. Most foreign readers do not seem to display the characteristics of experienced readers. Reading may become habitual (decisions do not have to be made for every letter), but not effortless; the words do not "fly out" at the reader. The few anecdotal reports of very fluent foreign readers involve persons who read intensively for many years, such as an elderly missionary who has spoken, read literature, and written poetry in Bangla for forty-three years.

As a result of these problems, reading in a foreign script is not fun . It takes effort, and people tend to avoid it. The reading skills of fluent adults who spend years in a foreign-script country may be like those of first graders and may not necessarily improve. Unless people take the trouble to decode store signs and newspaper headlines, written messages just go by them, and like students of literacy classes they "drop out" of trying.

It is tempting to form analogies between foreign readers and illiterate adults. If a person of thirty-five years with a Ph.D. and with good language skills cannot achieve fluency in a script, what should be expected of an illiterate 
What We Know about Acquisition of Adult Literacy

native speaker of the same age who has no concept of sound-letter correspondence? The analogy, of course, is not perfect. The native reading system of foreign readers may interfere in some way with the new one. Concerns with tedious reading may reflect high expectations; these readers have a reference point of how well they can read as well as an ability to express how they react to written text. They may face problems because they read texts that contain relatively long words and possibly difficult ideas. (Children, on the other hand, are taught through extremely simple concepts such as "see Jack run" and through vocabulary of three-and four-letter words.) Since reading consists of an interaction between the printed patterns and a person's knowledge of a language, foreign readers may face these problems because of their limited vocabulary and usage of a foreign language. Some researchers (for example, Alderson 1984) have concluded that reading difficulties are mainly due to language deficiencies, particularly for low levels of foreign language competence.

However, language deficiencies, interference by another script, and word size do not adequately account for the difficulties. Foreign readers have trouble deciphering the print before they determine which language it is written in. Furthermore, they have much greater difficulty reading, for example, English-language text in the devanagari script than Nepali text, although word meanings should be more accessible to them. And even experienced readers report finding it easier to read a foreign-language text in the Latin script than reading the foreign script, although the Latin letters may create ambiguities in meaning. It is possible, therefore, that the difficulties of foreign readers can provide a viable model for delving into the reading problems of native adult neoliterates. To illustrate how this may can happen, the following sections present how people read.

\section{How Reading is Acquired}

As in other cases related to literacy, information on reading acquisition comes from studies of children who are developing neurologically while learning to read. Although some anecdotal observations indicate that illiterate adults follow the same pattern, this is not certain, nor is it known how long adults spend in each stage.

Frith (1986), a prominent researcher of dyslexia, hypothesized that a beginner uses logographic, alphabetic, and orthographic phases (or strategies). These phases have processing differences but they also follow in sequence and each is developmentally contingent on the previous one. So, later strategies cannot be attained unless prior ones have been achieved at a certain level of mastery. These are:

- Logographic phase: This is equivalent to picture recognition. Words are recognized like pictures and also independently of each other. Not all letters in a word are crucial. The first letter acts as a salient feature but irrelevant detail can also be incorporated (for example, STOP with a hexagon around it). Adult illiterates who are exposed to letter signs that concern them may have logographic recognition of some words.

- Alphabetic phase: This involves analyzing words into component letters and phonemes and devising rules for mapping the two onto each other. Children develop this skill while they experiment with writing. Individual letters consolidate their representations, and a set of mapping rules is set up between them and the phonemes. The spellings children produce in English show an analysis of the segmental structure of speech, sometimes arriving at a phonetic rather than a phonemic analysis. As alphabetic reading ability develops, the child is able to pronounce all regular words correctly but may lose the ability to recognize irregular words learned in the logographic phase. Graphic substitution errors may also increase. This may signify a change in strategy toward increased use of graphic information in word identification.

- Orthographic phase: This involves construction of recognition units above the alphabetic level, which enables the morphemic parts of words to be recognized instantly. At this stage, reading, linguistic knowledge, and the general processes of cognitive abstraction interact to form meaningful reading. The vast majority of children progress from the alphabetic to the orthographic phase successfully. The extent to which illiterate adults do so is unknown. 
The process of phonemic segmentation of the alphabetic phase is the single most important aspect of learning to read. Many problem readers remain in the logographic stage because they cannot segment words, an observation some adult readers have also made about their habits. During early alphabetic reading children cannot understand the words they read. This may be because output is sent to a response buffer rather than processed for meaning (Morton 1989). Initially there is no connection between the response buffer and the semantic system, but reading eventually comes under lexical control, and the various processing mechanisms (see below) become activated and provide feedback to the reader about the meaning of the texts. It is unknown whether this connection becomes possible due to maturation or due to practice.

\section{What Happens While People Read}

The most widely accepted model of how reading takes place (Seidenberg and McClelland 1989) involves four processing mechanisms: phonological, orthographic, meaning, and context (figure B-1). As the visual image of a string of letters is being processed, excitatory stimulation is sent to corresponding units in the phonological processor. If the letter string is pronounceable, the phonological processor will then send excitatory stimulation back to the orthographic processor. The phonological processor is also connected to the meaning processor. So the activation of a word's meaning results in the excitation of the phonologial units underlying its pronunciation. Conversely, the activation of its pronunciation automatically arouses its meaning. These connections make reading and learning to read possible. The timing and logic of the interactions among all the processors are important and complex. A computational model of the hypothesis was tested with words of various frequencies and spellings; computer-generated data showed the same trends as data generated from human subjects.

How Reading Takes Place

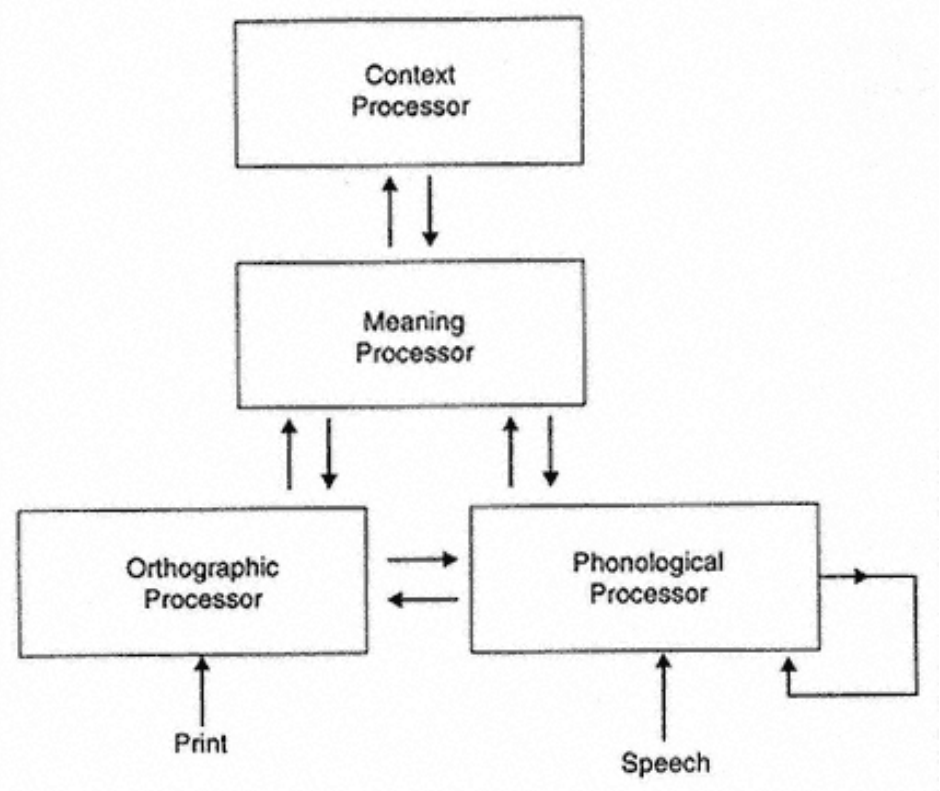

Figure B-1

How Reading Takes Place

With practice, processing normally becomes automatic, and words are recognized through modularity (Stanovich 1991). Modular processes are encapsulated, that is they occur rapidly and without the individual's attention and are not influenced by prior knowledge structures stored in long-term memory. Because they are encapsulated, 


\section{What We Know about Acquisition of Adult Literacy}

efficient word recognition skills operate independently of context. Then readers can concentrate on the message of the printed text.

To read efficiently and understand according to the Seidenberg and McClelland model, the reader must have a good knowledge of a language: spelling, syntax, semantics, and the informal flow of discourse. Learning to read involves learning facts about the distribution of letter patterns in the language and the correspondences between spelling and pronunciation. This knowledge can be represented in terms of weights on connections in a distributed memory network that consists of simple processing units. Experience modifies the weights in reading and pronouncing words (Seidenberg and McClelland 1989). The accuracy and speed of written word recognition depend mainly on the readers's familiarity with the word in print. The more frequently a spelling pattern has been processed, the stronger, more focused, and faster will be its connections to and from the meaning processor. The more frequently a spelling pattern has been mapped onto a particular pronunciation, the stronger, more focused, and faster will be its connections to and from the phonological processor. In the reading of less familiar words, the presence of the circular connectivity of all processors serves in quickly obtaining likely responses (Adams 1990).

Reading depends first and foremost on visual processing. The output of the orthographic processor depends on the speed and accuracy with which the individual letters are perceived as well as on the familiarity of the spelling patterns comprising the word. The meaning processor, in turn, depends on the quality and completeness of the orthographic and phonological processors. If a word is highly predictable from text, relatively little orthographic or phonological information is needed. An expert reader frequently goes directly from the orthographic to the meaning processor (Adams 1990).

\section{Foreign Readers and the Four Processors}

It is understandable that foreign readers would have some difficulty reading in any script. To read efficiently and understand according to the Seidenberg and McClelland model, the reader must have a good knowledge of a language, that is spelling, syntax, semantics, and the informal flow of discourse, facts about the distribution of letter patterns in the language and the correspondences between spelling and pronunciation. The model predicts that, other things being equal, foreign readers would read more slowly than native readers; when Seidenberg and McClelland reduced the number of units that provided word meanings in the simulation, response latencies increased, and higher-frequency words produced the patterns associated with lower-frequency words. Still, the model implies that fluent speakers should be able to read well known material very quickly, something that reportedly does not typically happen with foreign readers of scripts learned in adulthood.

Both the immediate and long-term impact of reading, depend critically on the speed as well as on the accuracy with which readers can identify the individual letters and words of the text. As mentioned earlier, foreign readers have trouble deciphering the print before they determine which language it is written in and make many mistakes in reading letters. Their problems seem, therefore, to involve visual processing speed and accuracy, a domain of the orthographic processor. The input from the orthographic to the phonological processor is slow and erroneous. The phonological processor may compensate for the laborious output by creating repetition and syllabication. This may account for the frequent tendency

of foreign readers (but also of less experienced readers in general) to sound words out before understanding them. The incorrect and slow output often misleads the meaning and context processors into wrong interpretations or decisions that a word is unknown. The presumed deficiency in the orthographic processor may account for the difficulty foreign readers have with more artistic letters, which native proficient readers hardly notice.

Aside from the apparent difficulties of the orthographic processor, there is a question as to whether the other three processors can be made functional in adulthood with greater ease or with greater difficulty than in childhood. As mentioned earlier, children initially do not understand what they read, but it is unclear whether this difficulty is 


\section{What We Know about Acquisition of Adult Literacy}

due to lack of maturation or lack of practice. It is unknown how easily the semantic system becomes functional when initially activated during various ages. It is now understood that literacy alters the cognitive structures in the brain in complex ways (ASTD 1993), but it is not understood how these processors develop with maturation.

Despite the lack of research, the difficulties of learning to read a foreign script in adulthood and the need to acquire automaticity have been noted in recent years (Ramirez 1994). Bernhardt (1991a) found that when English-speaking readers of common European languages read, they are already fairly sophisticated in word recognition and need little oral reading practice. The same reader learning non-Latin alphabets is much more like a child learning to read a first language. She also concluded (1991b) that processing speeds depend upon fluency as well as familiarity with orthography. Students of languages with non-Latin scripts (such as Arabic and Chinese) pay considerable attention to graphemic features, and this process frequently overrides attention to meaning or syntax. This is essentially the same problem that neoliterates face when their attentional resources are used up in decoding and they cannot understand what they read. For some reason, in both groups the reading process does not become modular and word recognition is not instant. This means that these slow and inefficient readers cannot easily recognize, learn about, and understand what they have read. The laborious processing and lack of understanding of the text are often evident when one listens to neoliterates read. Are there psychophysiological mechanisms responsible for this difficulty?

Some recent brain research may point to a possible source of the problem. Petersen, Fox, Snyder, and Raichle (1990; see chapter 4, section on psychophysiology) showed that the brain does not recognize a word merely by the shapes of its letters. A word recognition spot that exists in the hind part of the left cortical hemisphere (in the left, medial extrastriate regions of the occipital lobe), very near the area that deals with visual information, may be in some way responsible for the phenomenon of automaticity. It seems that this area can easily learn to recognize hitherto unknown spelling patterns in a well-known script (Bernhardt 1991a), as is the case of foreign readers of languages that use the Latin script. It is possible, however, that this area somehow becomes less and less capable of instantly recognizing words spelled in a new writing system as age advances. This may doom adult learners of a writing system to slow, letter-by-letter recognition of a word, much like the disorder called alexia. It may also explain why foreign readers find it difficult to recognize words of their mother tongue in foreign scripts; they have a different set of spelling rules for them in their brains.

It is also possible that the difficulty is due to neural pathways or mechanisms that bring input to the word recognition areas. Perhaps the input comes in a form that cannot be used for rule checking. For example, the reaction time to letters might increase by a few milliseconds between adolescence and early adulthood. Such an increase might be considered insignificant, but it may prevent the almost simultaneous reading of letters and recognition of letter combinations as patters. However, research on reaction time and pattern recognition for the young and middle-adult ages is limited (appendix D) and

does not permit confirmation or refutation of the hypothesis. Furthermore, research has not been found on the minimum letter recognition speeds needed for letters to be perceived as patterns.

Can adult foreign readers achieve advanced skills with more practice? No methodology has emerged on how to teach efficiently for automaticity (Segalowitz, Poulsen, and Komoda 1991; Alderson 1984). Reading aloud probably helps in teaching a new script, as does the creation of mnemonics for specific letters, the match of transliterated words with the non-Latin script, and the review of flash cards (Red 1992). It is not known, however, for how long these processes must be applied before automaticity is reached. Young university students, who have been the subjects of foreign-language research, may need less time. Reports of persons in mid-adulthood, however (such as an American professor of Bengali, who has read it almost daily for 26 years), indicate continued performance problems despite significant amounts of reading. It is possible that the amount of practice needed to perceive patterns that will make the phonological processor work efficiently increases with age until it reaches an asymptote . 
What We Know about Acquisition of Adult Literacy

If learning of new visual patterns gradually becomes less efficient, pharmacological treatments might be possible. Drugs that enhance cognitive functions, such as hydergine and piracetam, might promote the consolidation of new letter patterns and help increase the speed of recognition. More testing of these drugs is being undertaken in order to find cures for degenerative diseases, and new functions may be found for them. Perhaps in the far-off future, participants in adult literacy classes might receive cognitive enhancers to optimize the little time and energy they have available for literacy instruction.

\section{Could There Be a Critical Period to Acquire Literacy?}

It is unknown at what age foreign readers start facing significant obstacles. The many people in the world who can function comfortably in two scripts learned both during their school years. Young adults who learn a language and script in order to study in a foreign university (such as Arab students in the US) eventually perceive many letter patterns, though years later they may still read more slowly than in their native script and not prefer it. It is possible that the difficulty becomes significant around age eighteen, but its progression in previous and subsequent ages is unknown. The few reports of fluent readers imply that effortless reading may eventually be achieved, but it is unknown how much practice is needed at various ages. The literature review on age-related differences in cognitively related variables (appendix D) has not revealed any data to help answer these questions.

Language acquisition becomes more difficult with the onset of puberty. Is it possible that reading might follow the same pattern? Studies (such as Johnson and Newport 1989) showed that earlier learners acquired language better in most cases, and there was a clear advantage until puberty (Appendix D). Lenneberg (1967) proposed that the brain, having reached its adult values by puberty, loses the plasticity and reorganizational capacities necessary for acquiring language; adults learn languages through higher-order processing, not with the effortlessness of children. In a similar vein, Genie, a child deprived of language and social interaction until the age of thirteen, showed a lack of linguistic competence, particularly in syntax, even after seven years of rehabilitation. (However, she also suffered from nutritional, cognitive, and social deprivation.)

According to an earlier view, language acquisition and learning to read are quite different tasks, and theories of language acquisition are irrelevant in reading (Wardhaugh 1971). However, the work on phonological awareness indicates that these functions may be somehow related. It is tempting to hypothesize a critical period of facilitation in learning to read until puberty, after which the task becomes

increasingly difficult, possibly due to changes that slow the reaction time to letters so that they are not perceived as patterns. But no data exist to support or refute these hypotheses.

\section{Implications}

Both neoliterates and foreign adult learners end up with reading skills of limited utility, and lengthy texts may be beyond their patience. Successful graduates of literacy courses often read slowly by sounding letters out and may make many mistakes. Word segmentation and instant recognition, the hallmarks of fluent reading, are not skills normally expected upon course completion. It is possible that the difficulties of foreign readers reported above manifest themselves and create barriers in the acquisition of functional literacy for neoliterates. If they exist, they may also influence early stages in undetermined ways. Could the difficulties be somehow related to the large dropout of literacy classes? Are they responsible for the relapse of neoliterates into illiteracy, as they seem to be for foreign readers? If reading is tedious, neoliterates may not engage in it unless absolutely necessary and may, therefore, lose the skill. It is conceivable that after the important instructional and motivational barriers are managed through improved program design, these difficulties may obstruct the acquisition of stable literacy skills.

It would be possible to design research that would separate the effects of language knowledge from childhood-acquired literacy. Potentially this could be done by teaching a script to educated native speakers who 
did not learn to read in their mother tongue as children, such as some French-educated Arabs or speakers of various Indian languages who grew up outside India. It would also be possible to measure reaction time to new letters and to determine what recognition speeds are associated with pattern development in literacy course participants of various ages.

One literacy or many? The reading difficulties of adult neoliterates have made some authors (such as Street 1984) think in terms of different "literacies". Considerable research indicates that people read better the texts about which they know more (Adams 1990). Many literacy experts, therefore, stress the importance of testing neoliterates with material they themselves choose (Rogers 1991b). Testing achievement with unknown text makes it more likely that the scores of participants can be compared, but it probably underestimates reading comprehension (particularly when they are asked to read aloud). However, testing people on subject matter with which they are familiar does not allow assessment of their actual decoding skills. Like dyslexic children, neoliterates probably rely on their context processor to guess a word that they have only partly read. This is a worthwhile coping mechanism, but rewarding the excessive use of the context processor detracts attention from the decoding problems that neoliterates may still face. A reader with relatively strong recognition skills does not rely on context (Stanovich 1991).

\section{What Data Exist On Differential Performance by Age?}

If younger people learn to read fluently more easily than older people, then younger participants of literacy courses may have higher success and lower dropout rates, other things being equal. Anecdotal observations confirm this trend. But the lack of rigorous evaluation designs in literacy leaves a lot of variables confounded and it is not possible to establish cause-effect relationships. The data collected by literacy projects include age rather rarely and when it is presented, wide ranges are shown, such as ages fifteen to thirty or thirty to sixty years. The fact that illiterates often do not know how old they are compounds the problem. The few evaluation studies found to include age data (mainly from Nepal) are given below.

In a Nepalese program, the age of female participants and literacy performance were negatively correlated, but the same percentages scored "excellent" and "good" in age groups fifteen to twenty and twenty-one to twenty-five. However, marital status was related to age. Unmarried women scored better than married ones, and those with fewer children performed better (Manandher 1989). Confounding with variables that adversely affect participation was quite evident; in a comparison of two other Nepalese programs, a curvilinear relationship was found to exist between age and literacy (New Era 1990). Children aged fourteen years and below and adults above thirty-five years scored lower (50.6 percent and 50.7 percent respectively) than persons aged fifteen to thirty-five years (62.3 percent). Similarly, Belbase (1989) found that in the Dhading district of Nepal younger ages had lower scores than a few individuals aged forty to forty nine years.

Semali (1991) found in Tanzania that age was a significant factor in reading and writing achievement, particularly in writing. The effect was very pronounced after age forty-five. Also, younger students performed slightly better in an Algerian program that was reviewed and financed by UNESCO/UNDP in 1976. Joshi (1989) in a study on Nepalese schoolchildren and children in out-of-school classes, used women's education classes as controls and found their performance significantly lower (Table B-1). While there are too many confounding factors and measurement difficulties to allow any conclusions, women's performance was lower than out-of-school children's, although both groups should have significant amounts of housework.

Somewhat more detailed information is available from two programs in Bangladesh, with data collected over three years for six-month courses (Jennings 1990; Table B-2; Figure B-2). Post-tests reflected results at the end of the courses over three years. Completion rates for ages fifteen to nineteen were slightly higher than for ages twenty to twenty-nine and thirty to sixty. A chi square test was statistically significant, which indicated that increased age was associated with lower levels of course completion and with lower levels of acquired 
proficiency (Table B-3). Again, marital status and number of small children, which would be related to age, could be confounding variables. The data reported by Jennings (1990) would likely profit from additional examination, perhaps by means of multiple regression analyses evaluating other variables at the same time as the age variable.

The data indicate that even if an effect exists at the basic literacy level, its magnitude is overshadowed by other very important variables. Without detailed age and performance data on specific skills related to reading, it is impossible to draw conclusions. As mentioned in the main text, it is quite customary to consider 15-year-olds (particularly married girls) as adults. Some researchers, (such as Jennings, 1990) have found that course participants tend to be disproportionately late adolescents, a fact that may influence findings or lack thereof.

One big problem with obtaining reliable age-related data is the relatively accurate assessment of age. Illiterates typically do not know how old they are, and researchers may have a hard time guessing. If their physical growth has lagged significantly, young people may appear younger than they are. On the other hand, repeated early pregnancies and extensive exposure to the sun may make slightly older adults look considerably older. Anthropological methods can be used to assess age (Pison 1980): asking people when they were born in relationship to significant events, rank-ordering with siblings and other people in the village in comparison to their height and weight, asking people to compare their age with that of a tree and measuring tree girth, onset of puberty, wrist size, emergence of second molars around age fourteen, emergence of wisdom teeth around age twenty. Future research should use such methods to assess age more accurately.

Table B.1 Post-Test Data from Two Bangladeshi NGOs

Percentage of "Good" score in

$\begin{array}{llllllll}\begin{array}{l}\text { Age } \\ \text { (years) }\end{array} & \begin{array}{l}\text { Total } \\ \text { number }\end{array} & \begin{array}{l}\text { Number } \\ \text { completed }\end{array} & \text { Percent } & \begin{array}{l}\text { Number } \\ \text { tested }\end{array} & \text { Writing } & \text { Reading } & \text { Numeracy } \\ 1519 & 954 & 661 & 69 & 494 & 66 & 61 & 51 \\ 2029 & 1,302 & 837 & 64 & 562 & 61 & 56 & 52 \\ 3060 & 734 & 445 & 61 & 291 & 58 & 52 & 58\end{array}$

Source : Jennings 1990.

Table B.2 Achievement Comparisons in Nepal

Children in school Mean score

Grade I 22.31

Grade II $\quad 37.23$

Grade III $\quad 38.80$

Out-of-school children $\quad 16.26$ (after two months of instruction)

Women's class $\quad 11.05$ (after two months of instruction)

Source : Joshi 1989. 
Table B.3 Chi Square Tests of Completion Rates by Age

\begin{tabular}{|c|c|c|c|}
\hline Age (years) & Completed & $\begin{array}{l}\text { Did not } \\
\text { Complete }\end{array}$ & Total Tested \\
\hline \multicolumn{4}{|c|}{ Completion of course $X 2=14.19, d f=2, p<0.05$} \\
\hline 1519 & $661.0(619.9)$ & $\begin{array}{l}293.0 \\
(334.1)\end{array}$ & 954.0 \\
\hline 2029 & $837.0(846.1)$ & $\begin{array}{l}465.0 \\
(455.9)\end{array}$ & $1,302.0$ \\
\hline 3060 & $445.0(477.0)$ & $\begin{array}{l}289.0 \\
(257.0)\end{array}$ & 734.0 \\
\hline Total & $1,943.0$ & $1,047.0$ & $2,990.0$ \\
\hline Age (years) & "Good" & Other & Total Tested \\
\hline \multicolumn{4}{|c|}{ Ratings of "Good" in reading X $2=16.64, d f=2, \mathrm{p}<0.05$} \\
\hline 1519 & $300.0(259.9)$ & $\begin{array}{l}361.0 \\
(401.1)\end{array}$ & 661.0 \\
\hline 2029 & $312.0(329.1)$ & $\begin{array}{l}525.0 \\
(507.9)\end{array}$ & 837.0 \\
\hline 3060 & $152.0(175.0)$ & $\begin{array}{l}293.0 \\
(270.0)\end{array}$ & 445.0 \\
\hline Total & 764.0 & $1,179.0$ & $1,943.0$ \\
\hline Age (years) & "Good" & Other & Total Tested \\
\hline \multicolumn{4}{|c|}{$\begin{array}{l}\text { Ratings of "Good" in reading relative to number starting } \\
\text { program } X 2=28.21, d f=2, \mathrm{p}<0.05\end{array}$} \\
\hline 1519 & $300.0(243.8)$ & $\begin{array}{l}654.0 \\
(710.2)\end{array}$ & 954.0 \\
\hline 2029 & $312.0(332.7)$ & $\begin{array}{l}990.0 \\
(969.3)\end{array}$ & $1,302.0$ \\
\hline 3060 & $152.0(187.6)$ & $\begin{array}{l}582.0 \\
(546.4)\end{array}$ & 734.0 \\
\hline Total & 764.0 & $2,226.0$ & $2,990.0$ \\
\hline
\end{tabular}

Source : Jennings (1990), table B, p. 308. 


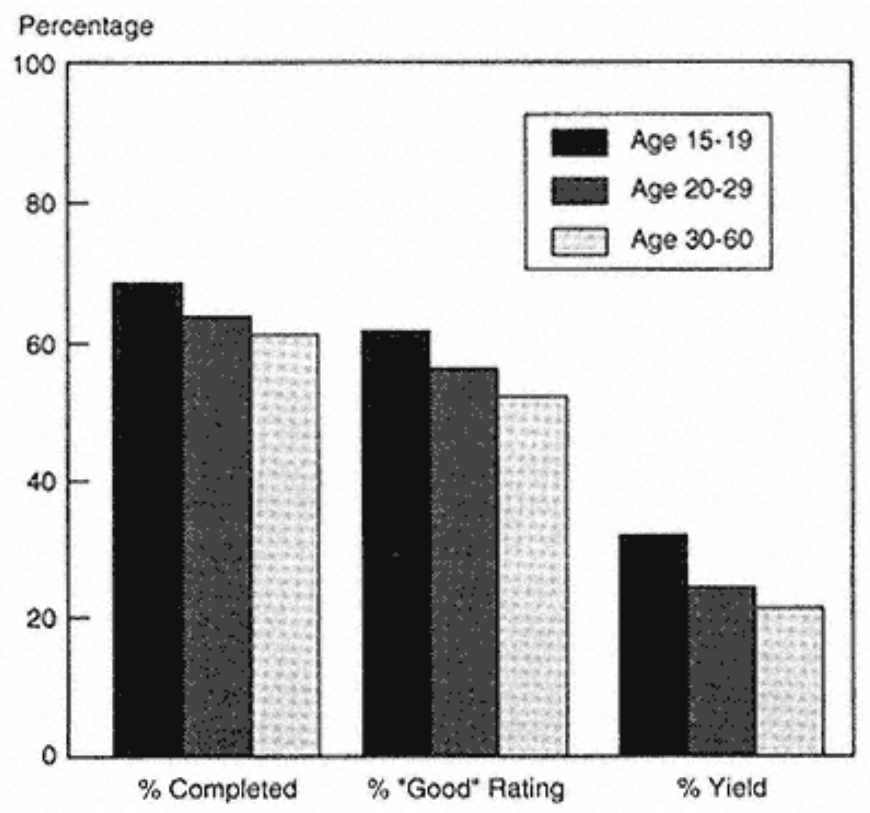

Figure B-2

Results from Two Bangladeshi Literacy NGOs

Source: Jennings (1990).

\section{Appendix C- How Illiterates Think}

\section{Informal Acquisition of Adult Literacy}

Adults learning to read accidentally or without help are extremely rare (Oxenham 1980). But there are examples of a few societies where literacy is disseminated in informal settings among adults. Some American Indian tribes in the past century provided such examples. The most renowned contemporary case is the Vai tribe in Liberia.

The syllabic script of the Vai is taught on a voluntary basis by friends or relatives. It is a culturally encouraged activity that men may undertake from their late teens to their thirties. They specifically learn reading in order to send and receive letters, which often deal with business and courtship. Learners considered Vai literacy easy to acquire. During a study conducted by Scribner and Cole (1981), persons reported having learned the script in informal sessions over a period of two to three months. They met with a teacher three to five times a week in lessons that lasted ten minutes to one hour, averaging forty-five minutes. When Scribner and Cole held experimental classes, acquisition of the script proceeded rapidly, and in one class four out of eleven students learned to write complex letters within a few weeks. The major difficulty seemed to be the managing of writing materials. Reading and writing were found to be inextricably related in letter-writing, given that texts were actual letters written earlier by friends and relatives. The well-understood function of reading and the role models in the community may have facilitated acquisition in comparison to most communities where reading seems to be an externally imposed function.

The Vai example indicates that learning and retaining literacy may be relatively easy with appropriate cultural expectations and under conditions of specific utility, even with a syllabic script that has 210 letters. However, self-selection may take place, and maybe only the most capable learn in this way. The incidence of literacy among all Vai was about 6 percent in the late 1970s. Although it is considered a high-status skill, only 20 percent 
What We Know about Acquisition of Adult Literacy

of adult males were found to be literate at that time (Scribner and Cole 1981). An undetermined number of men reported that they tried to learn but found it difficult or lapsed into illiteracy. Unfortunately, the Scribner and Cole study on the Vai did not research dropouts and relapses into illiteracy.

\section{Information Processing of Illiterates}

Very little is known about how adult illiterates process information, and if more were known, the effectiveness of literacy programs might increase. It appears that there are some significant differences in the cognitive processes of educated and uneducated people which may influence the probability that information will be retained and used. It is possible that the capacity to read depends on the appropriate structures being developed in the brain. Recent research indicates that abstract thinking is affected by the ability to read (ASTD 1993). Does that mean that those who never learned to read have in some ways limited capacities for abstract thought? The little information that is known is presented below.

Illiterates show less dominance of the left hemisphere in language than literate people (Lecours 1989). This is perhaps related to the observation that illiterate adults who are "close to the land" are likely to categorize concepts differently from schooled people. They are less likely to use superordinate and subordinate categories. If asked what a duck is, for example, a schooled individual would say that it is an animal or a bird; an illiterate might say that it is edible or that he killed one the day before (Laboratory of Comparative Human Cognition 1986). Also, illiterates draw their conclusions from concrete facts of from consensus and rely less on abstract reasoning than people do with four years of education. For example, an illiterate person asked the syllogism "All women in Mexico City are

beautiful. My friend is from Mexico City. Is she beautiful?" may reply "Of course she is because you like beautiful women." Education seems to facilitate the use of abstract reasoning and to diminish dependence on environmental validation of people's conclusions.

Reliance on consensus validation rather than on deductive reasoning might be a reason why people attend or discontinue classes when informal group leaders do so and why action-oriented groups might be effective in retaining people in a class. Also, remembering and retrieving information is dependent on how it is classified in the mind. If illiterates have not acquired the categorization skills that will make efficient storage and retrieval possible, they may not retain information that teachers think they taught clearly. This process may be a reason why recall of health or agricultural information presented during literacy classes is sometimes less than expected (Carron, Mwiria, and Righa 1989). On the other hand, the rote memorization of facts in school may make schooled individuals more likely to absorb information presented aurally (Joshi 1991; Carron, Mwiria, and Righa 1989) than unschooled individuals. As in every other area that concerns literacy, the subject has not been researched, and there are no clear recommendations for future literacy programs.

Does literacy instruction per se change the information-processing characteristics of illiterates? To some extent it may. For example, Korean words written in the Chinese logographs were remembered better than words presented in hangul (the alphabetic script) on recognition and free recall though not on pair-associate recall or serial anticipation (Park and Arbuckle 1977). But different scripts may impose different task requirements for achieving proficiency (Tzeng 1980). Also, strategies developed to meet these requirements are transferrable to situations with similar task requirements. Scribner and Cole (1978) found evidence of cognitive adjustments by Vai adults who had become literate in Vai or Arabic. Vai is a tonal language, but tone information is not marked in the script. Also, no word boundaries or punctuation are indicated, so the reader must group the syllables together to form words and then integrate these into meaningful linguistic units. On the other hand, Arabic is an alphabetic script, learned by the Vai mainly through rote memorization. (The Vai typically do not understand Arabic.) When students of these two scripts were tested in various cognitive tasks, Vai and Arabic literates did not differ in their ability to comprehend the word strings, but Vai literates were superior on tasks of picture reading 
and syllable integration, which mimicked their normal reading abilities. Arabic literates, in contrast, performed better than Vai literates on the incremental memory task which most closely resembled their everyday reading activities. Therefore, Tzeng (1980) hypothesized that becoming literate in certain scripts can have a long-lasting effect in molding people's information-processing system .

Nevertheless, the information-processing benefits of literacy may be small. Scribner and Cole (1981) tested the cognitive effects of literacy on the Vai separately from school effects (see below) and found that literacy by itself did not create significant cognitive changes. The major effect of literacy was classification changes; Vais schooled at western-type schools were only found superior to illiterates in solving logical problems, namely syllogisms.

In the section on malnutrition it was pointed out that protein-energy deficiency impairs cognitive functions (at least during childhood), such as the ability to learn and form categories. Given the frequent tendency for the malnourished also to be illiterate, an interaction effect may exist that has not yet been researched.

\title{
Appendix D- Age-Related Difficulties in Literacy Acquisition: A Literature Review
}

\author{
This appendix is an abbreviation of a report prepared in 1992 by Dr. Timothy A. Salthouse, Professor of \\ Psychology at the Georgia Institute of Technology, with funding from the World Bank's Research Committee .
}

Are there age-related barriers to the acquisition of literacy? Is there something analogous to a critical period for learning to read and write, such that learning is more efficient within a particular age range? If a relation exists between age and efficiency of literacy acquisition, how strong is that relation, both in absolute terms, and relative to other influences on the acquisition of literacy? These questions are the focus of this appendix.

Opinions vary regarding the possibility of qualitative or quantitative differences between children and adults in the acquisition of literacy. Some authors have claimed that there are no fundamental differences (Chall 1983, 1987; Jennings 1990). However, because adults are likely to have an advantage relative to children in the amount of knowledge and in the repertoire of cognitive skills (Chall 1987; Wagner 1987), some researchers (Chall 1987; Jennings 1990) have suggested that adults might be faster in the initial stages of learning than children. In support of this suggestion are the observations that adult literacy programs are usually much shorter than elementary education programs designed to achieve an equivalent level of literacy (Jennings 1990). For example, Jeffries (1967) has claimed that under favorable conditions an illiterate adult can generally learn to read within six weeks. The report by Scribner and Cole (1981) that Vai adults learn to read a special script in only a few months of studying two to four hours per week is also consistent with the claim that adults actually learn faster than children (appendix C).

The issue of possible differences between children and adults is by no means resolved, and both Chall (1987) and Wagner (1987) have argued that more research is needed before a definitive conclusion can be reached. At the present time there is still uncertainty with respect to whether children and adults learn to read by means of the same sequence of stages, and it is clearly not meaningful to compare the rate of progress through the stages if different stages are involved at different ages.

\section{How Can Age-Related Influences Be Investigated?}

What type of evidence would be relevant to determining whether there are age-related influences on literacy acquisition? The most pertinent evidence would undoubtedly consist of direct comparisons of efficiency in learning to read under identical situations among people of different ages, but who are similar in all other 
respects. An extensive literature search revealed no such studies, except for one close approximation (Jennings 1990). In the absence of direct evidence, any conclusions regarding age-related influences on reading acquisition will have to be based on two types of indirect evidence: an examination of the relations between age and variables previously found to be associated with success in reading acquisition; and a review of the literature concerned with age-related influences on other presumably relevant processes.

In attempting to identify important correlates of success in learning to read, many reviews of the literature were examined (Bryant 1986; Golinkoff 1978; Jorm 1983; Liberman and Shankweiler 1991; Mann 1991; Rayner and Pollatsek 1989; Share, Jorm, Maclean, and Matthews 1984; Stanovich 1986 1991; Venezky 1978). Only three predictors were identified for which substantial evidence was available

documenting a relatin with success in learning to read: phonological or phonemic awareness; memory for verbal material; and working memory.

Two omissions from this list are rather surprising. One is general intellectual ability, which is not considered a predictor because there is considerable variation in early reading proficiency among children of the same overall intellectual level. There was also little evidence that visual discrimination ability plays an important role in reading acquisition. Among the relevant evidence are the results that a relation between visual abilities and reading appears only if the material is verbal in nature (Bryant 1986, p. 54), and the lack of benefit on reading proficiency of training in visual discrimination of objects and shapes (Venezky 1978, p. 12).

Four points should be noted about these predictors. First, they are not necessarily independent, because, for example, phonological coding may be related to working memory or to verbal memory (Ellis 1988; Jorm 1983; Liberman and Shankweiler 1991; Mann 1991; Tunmer 1991; Wagner and Torgersen 1987). Second, the predictors may vary in importance at different stages of reading acquisition. That is, phonological awareness may be more important at Chall's Stages 1 and 2 than at her Stage 3 (Chall 1987), whereas the reverse may be true for working memory. Third, the predictors are not necessarily causes, because they could also be consequences of the development of literacy, or they could be involved in reciprocal relations with reading (for example, Stanovich 1986; Wagner and Torgersen 1987). And fourth, almost all of the relevant evidence is based on research with children from industrialized countries, and the possibility of generalizing the results to other populations, such as adults in developing countries, is not known. For all of these reasons, the variables will be referred to as predictors of reading acquisition because the linkage has been established primarily on the basis of correlational research, and the causal direction of the relations has not yet been definitively established.

\section{Phonological Awareness}

Phonological awareness has been defined by Stanovich (1986, p. 362) as " . . conscious access to the phonemic level of the speech stream and some ability to cognitively manipulate representations at this level." It is measured with a variety of tasks requiring the addition or deletion of a sound, production of rhymes, identification of words with the same initial sound, replacement of a sound with a different sound, and identification of different sounds within a word. All of these tasks are assumed to assess the ability to analyze words both from print and from speech into components, and to relate those components to one another. Phonological or phonemic awareness therefore refers to the knowledge, and the use of such knowledge, that speech is composed of phonemic units that have a direct correspondence to written units (graphemes).

A concept similar to phonological awareness has been mentioned in nearly all recent reviews as the most important single variable involved in learning to read. For example, Rayner and Pollatsek (1989, p. 343) claimed that " . . discovering the alphabetic principle is the key to successfully learning to read" and Stanovich (1991, p. 2223) recently stated that "Whereas there are many correlates of the ease of initial reading acquisition, a large number of studies have demonstrated that phonological abilities stand out as the most potent specific predictor." 
The conclusion that phonological awareness is a fundamental component of success in learning to read has also been reached by many other reviewers of the literature on early reading (for example, Alegria and Morais 1991; Bertelson 1986; Bertelson and deGelder 1989; Golinkoff 1978; Gough and Juel 1991; Liberman and Shankweiler 1991; Mann 1991; Rayner and Pollatsek 1989; Share, Jorm, Maclean,

and Matthews 1984; Spector 1992; Stanovich 1986; 1991; Torgersen, Morgan, and Davis 1992; Tunmer 1991; Wagner and Torgersen 1987).

Literacy —not age—facilitates phonological awareness. Phoneme deletion is a task quite sensitive to degrees of literacy as well as to native languages, while a written test of literacy is not sensitive to native language variation. But there is also a maturational component to this. Precocious readers less than six years of age could not perform the task (Scholes 1991).

Literacy knowledge positively correlates with overall metalinguistic skill (awareness of how various aspects of language function) and specifically with linguistic awareness (Chaney 1989). Illiterates perform lower than literates on vowel deletion and rhyme judgment but perform much lower on consonant deletion (Bertelson, DeGelder, Tfouni, and Morais 1989). The latter task may involve separate components that obey different developmental mechanisms.

\section{Verbal Memory}

Verbal memory refers to the ability to retain the identity and/or order of words or other verbal materials for brief periods of time. The relevant memory is specific to linguistic material or material that is easy to code linguistically because little or no relations have been reported between reading acquisition and memory for non-verbal material (Brady 1986; Bryant 1986; Jorm 1983; Liberman and Shankweiler 1991). Liberman, and others (1977, p. 207) have provided a plausible explanation for this relation. Their interpretation is that a basic characteristic of language is that the meaning of longer segments transcends the meaning of shorter segments, and hence the latter information must be temporarily held in memory in order to allow meaning to be extracted.

\section{Working Memory}

Baddeley (1986) has proposed a very influential model of working memory that incorporates three components: a central executive, and two slave systems consisting of an auditory articulatory loop, and a visual-spatial sketchpad. It has therefore been hypothesized that working memory may be involved in reading because the articulatory loop may be closely related to phonological coding abilities. Although Baddeley's is only one particular model of working memory, there is general agreement that working memory is involved whenever simultaneous processing and storage are required. Working memory could therefore play an important role in learning to read because early products need to be preserved when converting later print segments to sound and to meaning, and words from the beginning of a sentence need to be preserved when analyzing words from later portions of the sentence.

Research documenting a linkage between working memory and fluency of reading has been described in several sources (Ellis 1988; Jorm 1983; Liberman, Shankweiler, Liberman, Fowler, and Fischer 1977; Mann 1991; Tunmer 1991; Wagner and Torgersen 1987). In virtually all cases, reading fluency has been found to be highest among individuals with the most efficient or effective functioning of working memory.

\section{Age-Predictor Relations}

This section is devoted to an examination of the relations between age and the three predictors described above. Paired-associate learning is included as an additional predictor despite the absence of convincing evidence 


\section{What We Know about Acquisition of Adult Literacy}

linking it to success in early reading. The reason for considering paired-associate

learning ability in this context is that it is postulated to be an important component in the pre-reading phase in both Chall's (1983) model, and in the model of Gough and Hillinger (1980).

There are several recent reviews of the research literature on the relation between age and cognitive abilities (for example, Craik and Salthouse 1992; Kausler 1991; Salthouse 1991). This literature can be summarized, in very general terms, as follows. There is little or no relationship between age and measures of acquired knowledge or the accumulated products of past processing, sometimes referred to as crystallized intelligence, but moderate to large negative relations are frequently reported between age and measures of the efficiency or effectiveness of processing at the time of assessment, which is sometimes referred to as fluid intelligence .

However, one of the most useful sources of data relevant to specific predictors of reading acquisition are the results from the normative sample in the Woodcock-Johnson Test of Cognitive Ability and Test of Achievement (Woodcock and Johnson 1989, 1990). The age relations in these tests are very similar to those from other research projects, but this test battery benefits from using a very large amount of data (over 6,000 individuals sampled to be representative of the United States population), a wide range of ages (six to eighty years of age), and measures on tests specially designed to be sensitive to a large range of ability levels.

All of the results to be discussed are expressed in standard deviation units of young adults (typically eighteen years of age). This transformation has two advantages over reporting the results in terms of the original units of measurement: it facilitates comparisons across measures because they are all expressed in the same scale; and the units of the scale are inherently meaningful in terms of proportions of the reference distribution. For example, a mean of -1 standard deviation indicates that approximately 50 percent of the target group perform below 84 percent of the reference group of young adults.

\section{Paired Associate Learning}

The Woodcock-Johnson battery contains two tests assessing paired-associate learning ability. One requires association of visual figures with names (Memory for Names), and the other of symbols with words (Visual Auditory Learning). The results summarized in figure D-1 indicate that performance on these tests averages one standard deviation or more below the mean at age eighteen for children under the age of nine, and again for adults over the age of thirty-five.

\section{Phonological Awareness}

Several tests in the Woodcock-Johnson battery are relevant to the construct of phonological awareness. For example, the Sound Blending Test assesses the ability to combine sounds to form words, the Sound Patterns Test assesses the ability to discriminate sounds, the Letter-Word Identification Test assesses the ability to identify words from print, and the Word Attack Test assesses the ability to pronounce words from the spelling patterns. Figure D-2 illustrates that there is a dramatic increase in all of these abilities with increased age in childhood, followed by a relatively slow decline after maturity. The most pronounced age relation is with the Sound Blending Test, but even at the oldest ages the average performance in this test is still at or above the level of children aged six to nine years. 
What We Know about Acquisition of Adult Literacy

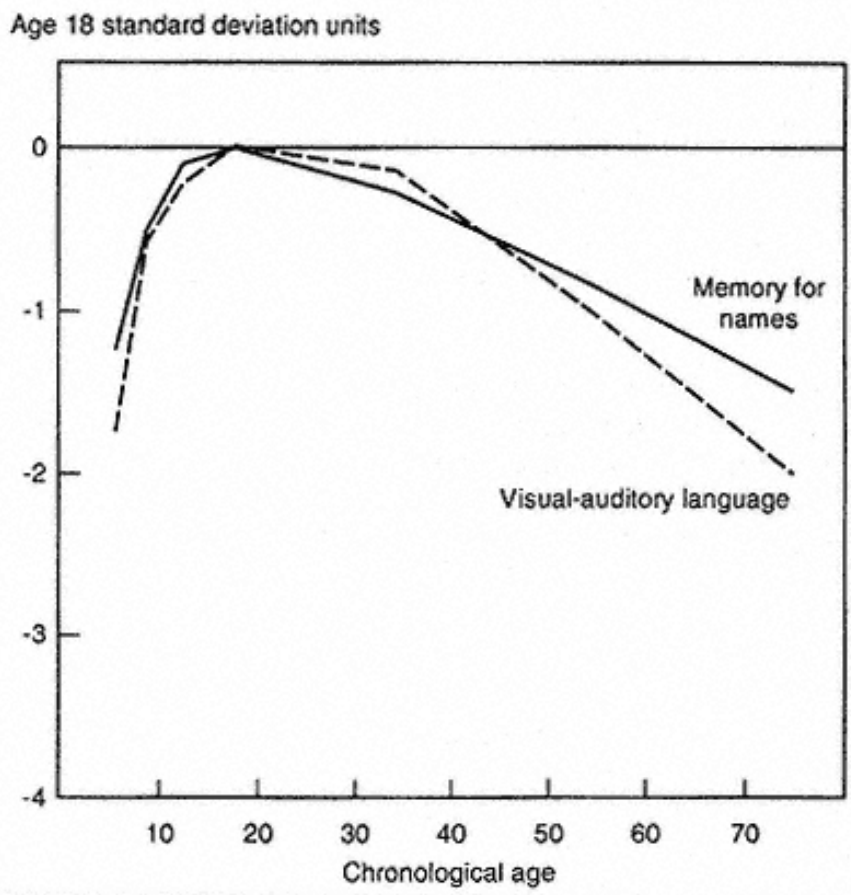

Figure D-1

Paired-Associate Learning

Source: Woodcock \& Johnson $(1989,1990)$.

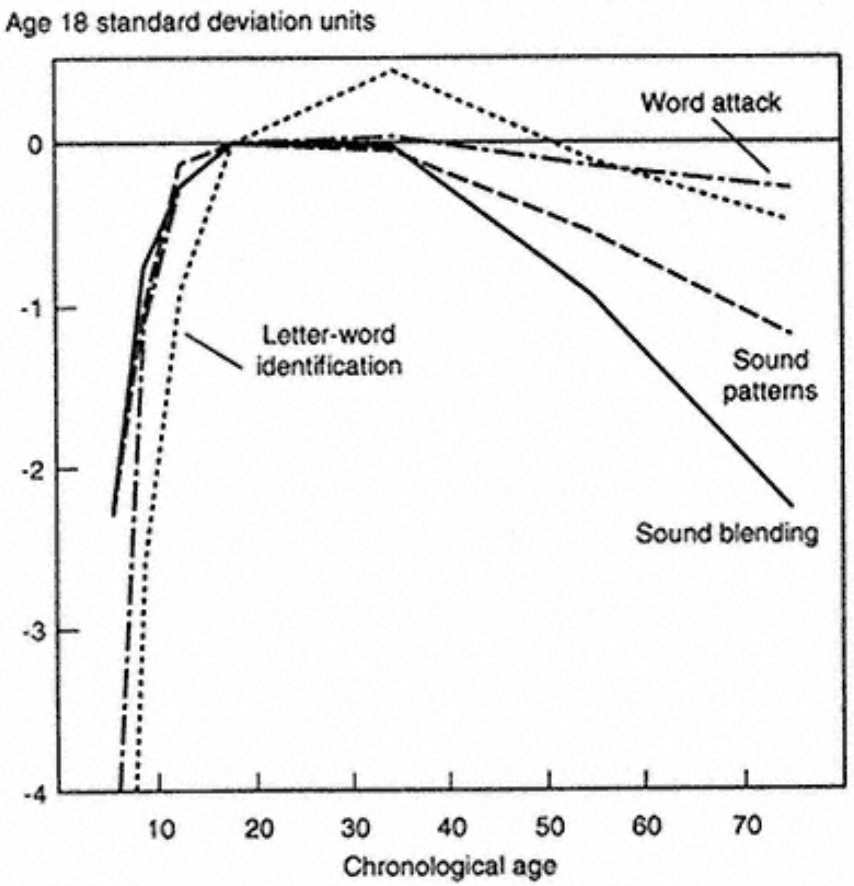

Figure D-2

Phonological Awareness

Source: Woodcock \& Johnson $(1989,1990)$. 
What We Know about Acquisition of Adult Literacy

\section{Verbal Memory Span}

Most memory span tests assess the largest number of items that can be remembered in the correct order. The Memory for Words test involves unrelated words, and the Memory for Sentences test involves memory for words in the context of sentences. Age trends for these tests are presented in figure D-3. (Performance in the Numbers Reversed test is also illustrated in figure D-3 although it should probably be considered a measure of working memory because the subjects have to carry out some processing, in the form of reordering the items, before recalling them.) Note in figure D-3 that although average performance is more than two standard deviations below the eighteen-year-old mean at age nine, the average level at age seventy-five is only one standard deviation below that mean.

Similar data on Digit Span and Word Span tests, in which the task was immediate serial recall of either digits or words, were collected from a total of 462 adults in a recent project by Salthouse and Babcock (1991). The results, portrayed in figure D-4, closely resemble those in the adult portion of figure D-3 in that the average performance of adults in their seventies is about 1 to 1.5 standard deviations below the mean of young adults.

It is interesting to note that negative relations between adult age and measures of verbal memory were also reported by Scribner and Cole (1981) in their studies of the Vai people in Liberia. For example, age-related decreases were reported in memory tests involving free recall of words (page 125), sentences (page 183), incremental serial recall of words (page 230), and gist recall of stories (page 233).

\section{Working Memory}

As mentioned earlier, one of the defining characteristics of working memory is simultaneous processing and storage. One method of assessing working memory therefore requires that some type of processing be performed on the information to be recalled. Because the sequence of items must be reordered in the backwards digit span task, the results from the Numbers Reversed Test in Figure D-3 can be interpreted as reflecting age-related differences in working memory.

Another method of assessing working memory is to require that a specified type of processing be carried out, and then to measure accuracy of recall of a set of items. In tasks used by Salthouse (Salthouse 1992a; Salthouse and Babcock 1991), the processing involves answering questions about sentences while trying to remember a sequence of words, or solving simple addition and subtraction arithmetic problems while trying to remember a sequence of digits. For example, the reading span task, originally introduced by Daneman and Carpenter (1980), involves the presentation of a series of sentences each accompanied by a question and three alternative answers, followed by a request to recall the last word from each sentence. The computation span task is formally similar, but involves the presentation of a series of arithmetic problems with three alternative answers, followed by a request to recall the last digit from each problem. A typical trial in each task is illustrated in figure D-5.

Figure D-6 summarizes data on these two working memory tests from 1,272 adults across a wide range of ages. Notice that the age relation is similar to that evident in the preceding figures in that performance at age seventy is about 1 to 1.5 standard deviations below the mean of young adults. In a similar vein, a literacy survey in the State of Mississippi found that age along with race and educational attainment were predictors of reading performance (Adams-Price 1991). Older adults had more difficulty reading and answering test questions, which often included distracting bits of information. This might be due to reduced working memory capacity that would make it harder to remember facts from one part of a long text to another. 
What We Know about Acquisition of Adult Literacy

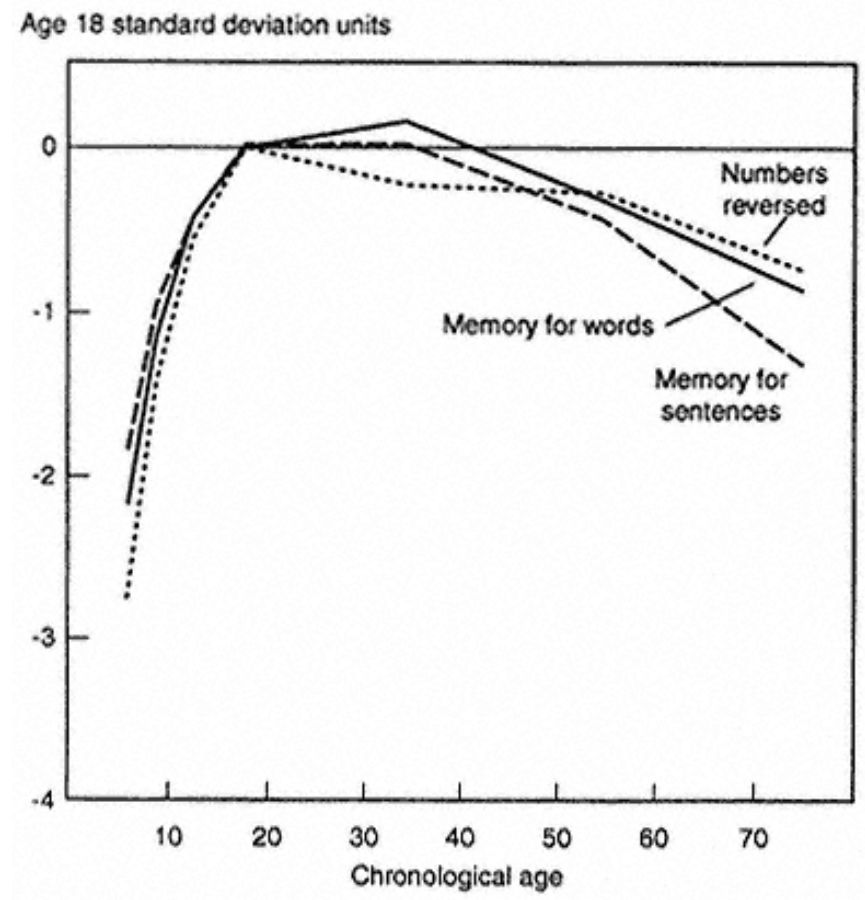

Figure D-3

Verbal Memory Spans

Source: Woodcock \& Johnson (1989, 1990).

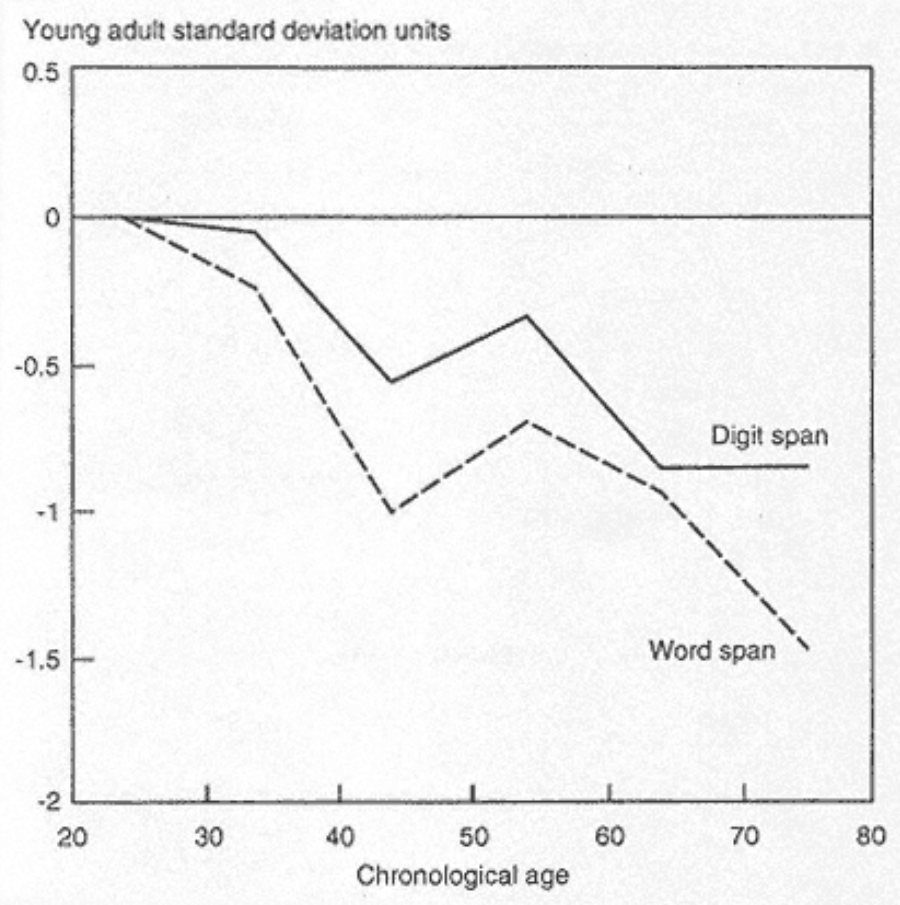

Figure D-4

Verbal Memory Span

Source: Salthouse \& Babcock $(1989,1990)$. 
What We Know about Acquisition of Adult Literacy

Working Memory Tasks

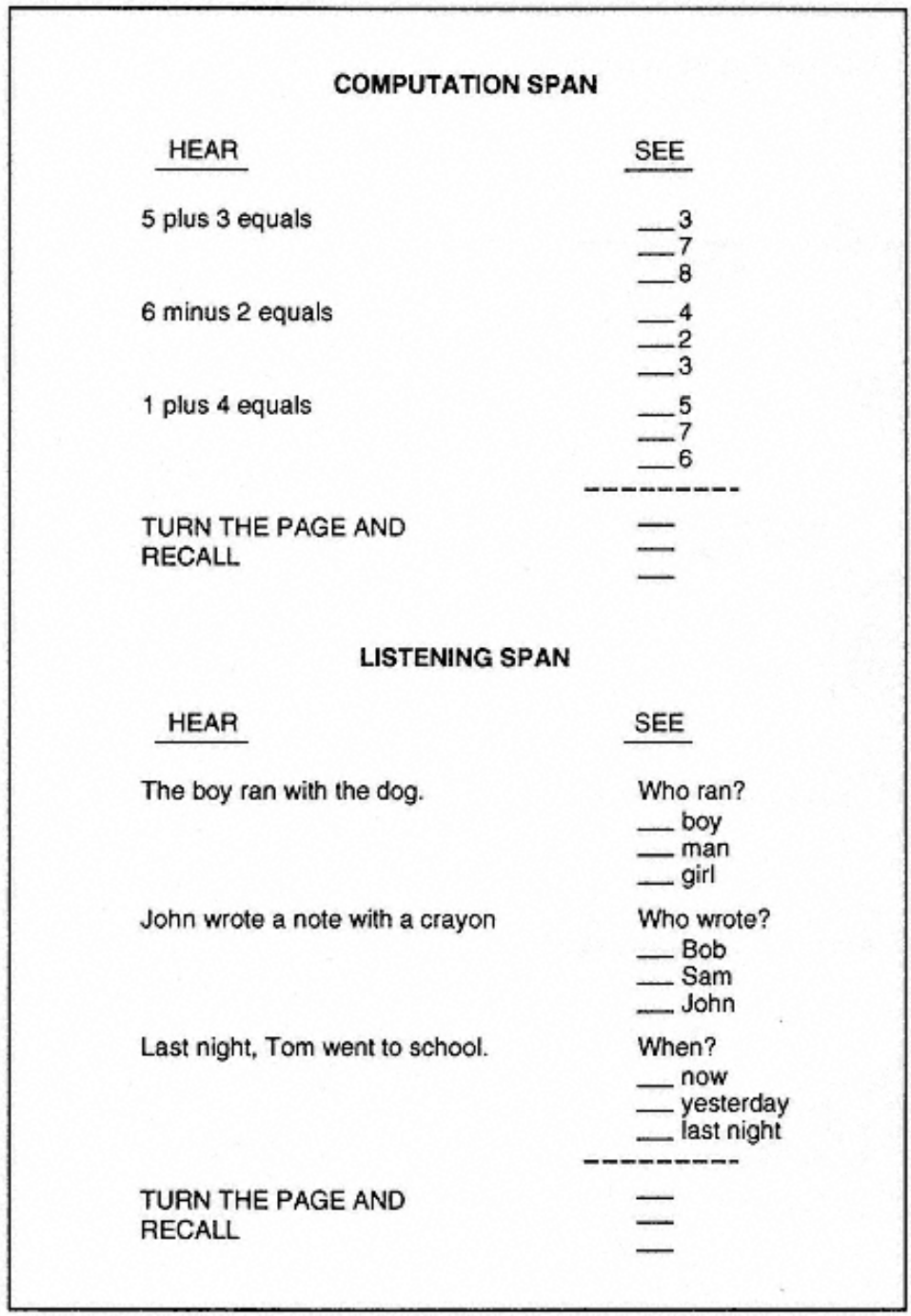

Figure D-5

Working Memory Tasks 


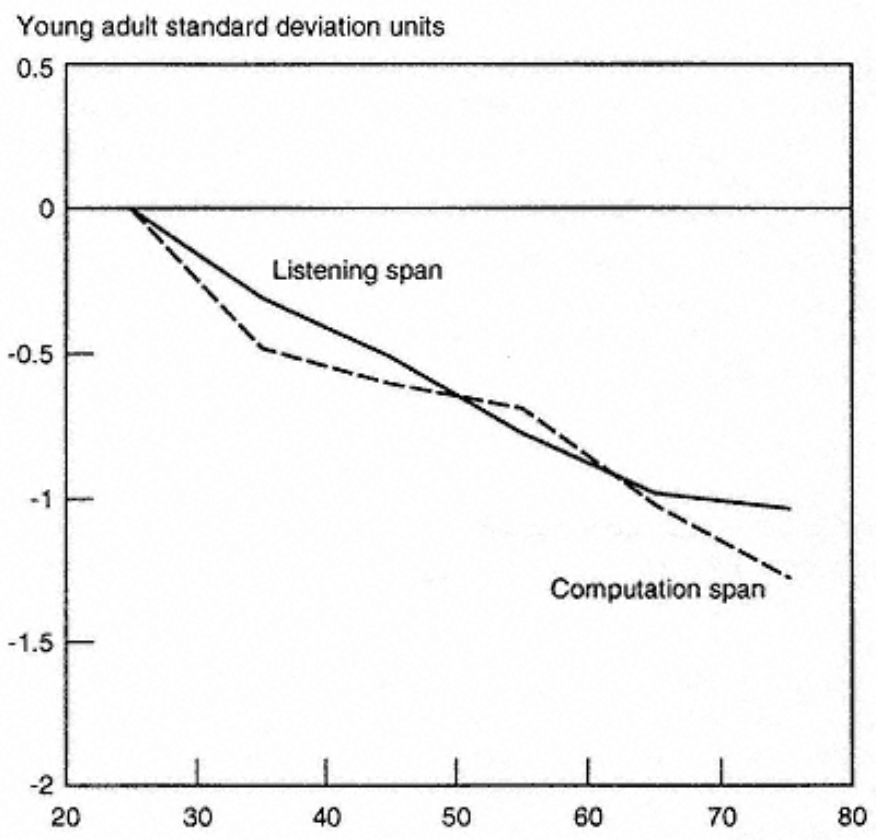

Figure D-6

Working Memory

Source: Salthouse (1992b).

Although the age-related effects in each of the preceding figures are systematic, it is important to emphasize that in all cases the cumulative age difference is rather small relative to the difference between children and adults. That is, even at age seventy the mean level of performance is generally within 2 standard deviations of the means of young adults. Because the means of six-year-old and nine-year-old children are also below this level and yet most learn to read successfully, it seems unlikely that the age-related declines in the abilities found to be related to reading success would prevent one from learning to read until at least beyond age seventy.

\section{Other Age-Related Differences}

In addition to the variables for which there is evidence of a relation to success in learning to read, it is also of interest to examine the age-related effects on other variables that may have some relevance to reading acquisition. Research on variables representing processes of segmentation and integration, rapid access to long-term memory, and learning is therefore briefly reviewed in this section. Although the results to be described are robust, in the sense that they have been replicated many times, it should be noted that many of the studies involved extreme group designs in which a group of eighteen to twenty-five-year olds were compared with a group of sixty to eighty-year olds. A limitation of this type of research is that no information is available about the influence of age between twenty-five and sixty, which may be of greatest interest in the present context.

\section{Segmentation and Integration}

Segmentation and integration processes may be involved in reading because of the necessity of segmenting the written material into discrete units, such as words, and of integrating a sequence of smaller elements, such as letters, into larger units.

The type of research most relevant to segmentation ability is probably that based on versions of the embedded figures test. This test typically consists of a target pattern that is to be located within a complex figure. Because embedded figures tests require the individual to detect or locate a small target figure within a large and complex 
pattern (usually composed of geometric figures or line segment), it is assumed that the complex pattern must be segmented into smaller parts. Performance is frequently measured in terms of the number of targets correctly identified in a fixed period of time. In a recent review (Salthouse 1991), nineteen independent studies were identified in which increased age (generally range twenty to seventy-five years) was associated with slower, or less accurate, segmentation performance. A few studies have looked at comparisons between young and middle-aged individuals and find that the age differences are smaller but still noticeable.

No studies have been located that used script or writing as stimuli. However, Cerella (1985) found a deficit in identification speed and accuracy for letters placed at increasing distances from the fovea. His decline reached a level of significance for learning only with subjects aged on the average 72.2 years. As mentioned in chapter 2, speed depends partly on the fact that the eyes can resolve three or four letters to the right and left of the fovea. It is possible that being able to read fewer letters at a glance might make reading slower and pattern formation as well as segmentation more difficult.

A variety of different types of tasks have been used to assess spatial integration abilities in adults of different ages. The tests likely to be most relevant to reading require the examinee to identify degraded or incomplete words or figures. A consistent finding across numerous studies is that older adults require more time or perform at lower levels of accuracy than young adults in these types of tests. (See Salthouse 1991 for a review.)

The results just summarized suggest that increased age is associated with reductions in the efficiency or effectiveness of segmenting and integrating perceptual displays. What is not yet clear from these results is whether any differences that might be evident between adolescence and middle adulthood would be great enough to affect success in learning to read.

\section{Rapid Access to Long-Term Memory}

Several studies have reported a significant relation in college student samples between reading fluency and the speed of accessing information in memory (Jackson 1980; Jackson and McClelland 1979; Palmer, MacLeod, Hunt, and Davidson 1985). One task used to investigate the speed of access to long-term memory requires the research subject to decide if two letters are different (such as Ab), physically identical (such as AA), or nominally identical (such as Aa). An estimate of the time needed to access information from long-term memory is derived from the difference in reaction time to nominally identical stimuli and to physically identical stimuli. A finding that has been replicated in several studies is that, relative to less skilled readers, college students who score highest on tests of reading speed and comprehension have smaller reaction time differences between the two types of trials, suggesting that they are faster at gaining access to the name codes stored in long-term memory.

At least four separate studies (Hines and Posner 1976; Lindholm and Parkinson 1983; Poon, and others 1976; Wright 1981) have found that the difference between name identity and physical identity decisions is greater for older adults than for young adults. These results therefore imply that with increased age more time is needed to access information from long-term memory.

\section{Learning}

Another category of evidence relevant to possible age-related barriers in the acquisition of literacy derives from research concerned with adult age differences in learning. The number of published studies is not large, but several articles have examined adult age differences in acquiring proficiency in perceptual-motor skills, cognitive skills, and the use of computers.

Studies of perceptual-motor skills have frequently found that although older adults perform at lower levels than young adults, they exhibit similar amounts of improvement with moderate to extensive practice. This is true in 


\section{What We Know about Acquisition of Adult Literacy}

tasks ranging from perceptual discrimination (Ball and Sekuler 1986; Salthouse and Somberg 1982) to reaction time (Beres and Baron 1981; Berg, Hertzog, and Hunt 1982; Salthouse and Somberg 1982). However, somewhat contradictory results were reported in an early study of perceptual-motor learning by Thorndike, Bregman, Tilton, and Woodyard (1928). The major finding in their study was that adults above the age of thirty-five (with a mean age of forty-one) improved less than younger adults (with a mean age of twenty-two) in the speed of writing with the wrong (non-preferred) hand over fifteen hours of practice.

More detailed investigations of possible age differences in perceptual skill learning have also been conducted, with much of the focus on the development of automaticity. The criterion for automaticity most often used in this research is based on the slope of the function relating decision time to the number of items either in memory, or in a visual display. The typical finding early in practice is that each additional memory or display item requires more time, such that the slopes are substantially greater than zero. However, after moderate amounts of consistent practice (that is, practice in which the correspondence between stimuli and responses does not change), the slopes approach a value of zero. Because a slope of zero indicates that multiple items can be processed in the same amount of time as a

single item, the presence of a zero slope has been interpreted as an indication that certain processes have become automatic, or at least executable in parallel.

A number of studies have compared young and old adults with respect to the effects of practice on the slopes relating decision time to number of display or memory items. A consistent finding is that both young and old adults reduce the values of the slope parameters with practice (Fisk, McGee, and Giambra 1988; Fisk, Rogers, and Giambra 1990; Fisk and Rogers 1991; Madden 1983; Madden and Nebes 1980; Plude and Hoyer 1981; Plude, and others 1983; Salthouse and Somberg 1982). Fisk and his colleagues have argued that older adults may be less capable than young adults of acquiring automaticity in these types of tasks because the slope values of young adults were not significantly greater than zero in several studies, whereas those for older adults after equivalent amounts of practice were greater than zero (Fisk, McGee, and Giambra 1988; Fisk, Rogers, and Giambra 1990). However, small or no age differences were apparent in conditions comparable to those in these studies in two subsequent experiments reported by Fisk and Rogers (1991), and thus the factors contributing to possible age differences in the development of automaticity are still not well understood. One possibility suggested by Fisk and Rogers (1991) is that age effects in the development of automaticity are evident when the search is through a visual display but not when the search is through items in memory. Although the Fisk and Rogers (1991) results are consistent with this interpretation, they do not account for the discrepancy between the results of the two earlier studies (Fisk, McGee, and Giambra 1988; Fisk, Rogers, and Giambra 1990) and those in the Fisk and Rogers (1991) article.

Several studies have investigated the relation between age and the acquisition of cognitive skills such as mnemonic procedures, or algorithms for mental computation. For example, Kliegl, Smith, and Baltes (1989) trained young and old adults to remember a serial list of words with the method of loci mnemonic procedure. Young adults were found to improve more than older adults in the initial mastery of the procedure, but the two groups exhibited similar improvements in the application of the technique with subsequent practice. (See also Baltes and Kliegl 1992 for an extension of this finding.)

Another study examining the influence of aging on cognitive skill acquisition is that of Charness and Campbell (1988), involving the skill of computing the square of two-digit numbers. These investigators found little or no age differences in the efficiency of learning and applying an algorithm for mental squaring of two-digit numbers. Adults of greater ages were slower at all stages of practice, but the rate of improvement was similar among young, middle-aged, and older adults. 
What We Know about Acquisition of Adult Literacy

Adults of different ages have also been compared with respect to their efficiency of learning to use different types of computer packages, such as word-processing systems. In some studies older adults have been found to exhibit slower improvement than young or middle-aged adults (see for example Egan and Gomez 1985; Elias, Elias, Robbins, and Gage 1987), and in other studies older adults have been reported to execute relevant operations (such as delete, move, search and replace) more slowly, or to require more assistance after training, than young adults (see for example, Gist, Rosen, and Schwoerer 1988; Hartley, Hartley, and Johnston 1984; Zandri and Charness 1989).

There have also been several reports investigating relations between age and the successful completion of Air Traffic Controller training. Perhaps because this is an occupation with high demands for rapid processing of visual and spatial information, increased age has been found to be negatively related to probability of success (Cobb, Lay, and Bourdet 1971; Trites 1963; Trites and Cobb 1964a and 1964b). In fact, the failure to success ratio has been reported to be 1 to 1 for trainees under the age of 35, 4.7 to 1 for trainees over the age of 35, and as high as 7.4 to 1 for trainees over the age of 39 .

Unfortunately, analytical studies that might have been informative about the reasons for the relation between age and rate of failure have apparently not been conducted.

If the research on adult age differences in learning is meager, that concerned with relations between age and retention is almost non-existent. Nevertheless, three studies have reported little or no age differences across intervals of thirty to ninety days in retention of perceptual-motor skills (Salthouse and Somberg 1982), mental calculation skills (Charness and Campbell 1988), and aspects of a newly learned language (Thorndike, Bregman, Tilton, and Woodyard 1928).

It is difficult to draw any strong conclusions regarding possible age differences in learning efficiency based on the available research. There are several reports of no differences between young and old adults in the amount of practice-related improvement in performance, but there are also reports of age-related limitations in learning effectiveness. Perhaps the strongest statement that can be justified at this time is that increased age is definitely not an absolute barrier to learning. Phrased somewhat differently, old dogs can in fact learn new tricks, even if the rate of learning, and possibly the ultimate level of proficiency, may be somewhat lower than that of young dogs.

\section{Second Language Acquisition}

A fairly extensive literature exists relevant to the issue of child-adult differences in learning a second language. The general conclusion seems to be that there is an advantage for adults early in learning, but that children are superior in the ultimate level of proficiency achieved (Johnson and Newport 1989; Krashen 1982; Krashen, Scarcella, and Long 1982; Snow 1983).

An example of the type of research leading to this conclusion is a study by Johnson and Newport (1989). These researchers found that proficiency in English was better if the period of exposure, and hence the opportunity for learning, began before the age of puberty. The correlation between age of initial exposure and English proficiency as assessed by their measures was -0.87 between the ages of three and fifteen, but in the range between seventeen and thirty-nine years of age the performance levels were lower, and the correlation between age and proficiency was only -0.16 . It is important to point out that in this and several other studies language proficiency was evaluated not merely in terms of pronunciation, but also by means of tests of grammatical and syntactic knowledge.

In a recent article, Newport (1990) summarized the research in the area of second-language learning with the claim that the later the language is learned, the less its use is native. Based on her own research on deaf 


\section{What We Know about Acquisition of Adult Literacy}

individuals learning American Sign Language, she also suggested that a similar relation exists between age and the acquisition of a first language.

An early study of adult age differences in second language learning, but still one of the most comprehensive, was reported by Thorndike, Bregman, Tilton, and Goodyard (1928). The language learned in this study was the artificial language Esperanto. An average of about twenty hours of instruction was administered, followed by a test of vocabulary, two written comprehension tests, and an oral comprehension test. Little or no differences were found between ages twenty and fifty in the amount of improvement in the vocabulary test, but there was a smaller improvement in oral comprehension for adults above age thirty-five than for those below age thirty-five. The age relations in this test may be associated with a slower speed of processing information because of the necessity of rapid processing in oral comprehension.

Thorndike and his collaborators also included several comparisons of the rate at which children learned Esperanto. As in later studies of second-language acquisition, their results suggested that children learned at a slower rate than adults. The authors summarized their findings as follows:

All the evidence points to a curve for ability to learn a systematic logical language with a vocabulary based largely on Latin, French, German, English, and Italian, of the following type for individuals who attend school through college: Rising from 8 to 16 and probably to 20, or later, then remaining parallel to its base line to 25 or later, then dropping very, very slowly to 35 , and somewhat more rapidly, but still very slowly, to 45 or later (p. 239).

It should be noted that this pattern is very similar to the empirical results with the predictor variables illustrated in figures D-1 to D-6.

The early stages of learning in the studies of second-language acquisition probably correspond to Chall's (1983) Stage 3, which can be interpreted as reflecting basis literacy. An implication from the research on second-language acquisition, therefore, is that late adolescents and young and middle-aged adults might actually be more efficient than children and early adolescents at acquiring early or basic levels of literacy.

Two classes of explanation have been proposed for the child advantage in the final level of proficiency achieved in a new language. One proposal was by Lenneberg (1967), who postulated that a critical period for language acquisition occurs because of neurological changes related to specialization of the cerebral hemispheres. An alternative interpretation was discussed by Newport (1990), who suggested that the apparent decline in language acquisition efficiency was a consequence of changing, and improving, cognitive abilities with increased maturity. Specifically, as children mature they become capable of handling larger units of information, which may actually be a disadvantage for critical aspects of language learning in which print and sound must be analyzed into small segments.

These two alternatives have not yet been empirically distinguished, and they may be only marginally relevant to the question of age-related influences between the periods of adolescence and late adulthood. Regardless of the reasons for the child-adult differences, however, the dominant pattern apparent in research on second language learning is for children to exhibit greater proficiency after extended exposure, but for adults to progress somewhat faster than children in the early phases of learning a new language.

\section{Neurological and Physiological Factors}

A fundamental assumption of the information-processing perspective to cognition is that processes and representations form a meaningful level of analysis or understanding independent of the type of "hardware" (such as neurons or computer chips) in which they are implemented. Furthermore, it is considered unlikely that any 
differences in neurological and physiological factors would affect a complex cognitive activity such as learning to read without also having an influence on simpler cognitive processes of the type discussed in previous sections. Nevertheless, it is useful to briefly summarize a few of the most important age-related differences in the central nervous system (see Cohen 1988).

The number of functional neurons in the brain decreases with age, but the cell loss is selective and greater in some regions (for example, the medial temporal lobe and the frontal lobe) than in others. There is also some reduction in certain neurotransmitters, and possibly a decrease in the extent of

dendritic branching. Even among healthy older adults there is an increase in neurofibrillary tangles and neuritic plaques, although they are much more frequent and numerous in pathologies such as Alzheimer's disease. Finally, gross measures of neural activity, such as the EEG, tend to decrease in rate and amplitude with increased age.

Although it is clear that certain neurological and physiological changes do occur with increased age, the significance of these changes for a cognitive activity such as learning to read are not obvious. One problem is that the consequences of these types of changes on behavior, and particularly on complex cognitive behavior, are not well understood. A second problem is that relatively little is yet known about the course of these changes across adulthood. That is, many of the changes that have been noted may be pronounced only very late in adulthood, and may be trivial or insignificant between approximately sixteen to sixty years of age.

\section{Retention of Literacy}

Assuming that an individual has successfully completed a literacy acquisition program and can read at a specified level of competency, it is then meaningful to ask about the degree to which these skills are maintained over time. That is, how effectively are literacy skills retained as a function of time since acquisition, and what variables influence degree of retention?

Although there are several articles in which literacy retention has been examined (Comings, Shrestha, and Smith 1992; Hartley and Swanson 1986), none could be located in which age of the individual was considered as a predictor variable. It is therefore not yet known whether adults of different ages but equivalent levels of reading ability at the completion of a literacy program will differ in the extent to which they maintain or improve their ability to read.

Perhaps the study most relevant to this issue is one by Roy and Kapoor (1975). These researchers found little or no relation between age and literacy retention within groups who learned to read in schools or in literacy classes. However, the individuals in the school groups were younger and scored higher in a test of literacy retention than did those in the literacy group. It is therefore possible that an age effect did exist but that it was not detectable because of the confounding between age and method of initial instruction.

Because of the lack of relevant information, no conclusions can be reached about age differences in the retention of literacy. Moreover, without reliable evidence about the nature of any age-related differences, it is premature to offer guidelines in terms of length, structure, or content of post-literacy programs that might minimize possible effects related to age.

\section{Considerations for Future Research}

It is desirable to conduct additional empirical research to attempt to provide a more definitive answer to the question of possible age-related barriers to the acquisition of literacy. In anticipation of that possibility, a number of suggestions are offered regarding what should be included in that research. 


\section{What We Know about Acquisition of Adult Literacy}

- Extensive information should be obtained about the background of each program participant, including age, gender, marital status, occupational and family time demands, and prior exposure to formal education and literacy programs.

- Information should also be obtained about the learning environment, such as the type, length, and quality of instruction (including teacher variables such as experience, motivation, and interaction style), and availability of suitable materials.

- Regardless of the nature of the literacy program, assessments should be obtained from each program participant for the following types of variables at the beginning of the program.

- Measures of reading proficiency for at least two levels of competency, one corresponding to Chall's (1983) Stage 3 and another at a higher level.

- Measures of selected cognitive abilities such as phonological awareness, working memory, and speed of access to long-term memory.

- Measures of success or effectiveness in the occupation of participants, modes of information acquisition, and other objective indices of the individual's functioning.

- Measures of motivation, contentment, life satisfaction, and other subjective indices of functioning.

- For as many of the variables as possible, assessments should be repeated immediately after completion of the program, and at periodic intervals for three or more years to determine the degree to which literacy was retained.

- The number of individuals in the program should be as large as feasible within practical constraints. Because the goal is to examine the influence of age as well as numerous other variables on the acquisition and retention of literacy, a sample of at least 1,000 entrants to the program, with nearly equal numbers in each of three or more relevant age ranges, is recommended.

- Multiple regression analyses should be considered as a method of determining the relative importance of each variable to the criterion measures. The most convincing evidence for an influence of age would be if the age variable accounted for a statistically significant proportion of variance after the influence of all other variables had been removed.

An example of, and rationale for, a research project incorporating these suggestions is as follows. The primary goal of the project should be to teach people from a wide range of ages in the target population to read at a specified level of competency. Smaller-scale studies could obviously be conducted to investigate selected components of reading with easily available research populations and greater control over relevant variables. However, until a large-scale realistic project is conducted, the generalizability of the results of smaller studies would not be known. Given the paucity of knowledge currently available, it seems desirable to begin with as realistic a situation as possible to obtain initial information about the relative importance of different types of variables to successful reading acquisition. Furthermore, because relatively large samples are needed to be able to estimate the proportion of variance associated with each predictor variable, a sample size in the hundreds if not thousands is needed to allow for the 50 percent attrition that is often found in literacy programs (Comings, Shrestha, and Smith 1992). Finally, thorough analyses should be conducted of the retention data in order to determine the variables likely to be important in maintaining and facilitating the retention of literacy. 
Although a project of this scope is quite ambitious and would be expensive, the results can be expected to be extremely valuable in identifying variables with the strongest relations to successful literacy acquisition. Many types of analyses of this rich data set would be possible, including structural equation modeling in which the plausibility of various causal pathways could be examined. The proposed project is admittedly exploratory and descriptive, but reliable information about the influence of age and other variables on literacy acquisition is greatly lacking, and data from a study such as this is needed before more focused research based on specific hypotheses would be very meaningful.

\section{Conclusion}

The primary conclusion of this paper was anticipated by Singleton $(1989$, p. 77) who stated " ... given the paucity of pertinent research of a rigorous kind, one cannot definitely attribute observed difficulties of reading acquirers to an age-related decline in reading acquisition capacity." The evidence relevant to age-related barriers in literacy acquisition is mixed, and plausible arguments can be generated on both sides of the issue. However, for the reasons discussed below, it is tentatively concluded that age-related changes in cognitive abilities probably do not contribute to meaningful differences in either the efficiency or effectiveness of learning to read.

Among the evidence that could be cited in support of the existence of age-related barriers to literacy acquisition are the following:

- There are significant age-related differences in measures of several variables that have been found to predict success in learning to read.

- There are significant age-related differences in a variety of other measures such as the efficiency of some types of learning, including the ultimate level of proficiency in a second languge.

- Significant age-related differences have been reported in a recent literacy project in Bangladesh.

In contrast, the following issues can be raised in support of an argument against age-related barriers in the acquisition of literacy:

- The relations between age in adulthood and predictors of reading success, although usually statistically significant, are generally small, particularly relative to the magnitude of the differences apparent between about six and eighteen years of age.

- Although adult age differences have been reported in many potentially relevant abilities, age is not an absolute barrier to learning because substantial improvement has been found to occur at all ages in nearly every measure that has been examined, and adults have actually been reported to learn faster than children in the early stages of second language acquisition.

- While the results from the field study are provocative, they cannot be considered definitive with respect to age-related influences on literacy acquisition because of many unresolved questions, and particularly since it has been found in many adult literacy programs that adults can achieve the same level of basic literacy in a much shorter period than that taken by children to learn to read.

In summary, it is suggested that if they exist, age-related influences on literacy acquisition are most likely quite small relative to other factors such as the quality of instruction, the availability of suitable materials, opportunity for practice and development of the skill, the value of literacy in the community, and the purpose or function of literacy in the individual's life. Scribner and Cole (1981) reported that when a need existed to communicate with distant friends and relatives among the Vai people, some level of literacy (perhaps equivalent to Stage 2 in Chall's 
scheme) was acquired fairly rapidly by adults (appendix C). Because there is no evidence of absolute or total cognitive impairments or barriers associated with age, if a criterion such as capability to benefit from instruction is to be used, then there does not appear to be any justification to restrict opportunities to acquire literacy based solely on chronological age.

\section{Notes}

1. Dollar amounts in this document represent US dollars.

2. UNESCO distinguishes between basic literacy, the ability to read a few words and sign one's name and functional literacy, the ability to obtain information from written materials (Lind and Johnston, 1987).

3. Chall (1983) postulates six stages. Her model describes advanced reading in greater detail.

4. The term generally connotes an effortless form of processing in which minimal demands are placed on resources which have limited capacity, such as attention and working memory.

5. The large-scale data available, therefore, date from the 1970s, and more recent data do not exist in enough detail to indicate possible improvements.

6. The UNESCO/UNDP program was criticized for its excessively "westernized" approach to evaluating achievement. Another reviewer (Edstroem, 1976) found the influence of functional literacy plausible and favorable in about $42 \%$ of the observations.

7. NGO surveys in Bangladesh report an average dropout rate of only $25 \%$ which may be to some extent due to (a) the emphasis on out-of-school children who have low dropout rates and (b) to replacement of dropouts with new students, who keep class sizes about the same.

8. Restriction of range may have produced a lower correlation that would have been obtained from the general population.

9. Unit costs per person made literate are much more informative than unit costs per participant.

10. Without practice, memory traces initially decay abruptly, then more slowly over two to three years and then reach a plateau. The level of the plateau depends on the skill level achieved during acquisition.

11. Although test scores are presented, they are not comparable or standardized. 
12. In order to guide out-of-school programs, consolidation of literacy among children requires more research. Children in these short programs, which often have low dropout rates and monitor students carefully, typically learn to read fluently, but no data exist about their retention curves. In the early primary-school ages, children are likely to rapidly learn and forget languages, but it is unknown whether the same skills are involved in reading.

13. Motivation is a theoretical concept used to explain how behavior is instigated, energized, and directed toward some goal or incentive (Smith, Sarason, and Sarason, 1982).

14. Also mentioned in literature as phonemic awareness.

\section{References}

Abadzi, H. 1990. Cognitive Psychology in the Seminar Room . World Bank, EDI Seminar Paper 41. Washington, DC.

1994. Nonformal Education for Women in Latin America and the Caribbean. Washington, DC: World Bank, Education and Social Policy Discussion Paper Series No. 19.

Adams-Price, C. E. "Age, Education, and Literacy Skills of Adult Mississippians." The Gerontologist 33: 741746.

Adams, S. J. 1982. "Scripts and Retention of Unfamiliar Vocalizations: Enhancing Second-Language Reading Skills." Modern Language Journal 66: 15559.

Adams, M. J. 1990. Beginning to Read: Thinking and Learning about Print . Cambridge, Mass.: MIT Press.

Alderson, J. C. 1984. "Reading in a Foreign Language: A Reading Problem or a Language Problem?" In J. C. Alderson and A. H. Urquhart, eds., Reading in a Foreign Language . London: Longman.

Alegria, J. and J. Morais. 1991. "Segmental Analysis and Reading Acquisition." In L. Reiben and C. Perfetti, eds., Learning to Read: Basic Research and Its Implications . Hillsdale, N.J.: Lawrence Erlbaum Associates.

American Optometric Association. 1992. Report of the AOA Task Force on Optometric Manpower . St. Louis, Mo.

Arnove, R. F. and H. J. Graff, eds. 1987. National Literacy Campaigns: Historical and Comparative Perspectives . New York: Plenum Press.

American Society for Training and Development (ASTD). 1993. "Brain Research and its Implications for Learning, Training, and Development." Mind/Brain Network Newsletter . Alexandria, Va.: ASTD.

Baddeley, A. D. 1986. Working Memory . Oxford, U.K.: Oxford University Press.

—. "Working Memory." Science 255: 55659.

Ball, K. and R. Sekuler. 1986. "Improving Visual Perception in Older Observers." Journal of Gerontology 41: 17682. 


\section{What We Know about Acquisition of Adult Literacy}

Baltes, P. B. and R. Kliegl. 1992. "Further Testing of Limits of Cognitive Plasticity: Negative Age Differences in a Mnemonic Skill are Robust." Developmental Psychology 28: 12125.

Barton, D. 1990. "Developing a Practice Account of Literacy from Adult Learners' Perceptions of Literacy and Learning." Paper presented at the World Congress of Applied Linguistics, Thessaloniki, Greece.

Baucom, K. L. 1978. The ABCs of Literacy: Lessons from Linguistics . Amersham, U.K.: Hulton Educational Publications.

Belbase, L. N. 1989. Nonformal Education in Dhading District . Kathmandu: Dhading District Development Project.

Beres, C. A. and A. Baron. 1981. "Improved Digit Symbol Substitution by Older Women as a Result of Extended Practice." Journal of Gerontology 36: 59197.

Berg, C., C. Hertzog, and E. Hunt. 1982. "Age Differences in the Speed of Mental Rotation." Developmental Psychology 18: 95107.

Bernhardt, E. B. 1991a. "A Psycholinguistic Perspective on Second Language Literacy." AILA Review 8: 3144.

—. 1991b. Reading Development in a Second Language . Norwood, N.J.: Ablex.

Bertelson, P. 1986. "The Onset of Literacy: Liminal Remarks." Cognition 24: 130.

Bertelson, P. and B. De Gelder. 1989. "Learning about Reading from Illiterates." In A. M. Galaburda, ed., From Reading to Neurons . Cambridge, Mass.: MIT Press.

—. 1991. "The Emergence of Phonological Awareness: Comparative Approaches." In I. G. Mattingly and M. Studdert-Kennedy, eds., Modularity and the Motor Theory of Speech Perception . Hillsdale, N.J.: Lawrence Erlbaum Associates.

Bertelson, P., B. De Gelder, L. V. Tfouni, and J. Morais. 1989. "Metaphonological Abilities of Adult Illiterates: New Evidence of Heterogeneity." European Journal of Cognitive Psychology 3: 23950.

Bordia, A. 1985. "Planning and Management of Post-Literacy Programmes." In G. Carron and A. Bordia, eds., Issues in Planning and Implementing National Literacy Programmes . Paris: International Institute for Educational Planning, UNESCO.

Brady, S. 1986. "Short-Term Memory, Phonological Processing, and Reading Ability." Annals of Dyslexia 36: 13853.

Bryant, P. 1986. "Phonological Skills and Learning to Read and Write." In B. R. Foorman and A. W. Siegel, eds., Acquisition of Reading Skills . Hillsdale, N.J.: Lawrence Erlbaum Associates.

Campaign for Popular Education (CAMPE). 1992. "Task Force Report on Literacy Materials of Bangladesh." Dhaka: CAMPE.

Carron, G., K. Mwiria, and G. Righa. 1989. The Functioning and Effects of the Kenyan Literacy Programme . Paris: International Institute for Educational Planning, UNESCO. 


\section{What We Know about Acquisition of Adult Literacy}

Cerella, J. 1985. "Age-Related Decline in Extrafoveal Letter Perception." Journal of Gerontology 4072736.

Chall, J. 1983. Stages of Reading Development . New York: McGraw-Hill.

1987. "Developing Literacy . . . in Children and Adults." In D.A. Wagner, ed., The Future of Literacy in a Changing World. New York: Pergamon Press.

Chaney, C. 1989. "Language Development, Metalinguistic Skills, and Emergent Literacy in Three-year-Old Children." Paper presented at the Biennial Meeting of the Society for Research in Child Development, Seattle, Washington, April 1820.

Charness, N. and J. I. D. Campbell. 1988. "Acquiring Skill at Mental Calculation in Adulthood: A Task Decomposition." Journal of Experimental Psychology: General 117: 11529.

Cobb, B.B., C. D. Lay and N. M. Bourdet. 1971. The Relationship Between Chronological Age and Aptitude Test Measures of Advanced-level Air Traffic Control Trainees (FAA-AM-71-36) Oklahoma City, OK: Federal Aviation Administration.

Cohen, G. D. 1988. The Brain in Human Aging . New York: Springer Publishing Co.

Cole, M. and B. Means. 1981. Comparative Studies of How People Think . Cambridge: Harvard University Press.

Comings, J. P. 1992. "The Impact of Women's Literacy Classes in Nepal on Health, Family Planning, and Child Education." Research Proposal, World Education.

1993. "Skill Retention in Adult Literacy Students in Developing Countries." Boston: World Education.

Comings, J. P., C. Shrestha and C. Smith. 1992. "A Secondary Analysis of a Nepalese National Literacy

Program." Comparative Education Review 26: 21226.

Courtault, M. 1989. Pre-literacy Training: A Useful Concept? Paris: UNESCO-UNICEF-WFP Cooperative Program (Notes, Comments ... No. 185).

Craik, F. I. M. and T. A. Salthouse, eds., 1992. Handbook of Aging and Cognition . Hillsdale, N.J.: Lawrence Erlbaum Associates.

Daneman, M. and P. A. Carpenter. 1980. "Individual Differences in Working Memory and Reading." Journal of Verbal Learning and Verbal Behavior 19: 45066.

Downing, J. 1973. "Comparative Reading, Cross-National Studies of Behavior and Process in Reading and Writing." New York: Macmillan.

Downing, J. 1987. "Comparative Perspectives on World Literacy." In D.A. Wagner, eds., The Future of Literacy in a Changing World. New York: Pergamon Press.

Edstroem, J. 1976. "UNESCO and Experimental World Literacy Program." Stockholm: Swedish International Development Authority (SIDA), 1976-08-13 (unpublished).

Egan, D. E. and L. M. Gomez. 1985. "Assaying, Isolating and Accommodating Individual Differences in Learning a Complex Skill." In R.F. Dillon, ed., Individual Differences in Cognition: Vol 2 . Orlando, Fl.: 


\section{What We Know about Acquisition of Adult Literacy}

Academic Press.

Ehri, L. C. 1991. "Learning to Read and Spell Words." In L. Rieben and C. A. Perfetti, eds., Learning to Read: Basic Research and Its Implications . Hillsdale, NJ: Erlbaum.

Elias, P. K., M. F. Elias, M. A. Robbins, and P. Gage. 1987. "Acquisition of Word-processing Skills by Younger, Middle-age, and Older Adults." Psychology and Aging 2: 34048.

Ellis, N. 1988. "The Development of Literacy and Short-term Memory." In M. Gruneberg, R.E. Morris, and R. N. Sykes, eds., Practical Aspects of Memory: Current Research and Issues . Chichester, England: John Wiley and Sons.

Ezzine, M. 1993. "Literacy and Schooling in Rural Morocco." Washington, DC: World Bank (MN1PH).

Feitelson, D. 1988. Facts and Fads in Beginning Reading . Norwood, N.J.: Ablex.

Fisk, A. D. and W. A. Rogers. 1991. "Toward an Understanding of Age-related Memory and Visual Search Effects." Journal of Experimental Psychology: General 120: 13149.

Fisk, A. D., N. D. McGee, and L. M. Giambra. 1988. "Age-related Effects on Consistent and Varied Semantic Category Search Performance." Psychology and Aging 3: 32333.

Fisk, A. D., W. A. Rogers and L. M. Giambra. 1990. "Consistent and Varied Memory/Visual Search: Is there an Interaction Between Age and Response-set Effects?" Journal of Gerontology: Psychological Sciences 45: 817.

Fitzsimmons, K. A. 1991. "African-American Women who Persist in Literacy Programs: An Exploratory Study." The Urban Review 23: 23150.

Freire, P. 1968. Pedagogy of the Oppressed. New York: Herder and Herder.

French, J. 1987. Adult Literacy: A Source Book and Guide . New York: Garland Publishers.

Frith, U. 1986. "A Developmental Framework for Developmental Dyslexia." Annals of Dyslexia 36: 6981.

Gay, J. and M. Cole. 1967. The New Mathematics and an Old Culture: A Study of Learning Among the Kpelle of Liberia . New York: Holt, Rinehardt, and Winston.

Gist, M., B. Rosen, and C. Schwoerer. 1988. "The Influence of Training Method and Trainee Age on the Acquisition of Computer Skills." Personnel Psychology 41: 25565.

Gleitman, L. R. and P. Rozin. 1977. "The Structure and Acquisition of Reading: Relations Between Orthographies and the Structure of Language." In A. S. Reber and D. L. Scarborough, eds., Toward A Psychology of Reading . Hillsdale, N.J.: Lawrence Erlbaum Associates.

Golinkoff, R. M. 1978. "Critique: Phonemic Analysis Skills and Reading Achievement." In F.B. Murray and J. J. Pikulski, eds., The Acquisition of Reading . Baltimore, Md.: University Park Press.

Gough, P. B. and C. Juel. 1991. "The First Stages of Word Recognition." In L. Reiben and C. Perfetti eds., Learning to Read: Basic Research and Its Implications . Hillsdale, N.J.: Lawrence Erlbaum Associates. 


\section{What We Know about Acquisition of Adult Literacy}

Gough, P. B. and M. L. Hillinger. 1980. "Learning to Read: An Unnatural Act." Bulletin of the Orton Society 30: 17176.

Hartley, M. J. and E. V. Swanson. 1986. Retention of Basic Skills Among Dropouts from Egyptian Primary Schools . Washington, DC: World Bank.

Hartley, A.A., J. T. Hartley, and S. A. Johnston. 1984. "The Older Adult as Computer User." In P.K. Robinson, J. Livingston, and J.E. Birren, eds., Aging and Technological Advances . New York: Plenum.

Hartley, M.J. and E. V. Swanson. 1986. Relation of Basic Skills Among Dropouts from Egyptian Primary Schools . The World Bank: Discussion Paper.

Hatano, G. 1986. "How do Japanese Children Learn to Read? Orthographic and Eco-cultural Variables." In B.R. Foorman and A.W. Siegel, eds., Acquisition of Reading Skills . Hillsdale, N.J.: Lawrence Erlbaum Associates.

Hines, T. M. and M. I. Posner. 1976. "Slow but Sure: A Chronometric Analysis of the Process of Aging." In L.W. Poon and J.L. Fozard, eds., Design Conference on Decision Making and Aging . Boston: Boston Geriatric Research, Educational and Clinical Center, Technical Report 7601.

International Development Research Center (IDRC). 1979. The World of Literacy: Policy, Research, and Action . Ontario, Canada: IDRC.

Imel, S. 1990. "Adult Literacy Learner Assessment." ERIC Clearinghouse on Adult, Career, and Vocational Education (ED 325658).

Jackson, M. D. 1980. "Further Evidence for a Relationship Between Memory Access and Reading Ability." Journal of Verbal Learning and Verbal Behavior 19: 683694.

Jackson, M. D. and J. L. McClelland. 1979. "Processing Determinants of Reading Speed." Journal of Experimental Psychology: General 108: 15181.

Jeffries, C. 1967. Illiteracy: A World Problem . New York: Praeger.

Jennings, J. 1990. Adult Literacy: Master or Servant? Dhaka: University Press Ltd.

Johnson, J. S. and E. L. Newport. 1989. "Critical Period Effects in Second Language Learning: The Influence of Maturational State on the Acquisition of English as a Second Language." Cognitive Psychology 21: 6099.

Jorm, A. F. 1983. "Specific Reading Retardation and Working Memory: A Review." British Journal of Psychology 74: 31142.

Joshi, A. R. 1991. "Maternal Schooling and Child Health: New Evidence from Nepal." Doctoral Dissertation in Progress, Harvard Graduate School of Education (unpublished).

Joshi, B. 1989. Study of Nonformal Education Program for Out-of-School Children . Kathmandu: Ministry of Education.

Kahneman, D. and Miller, D. T. 1986. "Comparing Reality to its Alternatives." Psychological Review , 93: 13653.

Kausler, D. H. 1991. Experimental Psychology, Cognition, and Human Aging . New York: Springer-Verlag. 


\section{What We Know about Acquisition of Adult Literacy}

Kliegl, R., J. Smith, and P. B. Baltes. 1989. "Testing the Limits and the Study of Adult Age Differences in Cognitive Plasticity of a Mnemonic Skill." Developmental Psychology 25: 24656.

Knowles, M. S. 1973. The Adult Learner: A Neglected Species . Houston, Gulf Company.

Krashen, S.D. 1982. Principles and Practice in Second Language Acquisition . New York: Pergamon Press.

Krashen, S.D., R. C. Scarcella, and M. H. Long. 1982. Child-Adult Differences in Second Language Acquisition . Rowley, Mass.: Newbury House Publishers.

Krishna, S. and L. Keith. 1988. Participatory Development: A Case Study of the Nonformal Education Project in Takukot Panchayat of the Gorkha District . Kathmandu: Save the Children.

La Belle, T. J. 1986. Nonformal Education in Latin America and the Caribbean: Stability, Reform, or Revolution ? New York: Praeger.

LaBerge, D. and S. J. Samuels. 1974. "Toward a Theory of Automatic Information Processing in Reading." Cognitive Psychology 6: 293323.

Laboratory of Comparative Human Cognition. 1986. "Contribution of Cross-cultural Research to Educational Science." American Psychologist 41: 104958.

Lecours, A. R. "Literacy and Acquired Aphasia." In A.M. Galaburda, ed, From Reading to Neurons . Cambridge, Mass: MIT Press.

Lenneberg, E. 1967. Biological Foundations of Language . New York: Wiley.

LeVine, R. A. 1992. "Maternal Schooling and Risks to Child Survival: Preliminary Findings from Mexico and Nepal." Harvard Graduate School of Education: Report to the Ford Foundation, the National Science Foundation, and the Spencer Foundation.

LeVine, R. A., S. E. LeVine, A. Richman, E. Medardo Tapia Uribe, C. Sunderland Correna, and P. M. Miller. 1991. "Women's Schooling and Child Care in the Demographic Transition: A Mexican Case Study." Population and Development Review 17: 45995.

Levinger, B. 1992. Nutrition, Health, and Learning . School Nutrition and Health Network Monograph Series 1. Newton, Mass.: Education Development Center.

Liberman, I.Y., D. Shankweiler, A. M. Liberman, C. Fowler, and F. W. Fischer. 1977. "Phonetic Segmentation and Recording in the Beginning Reader." In A.S. Reber and D.L. Scarborough, eds., Toward A Psychology of Reading . Hillsdale, N.J.: Lawrence Erlbaum Associates.

Liberman, I.Y. and D. Shankweiler. 1991. "Phonology and Beginning to Read: A Tutorial." In L. Reiben and C. Perfetti, eds., Learning to Read: Basic Research and Its Implications . Hillsdale, N.J.: Lawrence Erlbaum Associates.

Lind, A. and A. Johnston. 1990. Adult Literacy in the Third World: A Review of Objectives and Strategies . Stockholm: Swedish International Development Authority, Education Division Documents, 32. 
Lindholm, J. M. and S. R. Parkinson. 1983. "An Interpretation of Age-related Differences in Letter Matching Performance." Perception and Psychophysics 33: 28394.

Lundberg, I. and P. Linnakylä. 1993. Teaching Reading Around the World . The Hague: The International Association for the Evaluation of Educational Achievement.

Madden, D. J. 1983. "Aging and Distraction by Highly Familiar Stimuli During Visual Search." Developmental Psychology 19: 499507.

Madden, D. J., and R. D. Nebes. 1980. "Aging and the Development of Automaticity in Visual Search."

Developmental Psychology 16: 37784.

Manandher, B. 1989. A Study on the Impact of Literacy Training for Women and Post-Literacy

Income-Generation Activities . Kathmandu: World Education.

Mann, V. A. 1991. "Phonological Abilities: Effective Predictors of Future Reading." In L. Reiben and C. Perfetti, eds., Learning to Read: Basic Research and Its Implications . Hillsdale, N.J.: Lawrence Erlbaum Associates.

Mattingly, I. G. 1984. "Did Orthographies Evolve?" Remedial and Special Education 6: 1823.

McGivney, V. and F. Murray. 1991. Adult Education in Development: Methods and Approaches from Changing Societies . Leicester, U.K.: National Institute of Adult Continuing Education.

Miller, J. C., P. G. Rourke, G. H. Davis, R. A. Howenstine, T. L. Morrison, and H. D. Reed. 1978. Reparation and Change . Washington, D.C.: CEGO Publications.

Morton, J. 1989. "Interaction of Information in Word Recognition." Psychological Review 76: 16578.

New Era. 1989. "Evaluation Study of Literacy Campaign in Surkhet Valley" (mimeo). Kathmandu, Nepal.

— 1990. "Evaluation Study of Literacy Programme of SFDP and PCRW" (mimeo). Kathmandu, Nepal.

Newport, E. L. 1990. "Maturational Constraints on Language Learning." Cognitive Science , 14: 1128.

Newport, E. L. and J. S. Johnson. 1989. "Critical Period Effects in Second Language Learning: The Influence of Maturational State on the Acquisition of English as a Second Language." Cognitive Psychology, 21: 6099.

Noor, A. 1982. "Managing Adult Literacy Training." Prospects 12: 16384

Ouane, A. 1989. Handbook on Learning Strategies for Post-Literacy and Continuing Education . Hamburg, Germany: UNESCO Institute for Education.

Ouane, A., A. A. Armengol, and D. V. Sharma. 1990. Handbook on Training for Post-Literacy and Basic Education . Hamburg, Germany: UNESCO Institute for Education.

Oxenham, J. 1975. Nonformal Approaches to Teaching Literacy. Michigan State University, Program of Studies in Nonformal Education, Supplementary Paper 2.

Oxenham, J. 1980. Literacy (Writing, Reading and Social Organization) . London: Routledge and Kegan Paul Ltd. 
Palmer, J., C. M. MacLeod, E. Hunt, E. Davidson, and J.E. Davidson. 1985. "Information Processing Correlates of Reading." Journal of Memory and Language 24: 5988.

Park, S. and T. Y. Arbuckle. 1977. "Ideograms Versus Alphabets: Effects of Script on Memory in 'Biscriptural' Korean Subjects." Journal of Experimental Psychology: Human Learning and Memory 3: 63142.

Perfetto, G. A., J. D. Bransford, and J. J. Franks. 1983. "Constraints on Access in a Problem Solving Context." Memory and Cognition 11: 2431.

Petersen, S. E., P. T. Fox, A. Z. Snyder, and M. E. Raichle. 1990. "Activation of Extrastriate and Frontal Cortical Areas by Visual Words and Word-like Stimuli." Science 249: 104144.

Pison, G. 1980. Calculating Age Without Asking for It . Selected Papers on Population 9. Institute Nationale d' Études Démographiques.

Plude, D. J. and W. J. Hoyer. 1981. "Adult Age Differences in Visual Search as a Function of Stimulus Mapping and Processing Load." Journal of Gerontology 36: 598604.

Plude, D. J., D. B. Kaye, W. J. Hoyer, T. A. Post, M. J. Saynisch, and M. V. Hahn. 1983. "Aging and Visual Search under Consistent and Varied Mapping." Developmental Psychology 19: 50812.

Poon, L.W., J. L. Fozard, B. Vierck, B. F. Dailey, J. Cerella, and P. Zeller. 1976. "The Effects of Practice and Information Feedback on Age-related Differences in Performance Speed, Variability and Error Rates in a Two-choice Decision Task." In L.W. Poon and J.L. Fozard, eds., Design Conference on Decision Making and Aging . Boston: Boston Geriatric Research, Educational and Clinical Center, Technical Report 7601.

Rayner, K. and A. Pollatsek. 1989. The Psychology of Reading . Englewood Cliffs, N.J.: Prentice-Hall.

Ramirez, A. G. 1994. "Literacy Acquisition Among Second-Language Learners". In Ferdman, B. M., R. M. Weber, and A. G. Ramirez (Eds.) Literacy Across Languages and Cultures . Albany, NY: State University of New York Press.

Red, D. 1992. "New Script, New Language - Learning to Read Hindi." Paper presented at the 42nd Annual Meeting of the National Reading Conference in San Antonio, Texas, December 15.

Rogers, A. 1991a. Letters in the Sun (videotape). Reading, U.K.: Education for Development.

—. 1991b. Partners in Literacy . Reading, U.K.: Education for Development. 1992. Adults Learning for Development . London: Cassell Educational Ltd.

- 1993. "The World Crisis in Adult Education: A Case Study from Literacy." Compare 23: 15975. in print. Adult Learning Maps and the Teaching Process. Reading, UK: Education for Development.

Romain, R. and L. Armstrong. 1987. Review of World Bank Operations in Nonformal Education and Training . Washington, DC. World Bank, Education and Training Series No. 63.

Roy, P. and J. M. Kapoor. 1975. The Retention of Literacy . Delhi: MacMillan Co. of India. 


\section{What We Know about Acquisition of Adult Literacy}

Salthouse, T.A. 1991. Theoretical Perspectives on Cognitive Aging . Hillsdale, N.J.: Lawrence Erlbaum Associates.

—. 1992a. "Influence of Processing Speed on Adult Age Differences in Working Memory." Acta Psychologica 79: 15570.

1992b. Mechanisms of Age-Cognition Relations in Adulthood. Hillsdale, N.J.: Lawrence Erlbaum Associates.

Salthouse, T.A. and B. Somberg. 1982. "Skilled Performance: Effects of Adult Age and Experience on Elementary Processes." Journal of Experimental Psychology: General 111: 176207.

Salthouse, T.A. and R. L. Babcock. 1991. "Decomposing Adult Age Differences in Working Memory." Developmental Psychology 27: 76376.

Sawyer, D. and C. Rodriguez. (undated) Native Literacy Research Report . Salmon Arm, B.C., Canada: Native Adult Education Resource Centre.

Scholes, R. J. 1991. "Phoneme Deletion and Literacy in Native and Non-native Speakers of English." Journal of Research in Reading 14: 13040.

Scribner, S. and M. Cole. 1978. "Unpacking Literacy." Social Science Information 7: 1940. 1981. The Psychology of Literacy . Boston: Harvard University Press.

Segalowitz, N., C. Poulsen, and M. Komoda. 1991. "Lower-level Components of Reading Skill in Higher-Level Bilinguals: Implications for Reading Instruction." AILA Review 8: 1530.

Seidenberg, M. S. and J. L. McClelland. 1989. "Visual Word Recognition and Pronunciation: A Computational Model of Acquisition, Skilled Performance, and Dyslexia." In Galaburda, A. M., ed., From Reading to Neurons . Cambridge, Mass.: MIT Press.

Semali, L. M. 1991. Postliteracy Education in Tanzania and the Retention of Literacy Skills in Adults: The Role of the Communication Media. University Microfilms International Dissertation Information Service.

Share, D. L., A. F. Jorm, R. Maclean, and R. Matthews. 1984. "Sources of Individual Differences in Reading Acquisition." Journal of Educational Psychology 76: 130924.

Sheffield, J. R. 1977. "Retention of Literacy and Basic Skills: A Review of the Literature" (mimeo). World Bank, Washington, DC.

Singleton, D. 1989. Language Acquisition: The Age Factor . Clevedon, U.K.: Multilingual Matters Ltd.

Slavin, R. E. 1986. Educational Psychology . Englewood Cliffs, N.J.: Prentice-Hall.

Smith, R. E., I. G. Sarason, and B. R. Sarason, eds., 1982. Psychology: The Frontiers of Behavior, eds., New York: Harper and Row.

Snow, C. E. 1983. "Age Differences in Second Language Acquisition: Research Findings and Folk Psychology." In K.M. Bailey, M.H. Long, and S. Peck, eds., Second Language Acquisition Studies . Rowley, Mass.: Newbury 


\section{What We Know about Acquisition of Adult Literacy}

House.

Solso, R. L. 1988. Cognitive Psychology . Boston: Allyn and Bacon.

Spector, J. E. 1992. "Predicting Progress in Beginning Reading: Dynamic Assessment of Phonemic Awareness." Journal of Educational Psychology 84: 35363.

Stanovich, K. E. 1986. "Matthew Effects in Reading: Some Consequences of Individual Differences in the Acquisition of Literacy." Reading Research Quarterly 21: 360406.

_. 1991. "Changing Models of Reading and Reading Acquisition." In L. Reiben and C. Perfetti, eds., Learning to Read: Basic Research and Its Implications . Hillsdale, N.J.: Lawrence Erlbaum Associates.

Stevenson, H. W. 1987. "Children's Problems in Learning to Read Chinese, Japanese, and English." In D. A. Wagner, ed., The Future of Literacy in a Changing World . New York: Pergamon Press.

Sticht, T. G. 1978. "The Acquisition of Literacy by Children and Adults." In T.B. Murray and J.J. Pikulski, eds., The Acquisition of Literacy . Baltimore, Md.: University Park Press.

Street, B. V. 1984. Literacy in Theory and Practice . London: Cambridge University Press.

Street, B. V., ed., 1990. Literacy in Development . Proceedings of a seminar sponsored by Education for Development and Commonwealth Institute. Kings Lynn, Norfolk, U.K.

Thorndike, E. L., E. O. Bregman, J. W. Tilton, and E. Woodyard. 1928. Adult Learning . New York: The MacMillan Co.

Torgersen, J. K., S. T. Morgan, and C. Davis. 1992. "Effects of Two Types of Phonological Awareness Training on Word Learning in Kindergarten Children." Journal of Educational Psychology 84: 36470.

Trites, D.K. 1963. "Ground Support Personnel." Aerospace Medicine 34: 53941.

Trites, D.K. and B. B. Cobb. 1964a. "Problems in Air Traffic Management: III. Implications of Training-entry Age for Training and Job Performance of Air Traffic Control Specialists." Aerospace Medicine 35: 33640.

1964b. "Problems in Air Traffic Management: IV. Comparison of Pre-Employment, Job-related Experience with Aptitude Tests as Predictors of Training and Job Performance of Air Traffic Control Specialists." Aerospace Medicine 35: 42836.

Tunmer, W. E. 1991. "Phonological Awareness and Literacy Acquisition." In L. Reiben and C. Perfetti, eds., Learning to Read: Basic Research and Its Implications . Hillsdale, N.J.: Lawrence Erlbaum Associates.

Tzeng, O. J. L. 1980. "Cognitive Processing of Various Orthographies." Los Alamitos, Ca.: National Center for Bilingual Education (ERIC Document Reproduction Service).

UNESCO/UNDP. 1976. The Experimental World Literacy Programme: A Critical Assessment . Paris: UNESCO Press.

USA Today. 1992. "Want to Learn the Easy Way? Dream On." October 28 (Cited research by Avi Karni, Weizmann Institute of Science, Israel). 
Venezky, R. L. 1978. "Reading Acquisition: The Occult and the Obscure." In T.B. Murray and J.J. Pikulski, eds., The Acquisition of Literacy . Baltimore, Md.: University Park Press.

Wagner, D. A. 1987. "Literacy Futures: Five Common Problems from Industrialized and Developing Countries." In D.A. Wagner, eds., The Future of Literacy in a Changing World . New York: Pergamon Press.

UNESCO.

1991. Literacy: Developing the Future . International Yearbook of Education, Volume XLIII. Paris:

Wagner, D. A., J. E. Spratt, G. D. Klein, and A. Ezzaki. 1989. "The Myth of Literacy Relapse: Literacy Retention among Moroccan Primary School Leavers." International Journal of Educational Development 9: 30715.

Wagner, R. K. and J. K. Torgesen. 1987. "The Nature of Phonological Processing and its Causal Role in the Acquisition of Reading Skills." Psychological Bulletin 101: 192212.

Wardhaugh, R. 1971. "Theories of Language Acquisition in Relation to Beginning Reading Instruction." Reading Research Quarterly 7: 16894.

Woodcock, R. W. and M. B. Johnson. 1989 and 1990. Woodcock-Johnson Psycho-Educational Battery Revised. Allen, Texas: DLM Teaching Resources.

Wright, R.E. 1981. "Aging, Divided Attention, and Processing Capacity." Journal of Gerontology 36: 60514.

Zandri, E. and N. Charness. 1989. "Training Older and Younger Adults to Use Software." Educational Gerontology 15: 61531.

\section{Index}

\section{A}

absenteeism $\underline{7}, \underline{8}, \underline{18}, \underline{30}, \underline{31}, \underline{38}$

$\operatorname{accuracy} \underline{3}, \underline{47}, \underline{63}, \underline{68}$

adult education theory 19

age $\underline{2}, \underline{6}, \underline{15}, \underline{18}, \underline{20}-22, \underline{24}, \underline{36}, \underline{37}, \underline{40}, \underline{42}-44, \underline{48}-53, \underline{57}-76$

agriculture 10

air traffic controller training $\underline{70}$

alexia $\underline{23}, \underline{48}$

alphabetic phase $\underline{45}$

andragogy 19 
animators $\underline{30}$

anthropological assessment of age $\underline{51}$

articulatory loop $\underline{59}$

$\operatorname{astigmatism} \underline{24}$

attendance of literacy classes $\underline{6}, \underline{8}, \underline{10}, \underline{19}, \underline{25}, \underline{33}, \underline{40}, \underline{41}$

attention span $\underline{17}, \underline{20}, \underline{21}, \underline{30}, \underline{31}, \underline{37}$

attitudes $\underline{4}, \underline{10}, \underline{15}, \underline{18}, \underline{30}, \underline{31}$

audiovisual means $\underline{31}$

automaticity of reading $\underline{4}, \underline{21}, \underline{22}, \underline{33}, \underline{48}, \underline{49}, \underline{69}, \underline{70}$

\section{B}

barriers to acquiring literacy $\underline{10}, \underline{17}, \underline{35}, \underline{50}, \underline{57}, \underline{69}, \underline{73}-76$

basic literacy $\underline{2}, \underline{8}, \underline{11}, \underline{22}, \underline{41}, \underline{51}, \underline{72}, \underline{75}$

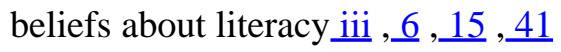

best practices 1

brain $\underline{19}, \underline{21}-23, \underline{48}, \underline{49}, \underline{54}, \underline{72}$

C

categorization of concepts $\underline{56}$

classroom management $\underline{30}, \underline{31}, \underline{34}$

cognitive enhancers $\underline{49}$

cognitive processes $\underline{4}, \underline{7}, \underline{19}, \underline{30}, \underline{31}, \underline{37}, \underline{55}, \underline{72}$

comprehension of text $\underline{3}, \underline{4}, \underline{12}, \underline{41}, \underline{50}, \underline{69}, \underline{71}$

consensus validation $\underline{29}, \underline{56}$

context $\underline{3}, \underline{4}, \underline{34}, \underline{43}, \underline{46}-48, \underline{50}, \underline{60}, \underline{63}, \underline{68}$

context processor $\underline{50}$

cooperative learning $\underline{28}, \underline{34}$

coping skills $\underline{17}$ 
costs $\underline{10}, \underline{11}, \underline{35}, \underline{36}, \underline{38}, \underline{41}$

course duration $\underline{10}$

critical period $\underline{20}, \underline{49}, \underline{57}, \underline{72}$

crystallized intelligence $\underline{21}, \underline{60}$

curriculum $\underline{31}$

D

decoding $\underline{13}, \underline{22}, \underline{23}, \underline{43}, \underline{48}, \underline{50}$

deductive reasoning $\underline{56}$

devanagari script $\underline{42}, \underline{45}$

digit span $\underline{63}$

donors $\underline{33}, \underline{35}-37, \underline{39}$

dropout $\underline{1}, \underline{6}-8, \underline{10}, \underline{12}, \underline{13}, \underline{17}-19, \underline{24}-26, \underline{30}, \underline{31}, \underline{33}-36, \underline{38}, \underline{40}, \underline{50}$

E

embedded figures test $\underline{68}$

$\mathbf{F}$

facilitators $\underline{30}$

family planning $\underline{10}, \underline{35}, \underline{37}, \underline{41}$

foreign readers $\underline{2}, \underline{13}, \underline{21}-24, \underline{42}-45, \underline{47}-50$

Freire, Paulo 18

functional literacy $\underline{2}, \underline{8}, \underline{22}, \underline{36}, \underline{41}, \underline{50}$

G

general intellectual ability $\underline{58}$

graphemes $\underline{58}$

group action $\underline{18}, \underline{25}$ 


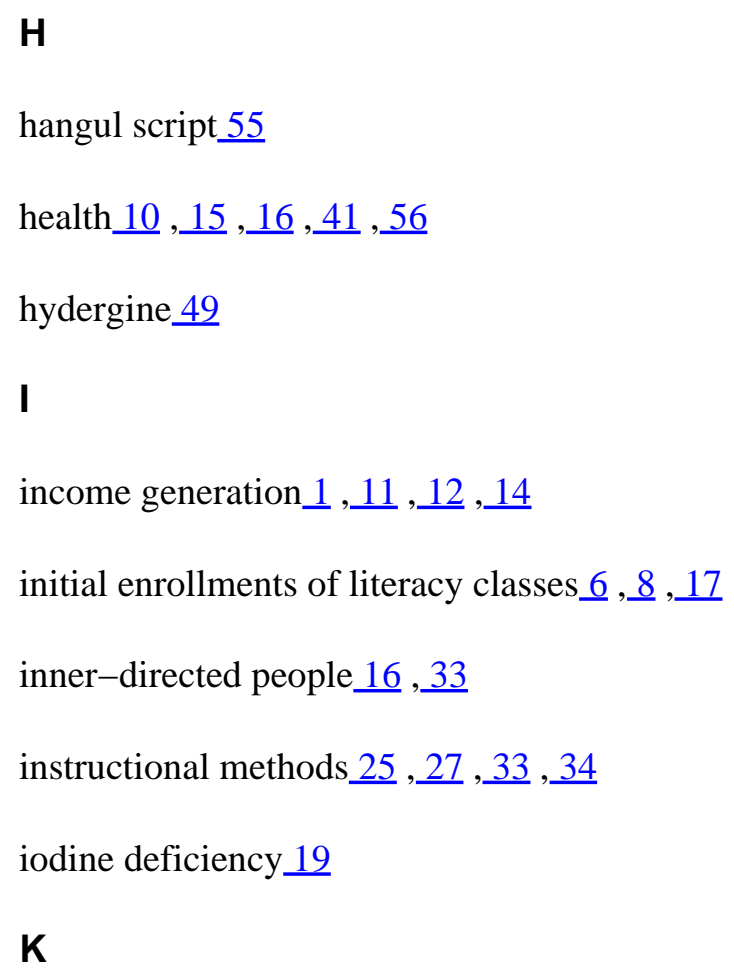


memory $\underline{4}, \underline{11}, \underline{13}, \underline{19}-21, \underline{23}, \underline{29}, \underline{34}, \underline{36}, \underline{43}, \underline{47}, \underline{56}-60, \underline{63}, \underline{68}-70, \underline{74}$

mental retardation $\underline{19}$

metacognitive skills $\underline{30}$

mnemonics $\underline{27}, \underline{29}, \underline{34}, \underline{37}, \underline{49}$

motivation $\underline{7}, \underline{9}, \underline{17}-19, \underline{74}$

multichannel inputs $\underline{29}, \underline{30}$

multiple regression $\underline{15}, \underline{51}, \underline{74}$

myopia 24

$\mathbf{N}$

neoliterates $\underline{2}, \underline{4}, \underline{5}, \underline{10}-14, \underline{16}-18, \underline{21}-24, \underline{27}, \underline{29}, \underline{31}, \underline{38}, \underline{40}-42, \underline{44}, \underline{45}, \underline{48}, \underline{50}$

neural activity $\underline{73}$

neurological issues $\underline{2}, \underline{15}, \underline{19}, \underline{21}, \underline{72}, \underline{73}$

norm theory 15

numeracy $\underline{11}, \underline{12}, \underline{22}, \underline{38}, \underline{52}$

0

orthographic phase $\underline{45}$

orthographic processor $\underline{46}-48$

$\mathbf{P}$

paired-associate learning $\underline{21}, \underline{59}, \underline{60}$

participatory method $\underline{9}, \underline{19}, \underline{26}$

peer tutoring $\underline{28}, \underline{34}$

perceptual constancy 24

perceptual-motor skills $\underline{21}, \underline{69}, \underline{71}$

performance $\underline{8}-10, \underline{12}, \underline{18}, \underline{19}, \underline{21}, \underline{27}-28, \underline{31}, \underline{34}, \underline{36}-38, \underline{40}, \underline{43}, \underline{49}-51, \underline{60}, \underline{63}, \underline{68}, \underline{70}$

phonics $\underline{27}, \underline{28}$ 
phonological awareness $\underline{20}, \underline{28}, \underline{36}, \underline{38}, \underline{49}, \underline{58}-60,743$

phonological processor $\underline{46}, \underline{47}, \underline{49}$

physiological factors $\underline{72}$

piracetam $\underline{49}$

political indoctrination $\underline{37}$

post-literacy $\underline{4}, \underline{11}-14, \underline{30}, \underline{38}, \underline{41}, \underline{73}$

pre-literacy $\underline{27}$

presbyopia 24

primary-school teachers $\underline{30}$

psychophysiological issues $\underline{23}, \underline{48}$

\section{$\mathbf{R}$}

reading fluency $\underline{59}, \underline{69}$

reading preparation $\underline{4}$

recall $\underline{11}, \underline{56}, \underline{63}$

refraction problems $\underline{24}$

retention $\underline{2}, \underline{10}-13, \underline{20}, \underline{21}, \underline{27}, \underline{29}, \underline{37}, \underline{38}, \underline{72}-75$

role modeling $\underline{15}, \underline{28}, \underline{34}$

S

second language $2, \underline{21}, \underline{71}, \underline{72}$

segmentation of words $\underline{21}, \underline{28}, \underline{44}, \underline{45}, \underline{50}, \underline{68}$

self-concept $16, \underline{17}, \underline{38}, \underline{41}$

skilled readers $\underline{3}, \underline{4}, \underline{69}$

small group work $\underline{27}$

social networks 16

stages of reading $\underline{4}, \underline{6}, \underline{7}, \underline{18}, \underline{27}, \underline{72}$

status $\underline{10}, \underline{16}, \underline{17}, \underline{26}, \underline{38}, \underline{40}, \underline{51}, \underline{55}$ 
study circles $\underline{30}-31$

supervisors and supervision $10, \underline{31}, \underline{32}, \underline{34}$

$\mathbf{T}$

target groups for literacy $\underline{36}$

teacher supervision $\underline{7}, \underline{31}$

teacher training $\underline{26}, \underline{28}, \underline{31}, \underline{34}, \underline{36}-38$

teaching methods $\underline{26}, \underline{27}$

team teaching $\underline{31}$

textbooks $\underline{7}, \underline{26}, \underline{27}, \underline{36}$

transfer of learning $\underline{27}$

U

understanding pictures $\underline{23}$

V

Vai tribe $\underline{11}, \underline{55}-56, \underline{63}$

verbal memory $\underline{20}, \underline{21}, \underline{36}, \underline{58}, \underline{59}, \underline{63}$

vision $\underline{20}, \underline{24}$

visual discrimination $\underline{58}$

W

within-class grouping 28

women and literacy $7, \underline{10}-12, \underline{15}-17, \underline{22}, \underline{23}, \underline{25}, \underline{38}, \underline{41}, \underline{51}, \underline{52}, \underline{56}$

Woodcock-Johnson tests $\underline{60}$

working memory $\underline{4}, \underline{20}, \underline{21}, \underline{36}, \underline{58}, \underline{59}, \underline{63}, \underline{74}$

writing $\underline{3}, \underline{11}, \underline{12}, \underline{15}, \underline{27}, \underline{28}, \underline{30}, \underline{31}, \underline{34}, \underline{45}, \underline{48}, \underline{51}, \underline{52}, \underline{55}, \underline{68}, \underline{69}$

Recent World Bank Discussion Papers (continued)

No. 217 Managing Fishery Resources: Proceedings of a Symposium Co-Sponsored by the World 
Bank and Peruvian Ministry of Fisheries held in Lima, Peru, June 1992. Eduardo A. Loayza

No. 218 Cooperatives and the Breakup of Large Mechanized Farms: Theoretical Perspectives and Empirical Evidence. Klaus W. Deininger

No. 219 Development of Rural Financial Markets in Sub-Saharan Africa. Sabapathy Thillairajah

No. 220 The Maritime Transport Crisis. Hans J. Peters

No. 221 Policy-Based Finance: The Experience of Postwar Japan. The Japanese Development Bank and The Japan Economic Research Institute

No. 222 Macroeconomic Management in China: Proceedings of a Conference in Dalian, June 1993. Edited by Peter Harrold, E. C. Hwa, and Lou Jiwei

No. 223 The Development of the Private Sector in a Small Economy in Transition: The Case of Mongolia. Hongjoo Hahm

No. 224 Toward an Environmental Strategy for Asia. Carter Brandon and Ramesh Ramankutty

No. 225 "Fortress Europe" and Other Myths about Trade: Policies toward Merchandise Imports in the EC and Other Major Industrial Economies (and What They Mean for Developing Countries). Jean Baneth

No. 226 Mongolia: Financing Education during Economic Transition. Kin Bing Wu

No. 227 Cities without Land Markets: Lessons of the Failed Socialist Experiment. Alain Bertaud and Bertrand Renaud

No. 228 Portfolio Investment in Developing Countries. Edited by Stijn Claessens and Sudarshan Gooptu

No. 229 An Assessment of Vulnerable Groups in Mongolia: Strategies for Social Policy Planning. Caroline Harper

No. 230 Raising the Productivity of Women Farmers in Sub-Saharan Africa. Katrine Saito

No. 231 Agricultural Extension in Africa. Aruna Bagchee

No. 232 Telecommunications Sector Reform in Asia: Toward a New Pragmatism. Peter L. Smith and Gregory Staple

No. 233 Land Reform and Farm Restructuring in Russia. Karen Brooks and Zvi Lerman

No. 234 Population Growth, Shifting Cultivation, and Unsustainable Agricultural Development: A Case Study in Madagascar. Andrew Keck, Narendra P. Sharma, and Gershon Feder

No. 235 The Design and Administration of Intergovernmental Transfers: Fiscal Decentralization in Latin America. Donald R. Winkler

No. 236 Public and Private Agricultural Extension: Beyond Traditional Frontiers. Dina L. Umali and Lisa Schwartz

No. 237 Indonesian Experience with Financial Sector Reform. Donald P. Hanna

No. 238 Pesticide Policies in Developing Countries: Do They Encourage Excessive Use? Jumanah Farah

No. 239 Intergovemment Fiscal Relations in Indonesia: Issues and Reform Options. Anwar Shah and Zia Qureshi 
No. 240 Managing Redundancy in Overexploited Fisheries. Joshua John

No. 241 Institutional Change and the Public Sector in Transitional Economies. Salvatore Schiavo-Campo

No. 242 Africa Can Compete!: Export Opportunities and Challenges for Garments and Home Products inn the U.S. Market. Tyler Biggs, Gail R. Moody, Jan-Hendrik van Leeuwen, and E. Diane White

No. 243 Liberalizing Trade in Services. Bernard Hoekman and Pierre Sauvé

No. 244 Women in Higher Education: Progress, Constraints, and Promising Initiatives. K. Subbarao, Laura Raney, Halil Dundar, and Jennifer Haworth 